\title{
Unemployment and human capital
}

Citation for published version (APA):

Zwick, T. A. (1998). Unemployment and human capital. [Doctoral Thesis, Maastricht University]. Universiteit Maastricht. https://doi.org/10.26481/dis.19980101tz

Document status and date:

Published: 01/01/1998

DOI:

10.26481/dis.19980101tz

Document Version:

Publisher's PDF, also known as Version of record

\section{Please check the document version of this publication:}

- A submitted manuscript is the version of the article upon submission and before peer-review. There can be important differences between the submitted version and the official published version of record.

People interested in the research are advised to contact the author for the final version of the publication, or visit the DOI to the publisher's website.

- The final author version and the galley proof are versions of the publication after peer review.

- The final published version features the final layout of the paper including the volume, issue and page numbers.

Link to publication

\footnotetext{
General rights rights.

- You may freely distribute the URL identifying the publication in the public portal. please follow below link for the End User Agreement:

www.umlib.nl/taverne-license

Take down policy

If you believe that this document breaches copyright please contact us at:

repository@maastrichtuniversity.nl

providing details and we will investigate your claim.
}

Copyright and moral rights for the publications made accessible in the public portal are retained by the authors and/or other copyright owners and it is a condition of accessing publications that users recognise and abide by the legal requirements associated with these

- Users may download and print one copy of any publication from the public portal for the purpose of private study or research.

- You may not further distribute the material or use it for any profit-making activity or commercial gain

If the publication is distributed under the terms of Article $25 \mathrm{fa}$ of the Dutch Copyright Act, indicated by the "Taverne" license above, 
Unemployment and Human Capital 

Promotores:

Prof. dr. Joan Muysken

Prof. dr. Hans Maks

Beoordelingscommissie:

Prof. dr. Hans Peters (voorzitter)

Dr. Andries de Grip

Prof. dr. Winfried Vogt (Universität Regensburg)

ISBN $90-5681-032-4$ 



\section{Preface}

Chapter two is based on Joan Muysken and Thomas Zwick: "Insider Power Breeds Human Capitalists," in: "Aspects of the Distribution of Income," Franz Haslinger and Oliver Stönner-Venkatarama (eds.), Marburg: Metropolis, 1998. Chapter three is based on Joan Muysken and Thomas Zwick: "A Note on Incentive Wages with Human Capital Formation," METEOR research memorandum 96/022, University of Limburg, Maastricht 1996. Chapter seven is based on economic experiments jointly performed at the IEW in Zürich with Armin Falk, Ernst Fehr, Urs Fischbacher and Sirnon Gächter.

\section{Acknowledgements}

First of all I like to thank my supervisors Joan Muysken and Hans Maks for their intensive support. This thesis greatly benefitted from their expertise. In addition I want to thank Andries de Grip and especially Winfried Vogt for reading the entire manuscript thoroughly and providing valuable suggestions for improvements.

Being a "mental information worker" (compare Klamer et al (1997) p. 34), I had to rely heavily on sacial interaction in order to acquire human capital. I am in debt to Frank Bunte, Ernst. Fehr, Simon Gächter, Erik de Regt, and Thomas Ziesemer for stimulating discussions.

I also want to thank all members of the group Fehr at the Institut fur Empirische Wirtschaftsforschung (IEW) of the University of Zürich for their hospitality and cooperation during my 4 month stay there. I especially enjoyed the economic experiments where those students who have been attributed to the rolle of "firms" sat in the sun light drenched comfortable Labor A, while the "workers" were packed in the basement Labor B where you always slightly smelled the exhaust gas from the parking garage next door. Generous financial support from the Netherlands Organization of Scientific Research (NWO) allowed me to stay as scientific visitor in Zürich.

I wish to thank Shell Nederland N.V. for a travel grant that allowed me to present, my work at the European Association of Labour Economists 1997 meeting in Aarhus, Denmark. 
Thanks are also due to Marco Haan for the relaxed and inspiring years at kamer 1.084, and to Sylvia and Francien for being always helpfol with the red tape and the practical parts of the work in an efficient and friendly way.

While writing a thesis you have to decide continuously how much time to allocate for work and how much for life. Bertrand, Christian, Hetti, Victoria, André, Dolores, Sabine, Ralph, Frank, Wendy, Conni, Arjan, Horst and Peter made the decision for living especially tempting. I am grateful for that. I also want to thank the musicians of RAAK for the thrilling music we explored together.

Above all this thesis is a product of my parents in more than one sense. 


\section{Contents}

1 Introduction 11

1.1 Motivation . . . . . . . . . . . . . . . . . . . . 11

1.2 Outline. . . . . . . . . . . . . . . . . 14

2 Unemployment and Human Capital-The Background 17

2.1 Introduction . . . . . . . . . . . . . . . . . . . . . . . . 17

2.2 Human Capital . . . . . . . . . . . . . . . . . . . . . 17

2.3 Unemployment . . . . . . . . . . . . . . . . . . . . 22

2.4 Insider-Outsider Models . . . . . . . . . . . . . . . . . . . . 24

2.5 Efficiency Wages Models . . . . . . . . . . . . . . . . . . . 27

2.5.1 Shirking, Gift Exchange, Fairmess and Profit Sharing . . . . . . 30

2.5 .2 Turnover and Adverse Selection . . . . . . . . . . . . 33

2.5 .3 Empirical Evidence . . . . . . . . . . . . . . . . . . 34

2.6 Conclusions . . . . . . . . . . . . . . . . . . . . 36

3 Human Capital Creates Insider Power 37

3.1 Introduction . . . . . . . . . . . . . . . . . . . . . 37

3.2 The Model . . . . . . . . . . . . . . . . . . . . . . . . . . . . . 38

3.2 .1 Time . . . . . . . . . . . . . . . . . . . . 38

3.2 .2 The Problem of the Firm . . . . . . . . . . . . . . . 39

3.2 .3 The Problem of the Workers . . . . . . . . . . . . . 41

3.2 .4 Insiders and Outsiders . . . . . . . . . . . . . 43

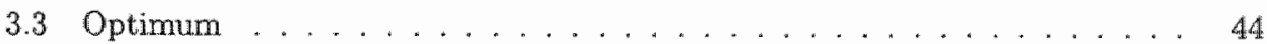

3.4 Insider-Outsider Scenario . . . . . . . . . . . . . . . . . . 46

3.4.1 Insiders Are Monopolists . . . . . . . . . . . . . . . . . . . 46

3.4 .2 Insiders Are Contested by Outsiders . . . . . . . . . . . . 49

3.5 Conclusions . . . . . . . . . . . . . . . . . . 56

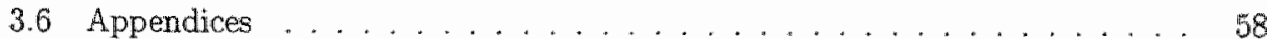

3.6.1 Different Demand Elasticities and the Revenue Function . . . . . 58

3.6.2 Insiders Prefer Full Employment . . . . . . . . . . . . . . . 59 
4 Human Capital and Wage Incentives 60

4.1 Introduction . . . . . . . . . . . . . . . . . . 60

4.2 Wages as Incentive to Invest in Human Capital . . . . . . . . . . 62

4.2 .1 Unemployment . . . . . . . . . . . . . . . . . 62

4.2 Full Employment . . . . . . . . . . . . . . 65

4.3 Conclusions . . . . . . . . . . . . . . . . . . 68

5 Why Do not all Workers Invest in Skills?

5.1 Introduction ......................... 70

5.2 Labour Demand. . . . . . . . . . . . . . . . . . . . . . . . 74

5.3 Workers' Surplus . . . . . . . . . . . . . . . . . . 75

5.4 First Best Solution . . . . . . . . . . . . . . . . . 78

5.5 Monopolistic Competition . . . . . . . . . . . . . . . . . . . 80

5.6 Remedies ............................. . . . . 87

5.7 Conclusions . . . . . . . . . . . . . . . . . . . . . . . 90

5.8 Appendix . . . . . . . . . . . . . . . . . . . . . . . . . 92

6 Human Capital in a Neo-Keynesian Model 95

6.1 Introduction . . . . . . . . . . . . . . . . . . 95

6.2 A Traditional Neo-Keynesian Model . . . . . . . . . . . . . . . . . 97

6.3 A Model with Human Capital . . . . . . . . . . . . . . . . . . . . 999

6.3 .1 Training Costs ... . . . . . . . . . . . . . 101

6.3 .2 Skills Update . . . . . . . . . . . . . . . . . . 103

6.4 Conclusions . . . . . . . . . . . . . . . . . 107

7 Incomplete Labour Contracts Lead to Worker Rents 109

7.1 Introduction . . . . . . . . . . . . . . . . . . . . . . . . 109

7.2 Experimental Design . . . . . . . . . . . . . . . . 112

7.2 .1 Main Treatment. . . . . . . . . . . . . . . . . . 112

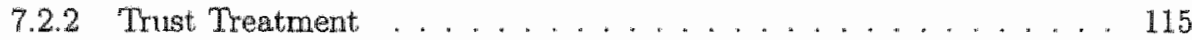

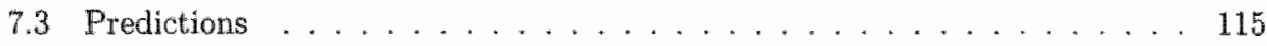

7.3.1 Game Theoretic Predictions . . . . . . . . . . . . . 116

7.3 .2 Behavioural Predictions ................ 118

7.4 Results . . . . . . . . . . . . . . . . . . . . . . . 120

7.4 .1 Main Treatment . . . . . . . . . . . . . . . . . 121

7.4 .2 Trust Treatment . . . . . . . . . . . . . . 127

7.5 Conclusions . . . . . . . . . . . . . . . . . . . . . 134

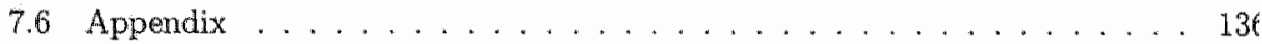

8 Conclusions $13 k$

References 14:

List of Symbols 15 ! 
Samenvatting

Zusammenfassung 163

Curriculum Vitae 



\section{Chapter 1}

\section{Introduction}

\subsection{Motivation}

"Turning the unskilled unemployed into skilled workers seems to be the one policy that almost everybody subscribes to." If we look on the one hand at the considerable amounts invested in human capital by the state and the individuals and at persistent and increasing unemployment figures especially for unskilled workers on the other hand, ${ }^{2}$ some doubts arise about the effectivity of policies to decrease unemployment by educating the population. The empirical link between a highly skilled population and few unemployed seems weak. Nevertheless, there is a broad consensus amongst economists that education and training is good for employment. ${ }^{3}$ Although a library can be filled with publications on unemployment and on human capital separately, strikingly little is found about the relationship between both. $^{4}$

Economists commonly accept that (involuntary) unemployment is a persistent and wide-spread phenomenon in developed economies. Nevertheless they are at pain explaining how this phenomenon can be reconciled with the neoclassical paradigm of individual rationality, price mechanisms and the "invisible hand". Models that successfully derive (involuntary) unemployment under this paradigm are rare and frequently rely on rather indirect arguments. In addition only few models based on individually rational behaviour that explain unemployment perform convincing in empirical tests (compare the literature

\footnotetext{
${ }^{1}$ See Alogoskoufig et all (1995) p. 118.

${ }^{2}$ Compare the nubmers presented in the literature survey in chapter two.

3. Investment in human capital, (..), is another policy action that hardly needs any recommendation today:" Lindbeck (1996) p. 628.

4t"The existing literature has relatively little to say on this (...) topic." Hart and Moutos (1995) p. 48.
} 
survey in chapter 2). This thesis adds to the literature about theoretical models explaining unemployment by individually rational behaviour since it concentrates on arguments related to human capital formation. It is an attempt to fill a serious gap in the economic unemployment literature where human capital formation frequently is not taken into account.

Neoclassical models have to assume labour market imperfections in order to explain unemployment. Labour market inefficiencies are for instance caused by market power, uncertainty, informational asymmetries, externalities or rigidities. This thesis shows that also human capital investments add to labour market inefficiencies or make them effective. The models derived in the following chapters demonstrate that the identified labour market inefficiencies which are caused by human capital formation bring about a lower than optimal employment level. Consequently investments in human capital have a negative impact on employment under certain circumstances. This is in contrast to the common view that investments in human capital are unequivocally beneficial for employment.

It is assumed that all participants on the labour market act individually rational. Workers maximize for example their utility by investing in human capital, while firms maximize their profit by hiring workers. This is the usual approach taken in explanations of un employment based on neoclassical principles. According to human capital theory worker: decide about their human capital investments themselves. Workers usually do not havi social welfare and firms' profits in mind when they decide about their education. In ad dition we see that human capital investments are necessary in order to preserve labou productivity when technological developments are rapid. Labour productivity declines $j$ workers are not trained and their skills are not up-dated on a permanent basis. The im plications of this compulsion to train and the necessity of topical skills in the productio process are frequently not taken into account in traditional models of human capital an unemployment.

In all models, fixed minimum wages and exogeneous unemployment benefits are a sumed. This assumption is also common in the literature about unemployment based $c$ individual maximizing behaviour. These rigidities affect labour markets without hume capital formation differently than labour markets with human capital formation. Adc tional labour market distortions result from fixed outside options for workers when t? assumption of fixed outside options is combined with human capital investments.

The hypothesis that (the necessity of) investments in human capital causes labo 
market imperfections is centered around two themes: sunk costs and rents. Both themes are crucial in almost all theoretical models developed afterwards.

\section{- Sunk costs}

Workers have to decide about their human capital investments before they know if they get an adequate job or if they can keep this job. This means that workers do not know if their investment will pay off in the future or not, when (re-)employment is uncertain. If the outside option of a worker is unemployment, he or she loses the irrvestment in human capital during an unemployment spell and does not see any (immediate) return on investment. Also if a worker only finds a job with a different or less education required or moves from one employment to another, the pay-off of human capital investment is reduced. Investment in human capital entails then sunk costs and is experienced as a burden by the workers. The investment costs cannot be recouped completely.

Depreciation of skills, job mobility, technological progress and fall into oblivion lead to the necessity of a frequent up-date of human capital. This also contributes to the sunk cost property of human capital, because investments have to pay off quickly and may be useless soon, if demand profiles for skills change quickly.

\section{- Rent}

Investments in human capital create rents which have to be distributed between the firm and the worker. These rents have public goods characteristics, because both parties are beneficiaries of worker's investment. Hereby, external effects are incurred.

In addition, skilled workers can not be replaced easily by other workers with different skills. This leads to market power of skilled workers and higher than market clearing wages as long as other workers do not learn these skills. Rents of skilled workers are threatened by unemployed and disadvantaged unskilled worker groups, however, when the latter decide to enter the same skill group. Market clearing and the disappearance of workers' rents is only reached, if the skilled workers are not able to prevent market entry or if all workers have equal human capital investment costs.

In this thesis the special interpretation of individual rationality used in neoclassical theory is employed in all theoretical models. Frequently, however, other market ontcomes than those predicted by neoclassical theory are observed in reality, because factors not accounted 
for in neoclassical theory play a role in individual decision making. In chapter seven it is argued that trust, uncertainty and tit-for-tat behaviour have an impact on labour market. outcomes and wages. In an economic experiment it is shown that the incompleteness of labour contracts adds inefficiencies and worker rents on the labour market which contribute to unemployment.

\subsection{Outline}

How are unemployment and human capital formation related to each other? This topic is approached from different angles that all focus on labour market imperfections caused by human capital investments that lead to less than efficient employment. The market imperfections are results of individually rational maximizing behaviour and inherent in human capital investment.

In chapter two, human capital theory and the literature about voluntary and involuntary unemployment based on individual maximizing behawiour are reviewed. In the human capital survey, rent creation and the sunk costs property of investments in human capital are digressed. In the survey about unemployment models the central question is, why unemployed workers are unwilling to or incapable of bidding the wage rate down to a level that ensures full employment and Pareto efficiency. The focus is on the insider-outsider approach and efficiency wage models, because here market imperfections are caused by individual optimizing behaviour. Insider-outsider and efficiency wage models are the basis of the models presented in chapters three and four. In other unemployment models motivated by individual maximizing behaviour like search models and implicit contract models, the inclusion of human capital formation proved to be difficult and therefore these models are not discussed in this book. The literature survey concludes that efficiency wage theory and insider-outsider theory can provide explanations for (involuntary) unemployment and identifies the inherent imperfections of labour markets that lead to labour rationing.

The research strategy pursued in chapters three to six is to add human capital formation to well-known models and focus on the effects this has on labour market efficiency and employment. The reference is always a social planner model where human capital investment and employment is efficient. When workers set human capital investments (and wages for skills) themselves, they incur labour market inefficiencies and reductions in employment. In chapter three, an insider-ontsider model with the inclusion of human capital for- 
mation is presented. Human capital formation gives insiders an additional possibility to erect barriers to entry. Insiders strategically sink costs in human capital such that outsiders cannot outperform them. Then insiders enjoy rents while outsiders stay involuntarily unemployed although full employment is efficient. It may also be in the interest of the insiders to allow entry of few outsiders if complete barriers to entry are too expensive. Then insiders, entrants and firms share the rents accruing from human capital investments.

In chapter four, the same formal objective functions of firm and workers as in chapter three are used to derive efficiency wage results from human capital formation. Human capital formation is a reason for the firm to set. wages above the market clearing level if the workers can decide over their investment themselves. Firms have to stimulate human capital investments by the wages offered. Workers do not invest enough in human capital, because the workers have to share rents with the firms. In addition the prospect of losing the human capital investment when labour demand is lower than labour supply further reduces the motivation of the workers to invest, in human capital.

In chapter five, a model with monopolistic competition on the skilled labour market is presented. Workers can freely decide to invest in skills or not. Investment in human capital gives skilled workers market power they can use for negotiating wage increases. The skilled wage mark-up may be more than compensating, i.e. the skilled wage is higher than the unskilled wage plus education costs. Then skilled workers in adequate jobs earn rents. A more than compensating skilled wage mark-up is observed if skilled workers cannot be easily replaced by workers with different skills or unskilled workers. The more than compensating mark-up for skilled wages induces a reduction in total labour demand, the expected surplus for all workers and social welfare. In addition, overqualification is needed for an equalization of expected surpluses of skilled and unskilled workers. Unskilled workers, attracted by the high skilled wage, invest in their human capital even if they face the risk not to find an adequate job afterwards. Overqualified skilled workers lose their sunk costs in human capital.

In chapter six, human capital is included in a traditional Neo-Keynesian model with sticky wages in the short run. Workers ask for a risk mark-up in wages before they invest in human capital if they expect involuntary unemployment in the wake of a negative aggregate shock. When unemployment increases, workers run the risk to lose their sunk human capital investment costs. In addition, unemployed workers have to be trained when they are employed again due to the lack of on-the-job training during their unemployment 
spell. Both effects reduce additional employment when the economy recovers after an adverse aggregate demand shock that incurred involuntary unemployment due to rigid wages. In this model, workers need human capital investments by assumption in order to be eligible for a job.

In chapter seven, some results of an economic experiment are reported that introduces incomplete labour contracts in an otherwise perfectly competitive labour market. A second experiment additionally allows for trust between the firm and insiders. Insiders voluntarily give up considerable rents in order to proof that they are trustworthy. These experiments show that workers earn rents when labour contracts are incomplete although there is an oversupply of workers. Firms do not structurally choose for the underbidding outsiders, because they correctly anticipate that insiders behave less unfair than outsiders who promise a higher profit. Rents increase further when insiders can build up trust between themselves and the firm. The rents paid to the workers reduce total labour demand because they are associated with a mark-up on wages and labour markets therefore do not clear.

All models presented in this book demonstrate that human capital formation causes labour market inefficiencies. These labour market inefficiencies reduce employment and social welfare. If we take into account the economic importance and pervasiveness of education and training, human capital formation potentially may have a significantly negative impact on total employment in developed economies. The notion of labour market ineffciencies caused by human capital formation adds to the explanations of high and persistent unemployment found in economic models based on individual rational decisions.

Chapter eight finally provides some consequences for economic policy that can be drawn from the models and the experiments described in the previous chapters. 


\section{Chapter 2}

\section{Unemployment and Human Capital-The Background}

\subsection{Introduction}

Unemployment is caused by labour market imperfections. Economists attribute these imperfections to individually rational behaviour and labour market rigidities. The focus in this book is on human capital formation and how this affects the efficiency of the labour market. In order to be able to discuss the impact of human capital on labour market performance, first a short introduction in human capital theory is given. Hereby the elementary characteristics of individually rational investment behaviour in human capital are presented. In the models developed in this book, voluntary and involuntary unemployment are derived. Therefore a short overview about the distinction between voluntary and involuntary unemployment is given in this chapter. Then a survey follows about efficiency wage models and insider-outsider models. Both classes of theories are successful in explaining unemployment from individually rational behaviour. They form the basis for the models in chapters three and four of this thesis.

\subsection{Human Capital}

Education and training are an enormous economic factor. In 1993, the OECD countries on average invested $6.3 \%$ of GNP in schooling. In Nordic countries even more than $8 \%$ of GDP is paid for education. ${ }^{1}$ Mincer notes that in the USA on average 5 weeks per year are dedicated to training by the workers (Mincer (1994) p. 22).

\footnotetext{
See OECD (1996a) p. 59.
} 
Governments subsidize education substantially. The share in OECD countries of public expenditures on total education expenditures in 1993 was almost, $92 \%$. These expenditures had on average a share of $12.3 \%$ on totall public expenditures ranging from $8.7 \%$ in Greece to $17.3 \%$ in Hungary (The Netherlands $9.2 \%$, Germany $9.5 \%$, United Kingdom 11.5\%, and United States $14.2 \%$ ). ${ }^{2}$ For labour market training which includes training for unemployed adults, those at risk to lose their jobs and for employed adults between 0.01 percent of GDP in Luxembourg and 1.15 percent of GDP in Denmark were paid in 1996. The newest figures are $0.45 \%$ for Germany, $0.12 \%$ for the Netherlands, $0.10 \%$ for United Kingdom and $0.04 \%$ for the United States. ${ }^{3}$ In Europe at least half of the annual costs of higher education of low income families are borne by the state (United Kingdom even 94\%, USA between $33 \%$ and $62 \%$ depending on university status). For middle income families the shares of public subsidies are still between $14 \%$ (Germany) and $38 \%$ (Sweden) ${ }^{4}$

What is the economic reasoning behind these huge investments and public subsidies? Education subsidization may be justified by equity reasons and by positive externalities of education such as promoting democracy and civic values. As the human capital market is imperfect and human capital does not serve as a collateral for a loan, subsidization is necessary to give everybody the same opportunity to train him-or herself and may bave an egalitarian effect. In addition the market for skilled workers may not be perfectly competitive, becanse skilled workers differ from each other (they own a bundle of skills) and only a limited number of firms competes for them. ${ }^{5}$ Empirical investigations suggest however that workers and firms share the returns from training. Therefore both parties have an interest in stimulating training, while public subsidies on training may just have consumptive effects and therefore are superfluous (compare the survey in Mincer (1994) pp. 26-29). On the other hand this thesis shows that workers do not have an incentive to invest efficiently in human capital, because they have to share the rent with the firm (compare also MacLeod and Malcomson (1993)).

The fundamental reasoning behind individual investments in human capital is that educetion leads to an increase in productivity. As earnings are equal to the marginal product of labour, income increases with human capital investments. Therefore time and money are invested in expected future pay, while the additional payment is only obtained

\footnotetext{
"See OECD (1996a) p. 92.

${ }^{3}$ Compare OECD (1997) pp. 183-190.

See Clotfelter (1991) p. 23.

${ }^{5}$ Compare Stevers (1994).
} 
if an adequate job is found.

The incorporation of human capital formation into growth and production theory did not start until the $1960^{\prime}$ s. Schuliz (1961, 1962) pointed out that investment in human capital may explain a considerable part of economic growth and that human resources have quantitative and qualitative dimensions. Therefore it is an oversimplification to take just the number of workers into account and assume that they are equal in the production function of the firm.

In Becker (1983) human capital is divided into two categories, general and specific human capital. General human capital increases productivity in all jobs, while specific human capital raises productivity only in one firm. Therefore general human capital is associated with experience (overall time in the labour market), while special human capital is associated with tenure (time spent in one firm). While the worker pays for the costs of general human capital increases, the firm and the employee share the costs of specifo human capital investments (or the difference between a worker's productivity at the firm in which that worker acquired tenure and that worker's productivity elsewhere). The employer's rent; share is a matter of bargaining power, the contract length and the competition between firms for the worker and not of specificity alone. ${ }^{s}$

The positive aspects of investments in human capital thus are evident. However, human capital formation can also lead to inefficiencies as a side effect. The main reasons for inefficiencies caused by human capital this thesis concentrates on are the sunk cosits property of human capital investments and rents induced by investments in skills.

Human capital investments are made under the uncertainty whether they pay off in the future. Education costs are in this sense sunk, because they cannot be re-earned when the job is lost or the gained ability is not required any more. The motivation of the workers to invest in human capital is reduced if they can not be sure that they are employed in an adequate job after investing in human capital (compare chapters three to six). Either workers ask a higher monetary compensation for human capital investments or they invest less at a given wage level if they expect a high risk not to be employed in an adequate job after imvesting in human capital.

Biesides the uncertainty about the pay-off of human capital investments if labour demand is lower than labour supply, depreciation of human capital contributes to the sunk

\footnotetext{
${ }^{6}$ Compare e.g. Stevens (1994) and Crawford (1990).
} 
cost property. Human capital depreciates because there are technological developments, obsolescence, job mobility while skills are specific for a certain job, qualitative changes in skills demanded and oblivion. Therefore permanent schooling and on-the-job training are required, ${ }^{7}$ while unemployed workers have to catch up with the increased level of human capital which employed workers have accumulated meanwhile by learning-by-doing (compare chapters three to six). If human capital depreciates, investment costs in human capital are sunk and can not be re-earned in the next period when starting at a new job. Pissarides (1992) demonstrates in an overlapping generation model that when unemployed workers lose some of their skills, the effects of a temporary shock to employment can persist. The average human capital of the unemployed labour pool decreases with unemployment duration and therefore firms" labour demand and aggregate employment also decreases (thin market externality). In chapter six a similar phenomenon is discussed when entrants need training in order to catch up with the lost training-on-the-job needed.

Human capital investment can be divided into two complementary phases, school and post-school education. Economic theory predicts that people attend school as long as benefits are higher than costs. Benefits of schooling are higher wages for higher educated workers and a lower job hazard. ${ }^{8}$ Costs of education are direct schooling costs and foregone income during schooling time. The time discount factor is crucial for schooling decisions, as the costs have to be made before the benefits can be reaped. Also ability obviously has an impact on schooling decisions, because it affects schooling costs. Post-school human capital investments are made such that the present value of lifetime earnings is maximized. In addition to the interest rate and ability also the length of the remaining working life is decisive for the post-school investment decision. A third important element of human capital formation is learning-by-doing. Here it is assumed that workers learn "costless" just by attending work and interacting with colleagues or consumers.

All theoretical models in this book focus on costly education and (permanent) postschool education needed for a certain job. In chapter six, the necessity of on-the-job training is additionally taken into account. Especially job entrants need on-the-job training in order to keep up with the human capital level experienced employees reached for free by learning-by-doing or also by investing in on-the-job training.

\footnotetext{
7 See e.g. Harroves Heop (1980) p. 613 .

8 Unemployment rates of skilled workers are considerably lower than those of unskilled workers, compare e.g. Mncer (1991) or Layord, Nickell and Jackman (1991) pp. 286-292 for surveys.
} 
An impressive variety of studies indicates that decisions about education are mainly taken according to economic incentives such as costs, probabilities to find an adequate job, the wage differential between jobs, rents and human capital depreciation. "Consumption" aspects of education such as intrinsic interest in knowledge, a higher chance to find an adequate mate or social status being a student do not have an decisive impact on education decisions (compare e.g. the survey in Freeman (1986) pp. 367-375). Therefore the following models also assume purely economic factors for the education decision.

In order to measure the relation between earnings, education and learning-by-doing, the so-called Mincerian earnings function (compare Mincer (1974)) proves to be useful. The equation is defined as:

$$
\ln w_{i}=\beta_{0}+\beta_{1} c_{i}+\beta_{2} t_{i}+\beta_{3} t_{i}^{2}+u_{i}
$$

where $w_{i}$ is individual $i$ 's earnings, $c_{i}$ education, $t_{i}$ working experience or human capital induced by learning-by-doing and $u_{i}$ the disturbance term with expectation zero, while the $\beta$ s are parameters. As $\beta_{2}>0$ and $\beta_{3}<0$ the equation predicts the familiar concave experience earnings profile. ${ }^{9}$

Empirical studies indicate that returns to schooling are more than compensating and increasing in recent years, compare e.g. Ashenfelter and Krueger (1994) and Juhn, Murphy and Pierce (1993), Topel (1997) p. 58 as well as the country surveys in Davis (1992) and the OECD Employment Outlook (1996a). There are lags in the response to changing profitability of education and the returns to education. Mincer calculates a lag of 8 years (compare Mincer (1994) p. 15). Therefore rents from schooling can be persistent over a rather long period, because workers can not react instantaneously on rents to be earned by education. In the 1980 s for example most countries experienced increasing rents from education, while rents only decreased gradually in the beginning of the 1990s (see chapter five of this thesis for a discussion of the consequences of this phenomenon).

An important determinant of the market power and rents of skilled workers is the cross elasticity between the demand for skilled and unskilled labour. There is a wide range of studies on this field who also yield very different results (compare e.g. Freeman (1986) pp. 364-367 or Nickell and Bell (1995) for surveys of literature). The main consensus seems to be that skilled workers can easily replace unskilled workers, while the elasticity is much smaller for unskilled workers replacing skilled workers (compare also van Zon et

\footnotetext{
${ }^{9}$ Compare also the discussion in Oasterbeel (1992) pp. 5-20.
} 
al (1997)). These are reasons for the observation that skilled workers enjoy rents. In addition skilled workers find a job more easily even if there is no adequate position free for their specialization. This leads to higher unemployment rates for unskilled workers in comparison to skilled workers. Chapter five discusses the implications of skilled workers" rents for education demand and social welfare.

In the conclusions (chapter eight) some remarks are made about the justification of public luman capital subsidies in the light of the results of the models presented in the chapters three to six. In addition sorne suggestions are given when the state should subsidize human capital formation.

\subsection{Unemployment}

It seems superfluous to mention that unemployment is one of the most severe economic problems today. In almost every OECD country unemployment is amongst the top 10 of people's concerns. Although the numbers declined slightly, in 1996 still an average of $7.6 \%$ in 21 OECD countries were unemployed while a much higher share of the work population experienced at least short unemployment spells caused by fluctuations. It is also fairly well-known that countries show a considerable spread in unemployment rates (the rate in 1996 was $9.6 \%$ for Central and Western Europe, 15.2\% for Southern Europe, 3.4\% for Japan and $5.4 \%$ for the United States). In addition, unernployment trends over time differ considerably between regions.

Still economists have problems in constructing consistent madels with (involuntary) unemployment. The models in this book are based on familiar models of unemployment assuming individual rational decisions. They explain why employment may be lower than efficient if all agents act individually rational taking the necessity of human capital investments into account. Therefore the thesis adds to the microeconomic literature by combining unemployment models with human capital formation theory. In this survey first the idea of involuntary versus voluntary unemployment is explained, because the models in this book result in voluntary and involuntary unemployment and this might have different implications for policy advice. Then the literature about insider-outsider and efficiency models is reviewed which forms the basis for the models in chapter three and four.

It is an intriguing question if workers are unemployed voluntarily or involuntarily. This thesis does not contribute to this discussion, but uses available definitions in order to 
classify unemployment found in the different models. Keynes' definition for involuntary unemployment is the basis for the distinction between voluntary and involuntary unemployment:

"Men are involuntary unemployed if, in the event of a small rise in the price of wage-goods relatively to the money-wage, both the aggregate supply of labour willing to work for the current money-wage and the aggregate demand for it at the wage would be greater than the existing volume of employment." ${ }^{10}$

In order to make Keynes' concept of involuntary unemployment operational, the definitions of Azariadis and Stiglitz and of Lindbeck may be of use:

"The employed workers receive a wage in excess of unemployment insurance, and are therefore to be envied by their laid-off colleagues - a situation that many economists would call "involuntary unemployment".

"Involuntary unemployment exists whenever some workers are unable to get jobs, even though they are willing to work at a lower wage than the prevailing one for jobs for which they are as qualified as those actually employed." 12

According to these definitions, the insider-outsider model in chapter three creates involuntary unemployment, because outsiders are prevented by entry barriers to enter while they are willing to work for the current wage. However, workers in the efficiency wage model in chapter four and in the monopolistic competition model of chapter five are voluntarily unemployed. It is utility maximizing for these workers to accept a small risk to get unemployed in exchange for a higher rent when they find an adequate job. In chapter six, workers get involuntarily unemployed because wages are rigid. Here labour demand is smaller than labour supply at the given wage after an adverse aggregate demand shock.

The main theories trying to provide a microeconomic foundation of unemployment are search theory, implicit contracts, efficiency wages (including fairness and profit sharing models) and insider-outsider models. ${ }^{13}$ This survey focuses on insider-outsider and efficiency wage models, because these theories are also used in the models developed afterwards.

\footnotetext{
${ }^{10}$ Keymes $(1936)$, p. 15.

${ }^{11}$ Azariodis and Stiglizz (1983) p. 5.

${ }^{12}$ Lindbeck (1991) p. 4.

${ }^{13}$ See e.g. De Wroey (1995) p. 20.
} 


\subsection{Insider-Outsider Models}

Insider-outsider models assume that all workers have the same capabilities. Some workers happen to be lucky and find a job, while some are unlucky and lose their job. The insider-outsider models provide arguments, why the wage mechanism does not work, i.e. why unemployment cannot be eliminated through underbidding and the outsiders stay unemployed (see the verbal survey in Lindbeck and Snower (1986)). The basic assumption of insider-outsider models is that wage determination mainly depends on insiders, while firms determine employment. As insiders do not (fully) take outsiders' utility into account in the wage determination process, wages may be too high for full employment.

In insider-outsider models, outsiders frequently are prevented to undercut the wage set by insiders by assumption. ${ }^{14}$ Here, just insiders set wages, while outsiders have to accept those in order to get a job. Insider wage setting is crucially dependent on insider membership rules. Wages are higher when membership is preserved during unemployment spells, while they are set lower when insiders lose their status if they get unemployed. If there is uncertainty about firm's labour dernand, on average wages may be set such by the insiders that labour demand is higher than current employment in order to avoid losing the insider privilege.

The assumption that outsiders may not undercut insiders seems objectionable. Therefore in the insider-outsider model presented in chapter three, both cases are discussed, i.e. outsiders may underbid or not. In the economic experiment described in chapter seven, outsiders freely can underbid the wage demand of the insiders. Lindbeck and Snower present arguments in a series of papers (e.g. Lindbeck and Snower (1986, 1988, 1990, 1991)) when insiders may keep market power even if outsiders can undercut their offer to the firm. Insider market power arises if specific labour turnover costs are present. These costs give insiders the possibility to set the wage above the reservation wage of the outsiders and enjoy rents. The outsiders would like to work for this wage, the firm however has to subtract the entry and/or exit costs from insiders' wage. Hence, the wage offered to the outsiders is so low that they do not want to enter. If the reservation wage of the insiders is equal to that of the outsiders (the unemployment benefit), insiders enjoy a rent, while outsiders are involuntarily unemployed and envy the insiders. Insiders may even try to augment ${ }^{14}$ See e.g. Blanchard and Surmers (1986), Carruth and Oswald (1987) and Gottfries and Horn
$(2987)$. 
the turnover costs, e.g. by forming trade unions, in order to achieve a higher mark-up. After a contractional shock, unemployment may be persistent, because the fewer insiders may adapt wages such that only they remain employed, while no outsiders are hired. ${ }^{15}$ This strategy maximizes the income of the insiders. They use the boom for rises in their wages and keep labour demand at the minimal level of insiders employed in the slump. There are several arguments put forward in the literature, why turnover costs may arise that prevent labour market clearing and lead to involuntary unemployment. Lindbeck and Snower (1986) name costs of hiring, training and firing.

Another possible source of insider market power may be the threat of insiders to withdraw cooperation from entrants that underbid their wages and therefore are accepted by the firm. This creates a productivity differential between insiders and outsiders (compare Lindbeck and Snower (1988)). The productivity differential can be a result of insiders" refusal to train entrants. Lindbeck and Snower assume that training is costless to insiders, reduces however their bargaining power when the number of insiders increases.

An additional argument for insider market power is active harassment which excludes entrants from necessary information or training-on-the-job (compare also Lmabeck and Snower (1988)). The firm, anticipating these discriminating activities, then abstains from hiring outsiders, because they are too expensive.

Finally, a high labour turnover may have negative effects on the working morale, because the workers' future reward for current effort is reduced. ${ }^{16}$ Therefore firms may use the turnover rate as an incentive device. Insiders" increased efforts are then rewarded by the firm with a lower probability to lose their jobs or even job guarantees. This creates a favourable position of the insiders which can be used to erect barriers to entry and leads to the appropriation of rents and involuntary unemployment (compare Lirudbech and Snower (1.989)).

Policies that reduce the power of insiders (legal restrictions on strikes and picketing or relaxing job security legislation) may lead to more employment. As insiders' incomes decrease, however, there can be serious obstacles to implementing these policies or efficiency losses by social unrest. Other compensating rent-gaining activities of the insiders could be experienced. Profit-sharing schemes, where employees receive part of the wages as a share of profits may promote employment, because the newly hired insiders will exercise their

\footnotetext{
${ }^{15}$ Compare Gottries and Horn (1987) and Carruth and Oswald (1987).

${ }^{76}$ See e.g. Lindbeck and Snower (1987) p. 411.
} 
wage-setting power to lower the wages in order to keep their jobs. This is also the case with job sharing schemes. Another effective way to enfranchise outsiders is to create new firms. This has to be on a permanent basis, however, because also in the new firms insider effects will be experienced as soon as the firm tries to increase the workforce which would put insider rents under pressure. Demand side policies such as an increase in government employment may also be effective in decreasing unemployment in insider-outsider models. Increases in aggregate government spending are only effective, if new firms enter, or the marginal product of labour is increased. ${ }^{17}$

Blanchard and Summers (1986), Lindbeck and Snower (1988) and Sanfey (1995) note that the results of the insider-outsider models are preserved, if it is assumed that the insiders are organized in a labour union interested in insiders' utility only. Stronger, it is assumed in most insider-outsider models from the outset that all insider behave symmetrically. This implies a coordinating force such as a union.

Fehr and Kirchsteiger (1994) note that there are market two-tier wage systems that are preferred by the insiders but also lead to the employment of entrants. They argue, however, that entrants being paid less than senior insiders would have a lower incentive to provide effort on the basis of reciprocity or fairness reasons as they compare their position with their reference group. Therefore wage discrimination between entrants and insiders is not widely observed and would be not market clearing. Huizinga and Schiantarell (1992) show in a dynamic general equilibrium insider-outsider model where the outside option is endogenous that there is a fundamental asymmetry between upturns and downturns. While employment rises gradually in upturns, downturns are characterized by a sharp drop in employment through lay-offs when insiders have market power. Carruth and Oswald (1987) stress that beyond some point in a boom phase it may be in the interest of the insiders to let in some outsiders after having translated increases in demand in pure wage rises first. Therefore employment increases slowly in a boom phase of the business cycle when insider power is present.

Chapter three presents a model that includes the possibility for insiders to invest strategically in human capital. The model is in the tradition of Lindbeck and Snower, i.e. identical outsiders can underbid the wages set by the insiders. There are however no transactions costs assumed that create market power in the well-known insider-outsider models. It is shown instead that human capital formation is an additional reason for insider market

\footnotetext{
${ }^{17}$ See Lindbeck and Snower (1990) p. $292 \mathrm{ff}$.
} 
power that prevents wages to decline to the market clearing level and therefore transactions costs are not needed here to motivate insider market power.

Chapter seven reports the results of an economic experiment. The basis is again an insider-outsider model without transaction casts for market entry or exit. Workers are able to skim a rent in a perfectly competitive labour market when they can determine effort after being hired by the firm. In addition factors like trust and reciprocity play a crucial role in incomplete labour markets.

The empirical evidence about the significance of the insider membership mechanism in generating persistent unemployment is not very convincing (compare e.g. the survey in Bean (1994) pp. 605-608 or Franz (1990) pp. 9-10). Most studies find that persistence of unemployment is much higher in European Union member states (without Austria and Sweden) than in Nordic countries, Japan and the USA. This reflects the observation that unemployment in the EU did not decline much in the boom phase at the end of 1980 s and increased sharply afterwards, while unemployment in Japan and European non-EU members was moderately decreasing and sharply decreasing in the USA in the $1980 \mathrm{~s}$. The reasons underlying these trends are not clear, however.

The prediction of insider-outsider models that the result of positive or negative shocks depends on the initial level of employment ("hysteresis in unemployment") is supported by Blanchard and Summers (1986). This observation is not reproduced in all studies, however. Wages are e.g. not inversely related to the size of the incumbent work force in Holmlund and Zetterberg (1991)). There is a wide array of studies that show that wages are influenced by other insider factors than the mumber of insiders. Insiders are able to bid up wages, if the product price level and firm productivity is higher than that of comparable other firms, compare Nickell and Wadhwani (1990) and Blanchflower, Oswald and Garrett (1990).

\subsection{Efficiency Wages Models}

Karl Marx already noted ${ }^{1.8}$ that the employer just buys the labour power, i.e. the capacity to do work, while she/he still has to ensure that the work actually has to be done. After being hired, the interests and objectives of the employer and employee are not identical any

\footnotetext{
${ }^{18}$ "Die eigenthümliche Natur dieser spezifischen Waare, der Arbeitskraft, bringt es mit sich, dass mit der Abschliessung des Kontrakts zwischen Käufer und Verkäufer ihr Gebrawchswerth noch nicht wirklich in die Hand des Käufers übergegangen ist. [...] aber ihr Gebrawchusuerth besteht erst in der nachträglichen Kraftäusserung." Marx (1867) p. 137.
} 
more. Frequently, employees are not intrinsically motivated to exert more than the minimal work effort, while the firm wants to extract the maximal productivity from the labour power hired. This is the conflict between employer and employee over the extraction of labour from labour power. ${ }^{19}$ This conflict is also the basis of the economic experiment described in chapter seven where the firm can not force the accepted worker to exert a certain effort. The extraction of labour conflict can be solved by detailed labour contracts or with piecerate payment. Frequently, however, labour contracts are inherently incomplete, i.e. not all possibilities that may occur during the labour relationship may be captured in a wage contract. Then workers have some discretion in how to perform on the job, while typically less effort hurts the employer but pleases the employee.

With incomplete labour contracts wages can be set such that the extraction of labour is optimal. Here a positive impact of the remuneration on labour productivity is necessary, i.e. workers voluntarily work harder when their wages increase. This idea is also explained in the work of Adam Smith ${ }^{20}$ and Max Weber. ${ }^{21}$ Several reasons why this might be the case are listed below. The incentive effect of wages can be used to decrease the wage costs per effective unit of labour. If the minimum of these costs is not market clearing, the wage set is called efficiency wage. Then the law of supply and demand no longer applies and wages are sticky.

A typical relationship between wages and costs per effective unit of labour is depicted in Figure 2.1. The crucial assumption hereby is that labour productivity more than proportionally increases over a certain range of wages. The efficiency wage $w^{*}$ is at the point where the inverse of wage costs per efficiency unit is minimal. The corresponding costs per efficiency unit are depicted in the second graph below.

\footnotetext{
${ }^{19}$ See Edwards (1979) pp. 11 ff and Bowles (1985) p. 19.

20 "Where wages are high, accordingly, we shall always find the workmen more active, diligent, and expeditious, than where they are low [.] " Smith (1937) p. 81 .

${ }^{21}$ "Akkordlohnchancen und Kündigungsgefahr bedingen in der kapitalistischen Erwerbsordnung primör die Arbeitswilligkeit". Weber (1972) p. 87.
} 


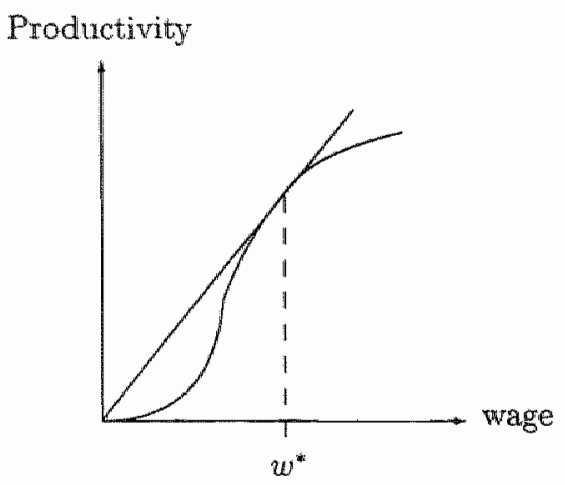

Cost per efficiency unit

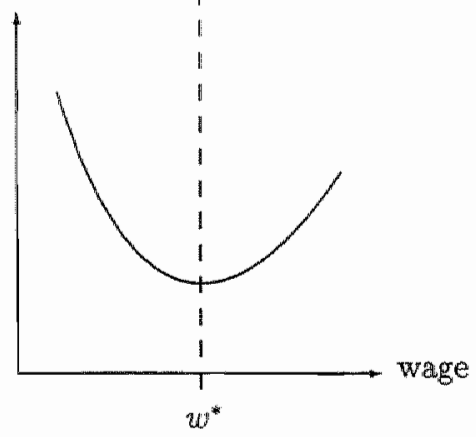

Figure 2.1: Efficiency Wages ${ }^{22}$

The main assumption of efficiency wage models is that labour efficiency more than proportionally increases in wages. The firm maximizes its profit in this case by setting the wage at the minimum of the term $\frac{\text { wage }}{\text { productivity }}$ which are the labour costs per efficiency unit of labour. This is the well-known Solow-condition where the wage elasticity of productivity is one. ${ }^{29}$ The relationship between productivity and wage may differ from industry to industry. Therefore identical workers may receive different wages, because they happen to work in different industries. Hence the Law of the Single Price is not applicable. ${ }^{24}$

Efficiency wages have two functions, namely to motivate, recruit and retain workers on the one hand and to determine employment on the other. If the first functions require higher than market clearing wages, unemployment is induced. Efficiency wage theories can be categorized into four main types: ${ }^{25}$

\footnotetext{
${ }^{22}$ Compare Figure 1 and Figure 2 in Stiglitz (1987b) p. 5.

${ }^{23}$ Compare Salow (1979) p. 81.

${ }^{24}$ See e.g. Yellen (1984) p. 201.

${ }^{25}$ See e.g. Thaler (1989), Katz (1986).
} 
- shírking models (e.g. Shapiro and Stiglitz (1984))

- gift exchange, fair wage and rent sharing models (e.g. Akerlof (1982) and Akerlof and Yellen (1988))

- turnover models (e.g. Stiglitz (1974) and Salop (1979))

- adverse selection models (e.g. Weiss (1980))

Extensive summaries of efficiency wage models are found in Akerlof and Yellen (1986), Katz (1986), Stiglitz (1987b) and Layard, Nickell and Jackman (1990).

The efficiency wage model described in chapter four is based on elements of shirking and rent sharing models. The mechanism that leads to labour market inefficiencies is the same in all shirking and fair wage models: The labour contract is incomplete and therefore wages have to motivate workers to perform adlequately in those variables of the worker that can not be enforced by the firm. First shirking models and gift exchange models are surveyed extensively before the mechanism that leads to labour market inefficiencies in turnover and adverse selection models is briefly reviewed. Finally empirical evidence of efficiency wage models is presented.

\subsubsection{Shirking, Gift Exchange, Fairness and Profit Sharing}

In shirking models firms have imperfect information concerning the actions of workers. The uncertainty about effort and the impossibility to formulate complete contracts on all contingencies of the labour process just leave the wage rate as an instrument to induce effort (compare e.g. Rasmussen (1994), chapter. 7.2, Fehr and Gaechter (1996)). Efficiency wage models assume that with imperfect monitoring and full employment and when piece rate wages are impracticable, workers have an incentive to shirk. In addition, it has to be assumed that there are no job switching (search) costs and no adverse reputational effects on workers, if they losi their job when caught shirking. In order to induce a punishment for the workers when shirking, the firms rise wages above the general level. If all firms do that, however, the punishment threat clisappears again and instead a wage-price spiral is launched. The next step is that the aggregate demand for labour decreases, if the general wage level increases and unemployment results. This introduces a "disciplinary device", because the workers are threatened by unemployment when caught shirking. As a higher unemployment benefit reduces the punishment of being fired, it induces higher 
wages and therefore higher unemployment. In equilibrium the bulk of unemployed are not those caught shirking, however, as the unemployment level will be that high that it is better for most workers not to shirk. Most unemployed are randomly fired non-shirking workers while there is a persistent oversupply of labour in shirking models. Oversupply is caused by the higher than market clearing wages. It is shown that the equilibrium unemployment is not socially optimal and labour market inefficiencies are incurred by informational asymmetries and incomplete labour contracts. ${ }^{26}$ Unemployment is predicted to be higher under the following circumstances: high monitoring costs, high discount rates for workers, high costs for employers from shirking.

The shirking model provides a rationale for dual labour markets à la Doeringer and Prone ${ }^{27}$ with an utility differential for equally skilled workers across the primary and secondary sector and rationing of primary sector jobs. Here, the detection of shirkers is difficult in the primary sector, while it is costless in the secondary sector. In addition shirking workers incur higher costs in the primary sector than in the secondary sector. Therefore primary-sector firms find it advantageous to pay more than the going wage in order to elicit effort from the workers, granting the workers a job rent. ${ }^{28}$

The wage has two economic functions in shirking models, labour allocation and incentives for adequate employee performance. It would be efficient to separate these functions and introduce bonds that are repaid at the end of the career, if the worker is not found shirking. ${ }^{29}$ In bonding models, moral hazard of the firm is, however, a large problem, because shirking is not easily verifiable. ${ }^{30}$ The reputation of the firm is the only reason not to steal workers' bonds at the end of the career, because there is no extra profit from the labour relationship in the future. Even the intervention of a third party as a referee bears the risk of collusion between the firm and the third party or might impose high enforcement costs.

Seniority wages or deferred compensation schemes also may be applied to reduce shirking and induce truthful behaviour (see Lazear and Moore (1984)). These implicit bonding schemes provide the worker with a wage that is lower than his or her marginal productivity at the start of the career and higher wages than labour productivity later. In reality these

\footnotetext{
${ }^{26}$ Compare e.g. Shapiro and Stiglitz (1984).

${ }^{27}$ See Doeringer and Piore (1972) and Katz (1986) p. 239 and Katz and Summers (1989) p. 211.

${ }^{28}$ See Bulow and Summers (1986).

${ }^{29}$ This is the so-called bonding critique (compare the survey in Katz (1986) pp. 243-246 and Lazear (1981)).

${ }^{30}$ See e.g. Yellen (1984) p. 202 or Saint-Paul (1995) p. $187 f$.
} 
indirect incentive schemes are found more often than direct performance bonds that face severe legal restrictions.

The model in chapter four is based on a shirking model. It adds human capital as an additional reason for firms paying higher than market clearing wages, because it is assumed that workers can decide themselves on humin capital investment. If the bonus for human capital payed by the firm is too low, workers are not motivated to invest sufficiently in human capital. Uncertainty is caused by the firm that does not indicate beforehand which worker is fired in case of an oversupply of workers. When a workers loses his or her job induced by high wages paid by the firm, the worker also loses the sunk investment costs. This provides a stronger motivation for the workers not to reduce labour demand too much in contrast to shirking models where laid-off workers earn their full outside option.

Like in the shirking models, it is assumed in fairness models that labour contracts are incomplete and firms have to use wages in order to motivate their workers. ${ }^{31}$ Workers exert more effort when they thinik that they are fairly paid. Firms solve the motivational problem however not by paying incentive wages, but by "gift exchange." The firm's gift is a voluntary wage that is higher than the market clearing level, while the worker's gift is a more than the minimal work effort. In fairness models, workers' effort frequently depends upon the group norms determining a fair work load and a fair wage which might be above the market clearing level. Here the relative payment of a worker with respect to peer groups plays a role. Therefore work effort is calibrated by social standards set by others and reference group norms determine performance. ${ }^{32}$ If for example less skilled workers take the wage of better skilled workers as anchor in determining a fair wage, this may result in unemployment for less skilled labour and wage compression. ${ }^{33}$ Here, unskilled workers are too expensive, because their fair wage exceeds their labour productivity. The firm can not afford then to have a higher wage differential between skilled and unskilled workers if it does not want to undermine the motivation of the unskilled workers. Here norms linked to work performance cause labour market inefficiencies.

Workers perceive it as lair that the firm shares profits in order to demonstrate its commitment to faimess and thereby induce effort of the workers. People do not seek uniformly to help other people, rather they do so according to how generous other people

\footnotetext{
${ }^{31}$ Compare e.g. Fehr and Gidechter (1996).

${ }^{32}$ Compare Akerlof (1982) pp. 552f.

${ }^{39}$ Compare Akerlof and Yellen (1988) p. 47.
} 
are (reciprocity). ${ }^{34}$

Faimess models can explain, why firms do not fire workers who tum out to be less productive, why piece rates are avoided and why firms set work standards exceeded by most workers. $^{35}$ Fairness models predict that firms share profits with their workers and that high wages are paid in industries where teamwork and worker cooperation are important.

\subsubsection{Turnover and Adverse Selection}

The main assumption of turnover models is that the lower the wage the higher is the rate of labour turnover. As long as the firm has to bear part of the turnover costs, turnover rednces the net productivity of a worker. Therefore exogeneous turnover costs induce labour market inefficiencies here. The turnover model predicts that high wages are found in firms where hiring and training costs are considerable. The wage premium should reduce the turnover rates in these firms, because workers are not tempted to accept a better paid job at another firm. Therefore different wage premia in different industries may be found. The labour market is in equilibrium when the costs of turnover to firms and the benefits of quitting to workers are equal ${ }^{36}$ or if the marginal sawings in turnover costs are equal to the extra efficiency wage costs. ${ }^{37}$ These labour turnover costs and benefits may not react on the conditions in the external labour market and therefore unemployment may be created. during the business cycle or by adverse aggregate shocks.

In adverse selection madels firms have imperfect information concerning the characteristics of the workers when these apply for a job. Adverse selection models use two critical assumptions: The wages received by the workers are not proportionate to their productivity, but the acceptance wages of workers are an increasing function of their productivity. ${ }^{38}$ Characteristics of the workers are not always readily discermible. Firms are however reluctant to pay for the measurement of these characteristics or link payments to characteristics which are not discemible to the workers. Workers on the other hand know their productivity and do not accept jobs with wages below it.

It is not in the interest of the firms to employ unemployed workers who demand a lower wage than the efficiency wage in adverse selection models, because this signals an upper

\footnotetext{
${ }^{3}$ Compare Rabin (1993) p. 1281 and Fehr et al (1997).

${ }^{3}$ See e.g. Yeller (1984) p. 204.

${ }^{36}$ See Salop (1979) p. 118.

as See Stiglitiz (1974) p. 199.

${ }^{3}$ See Weiss (1980) p. 527.
} 
bound for the worker's labour endowment that increases the expected cost per efficiency unit of labour. In equilibrium, efficiency wages are paid that minimize the cost per expected labour productivity unit. These wages may be higher than market clearing. Therefore job queues are observed, because workers earn rents while the unemployed workers want to work for even less. They are not accepted, however. Again, informational asymmetries are the reason for labour market inefficiencies. Differences in technology make it profitable to pay higher wages for those industries that are more sensitive to quality differences or have higher costs of measuring labour quality. This again leads to dual labour markets.

\subsubsection{Empirical Evidence}

Efficiency wages are found in empirical investigations, when particular industry and firm characteristics can be associated with industry wage premia. Frequently, empirical evidence for efficiency wages is hard to find, however. ${ }^{39}$ In studies by Levine (1988) and Wadhwandi and Wall (1990) it is shown that relative wage increases may raise output with an elasticity of up to unity. In Katz (1986), Krueger and Summers (1988) and Bulow and Summers (1986), the argument is advanced that considerable, stable and internationally similar inter-industry wage differentials may only be explained by rent-sharing induced by efficiency wage considerations (and not by compensating differentials or unobserved worker ability). ${ }^{40}$ Industry wage differentials are compensating for nonwage job attributes that directly affect the utility of workers. The high correlation in industry differentials among different occupations ${ }^{4 .}$ is especially consistent with fairness and profit sharing models in which norms are linked within a firm or industry. ${ }^{42}$ When one group of workers earns eff-ciency wages, fairness demands that also other occupations within that firm enjoy similar mark-ups although those are not necessary. Another aspect may be profit-sharing when an equal share of the profit is distributed on the labour force.

Krueger (1991) finds empirical evidence that efficiency wages are paid in order to prevent shirking and motivate the workers. He compared wage tenure earnings profiles in company-owned fast food restaurants and franchise-owned restaurants. He finds that in

\footnotetext{
${ }^{39}$ Compare e.g. Thaler (1989).

${ }^{40}$ The impact of observable differences in working conditions on wage differences is small, see $K r$ rueger and Summers (1988) pp. $268 \mathrm{Af}$, Murphy and Topel (1987). The latter doubt, howewer, the efficiency wage argument of wage differentials. They provide a story about matching of talents with the "right "industry.

4 See the study by Kotz and Summers (1989) and Dickens and Katz (1987)

42 See Thater (1989) p. 188, Kats and Summers (1989) p. 304, Lang and Kahn (1990) and Fehr et al (1995) p. 3.
} 
company-owned restaurants, where monitoring is assumed to be less rigorous, the slope of the tenure-earnings profile and the present value of compensation are larger, supporting the shirking variant of the efficiency wage notion. Rebitzer (1995) finds a negative correlation between high levels of supervision and average wage levels for contract maintenance workers in the petrochemical industry. In their survey, Layand, Nickell and Jackman (1991) pp. 164-168 conclude taking several empirical studies into consideration that as small firms are less capital intensive, have lower product market power and therefore lower profits, and find it easier to monitor the efforts of the workers, it is not surprising that they pay less. Efficiency wages are therefore just paid by large firms and small firms form a secondary, market clearing labour market. Krueger and Summers (1988) find that there is a negative correlation between industry wages and quit rates. This supports the turn-over wariant. Evidence for the adverse selection models is difficult to find, however.

A series of experiments ${ }^{43}$ demonstrates that reciprocal fairness plays a crucial role on wage determination. Evidence is presented that wages increase with the potential revenue from the worker and that worker performance increases with wages when effort can not be specified in a labour contract. This positive wage-effort relation increases efficiency. Also the hypothesis of the shirking-variant of efficiency wages are confirmed in economic experiments, i.e. higher wage offers are associated with less shirking behaviour (see e.g. Fehr, Kurchsteiger and Riedl (1995) or Fehr, Gächter and Kirchsteiger (1997)). Kahneman, Knetsch and Thaler (1986) find in telephone surveys that fairness may have an impact on wage setting. Wages may be relatively insensitive to excess labour supply, while wage decreases are accepted only then as being fair if the reference profit level of the firm (that may be higher than zero) is endangered otherwise. These observations support the gift exchange and reciprocal fairness notion in labour market relations that lead to job rents and involuntary unemployment.

Chapter seven provides additional arguments for the hypothesis that trust and faimess have an impact on labour market relations when labour market contracts are incomplete. The argument is related to that used in Fehr, Gächter and Kirchsteiger (1997), but is based on an insider-outsider relationship.

\footnotetext{
${ }^{43}$ See e.g. Fehr and Gachter (1996) for a survey.
} 


\subsection{Conclusions}

This chapter shows that human capital formation is an important economic activity attracting individual investments and public subsidies. In contrast to other investments, human capital investment entails sunk costs. Human capital formation also may lead to market power of skilled workers. Both aspects link human capital formation and labour market imperfections that cause unemployment. It will be digressed in the following chapters that the sunk costs property of human capital formation and market power of skilled workers can lead to (additional) unemployment although human capital formation increases labour productivity.

Insider-outsider and efficiency wage models present arguments for unemployment when all market participants act individually rational. In insider-outsider models market inefficiencies are incurred by the fact that insiders can decide (first) on wage demand and do not take into account the utility of outsiders. Several reasons such as entry and exit costs, harassment of entrants or non-cooperation between insiders and entrants are mentioned that explain why outsiders are not able to underbid the wage demand of the insiders although insiders earn rents.

In the shirking and fair wage variant of efficiency wage models, market inefficiencies are caused by incomplete labour markets. Workers have to be motivated to exert a higher share of their labour potential by higher than market clearing wages. Here workers voluntarily accept a certain risk to be unemployed in exchange to a higher wage for the employed workers. 


\section{Chapter 3}

\section{Human Capital Creates Insider Power}

\subsection{Introduction}

Most economists are inclined to think that education and training reduces unemployment. (compare also the introduction of this thesis). Firm-specific human capital acquired by training enhances flexibility of the workers and decreases the mismatch between skills demanded and supplied, especially in times of rapid technological change. In addition there is a negative empirical correlation between unemployment incidence and the level of human capital. ${ }^{1}$ The higher the level of education attained the higher are the chances to find a job. Therefore a positive relationship between education and employment is taken for granted. ${ }^{2}$ The theoretical economic literature widely accepts this as common sense and indeed does not contribute a lot about the relationship between employment and human capital, because it seems self-evident ( Hart and Moutos (1995) p. 48).

All arguments above are centered on the positive effect of investments in human capital on labour demand and productivity, however, while it is implicitly assumed that workers invest voluntarily in training such that the labour demand is maximal. This is not necessarily the case. From insider-outsider models, we know that insiders maximize their rents by asking a wage mark-up which reduces labour demand if labour demand is higher than the number of insiders. Outsiders have no possibility to underbid the insiders in these models due to a broad variety of reasons (compare the literature survey about insider-

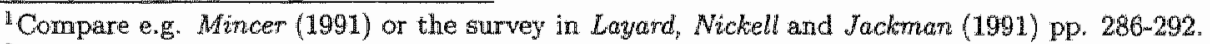

${ }^{2}$ Compare also the quotes of Lindbeck (1996) and Alogoskoufis et al (1995) in the introduction of this thesis.
} 
outsider models in chapter two). Insiders enjoy market power, because they have the right to set wages while firms determine enployment. If insiders' wages are higher than market clearing and outsiders are not able to underbid this wage, the firm does not hire (all) outsiders.

In this chapter the argument is made that strategic investment of insiders in human capital can be an additional reason for barriers to entry which creates involuntary unemployment, because it does not allow outsiders to underbid the higher than market clearing wage. Barriers to entry can be erected even if there are no transaction costs for labour turnover, outsiders and insiders have "identical conditions to work" 3 -i.e. the same access to training and the same initial human capital level-and insiders fully cooperate with outsiders when outsiders enter the labour market. Unemployment is involuntary in this case, because identical workers are randomly split first in insiders and outsiders and then insiders block the market access of the unemployed. The unemployed are willing to work under the ruling conditions that grant a higher rent to the insiders than the unemployment benefit, while all workers would be employed if the wage would decrease.

\subsection{The Model}

We assume an economy which consists of a single firm and a labour force of $N$ persons. In the insider-outsider scenario, the firm decides how many workers to employ, while the workers demand a wage invest in human capital. ${ }^{4}$ The agents maximize their objective functions taking the reactions of the other agents into account. For simplicity, and analom gous to other insider-outsider models, outsiders and insiders are modelled as homogeneous groups. ${ }^{5}$ In the bench mark scenario, a social planner sets all parameters simultaneously in order to maximize social welfare.

\subsubsection{Time}

In the insider-outsider scenario, it is assumed that $n$ insiders were employed in the previous period, while $N-n=m$ outsiders were unemployed. Insiders have the advantage to set

\footnotetext{
${ }^{3}$ Compare Lindibeck and Snower (1987), p. 414.

This assumes complete market power of the workers as usual in insider-outsider models (compare e.g. Blanchard and Sunmers (1986), Lindbect and Snower (1987), Gottfries and Horn (1987) or Carruth and Oswald (1987)]. (1987)

${ }^{5}$ Compare e.5. Lindbeck and Snower (1986, 1987), Carruth and Oswald (1987), Gott fries and Horr
} 
their bonus demand and investment in human capital before the outsiders. The outsiders on the other side know the offer of the insiders and react on it. Finally the firm decides whom to accept. The sequence of events is:

\begin{tabular}{|c|c|}
\hline stage & action \\
\hline 1 & insiders invest in human capital and set their bonus demand \\
\hline 2 & outsiders invest in human capital and set their bonus demand, or not \\
\hline 3 & the firm decides how many people and which ones to employ \\
\hline
\end{tabular}

Table 3.1: Time

All workers who want to invest in human capital have to do this before they know if they will be employed. The game ends at the end of the period. There is no uncertainty in this game about parameters and the behaviour of the agents. The insiders can therefore calculate their probability to be employed again by backward induction.

Firms replace insiders by outsiders if outsiders' profit offer is higher than that of the insiders. Outsiders may underbid the wage demand of the insiders or match (imitate) it. If outsiders underbid the wage offer of the insiders, the firm replaces all insiders by outsiders, if the aggregate profit increases then. If outsiders imitate insiders, outsiders are hired only if labour demand of the firm is larger than the number of insiders. Outsiders know the profit offer of the insiders to the firm before they have to decide about bonus demand and investment in human capital. They invest in human capital if this is beneficial for them, i.e. when there is a chance to get a job and investment costs are smaller than the expected revenues of investing in human capital.

\subsubsection{The Problem of the Firm}

In order to be able to compare the results of this model with the insider-outsider models developed by Lindbeck and Snower and others, we use their salient elements also in this madel. The firm maximizes profit $\pi$. For simplicity let the production function of the firm be of a Cobb-Douglas type. ${ }^{6}$ The revenues of the firm depend on the number of accepted workers $l$ and the amount of human capital investment per worker $c$ and the bonus demand b. Technological progress makes it necessary that workers continually educate themselves.

\footnotetext{
${ }^{6}$ This production function is virtually the same as in Lindbeck and Snower (1991) p. 194. The only difference is the interpretation of the productivity coefficient $c$ as investment in human capital instead of effort. This analogy is possible as both costly activities enhance labour productivity for the entire game in this static setting. The decisive difference between effort and human capital investment is the sunk cost property of the latter. "This will be discussed below in detail.
} 
In order to make the necessity to invest in human capital as pervasive as possible, it is assumed that without human capital investment, production is not possible.

The firm pays a "basic" wage $\bar{s}$ equal to the unemployment benefit that is independent of human capital and given exogeneously. In addition a bonus $b$ per unit of new human capital has to be paid as a reward for investment in training. This bonus is determined by the workers. Notice that the firm just accepts workers with the same amount of human capitala and the same remuneration. ${ }^{7}$ Therefore no differentiation in the production function between insiders and outsiders is necessary and labour demand is denoted $l$. The unemployment benefit $\bar{s}$ and labour productivity parameter $A$ are assumed to be exogeneously given.

The profit function of the firm reads as:

$$
\pi=A l^{\beta} c^{1-\beta}-(b c+\bar{s}) l
$$

with $0<\beta<1$. Here the price of the good produced is normalized to unity. It can be shown that the revenue function is applicable under different elasticities of demand or market structures. ${ }^{8}$ Therefore no assumptions about the goods market are necessary.

From the profit function of the firm (3.1), the demand for labour can be derived from the first order condition with respect to $l$ :

$$
l=c\left(\frac{\beta A}{b c+s}\right)^{\frac{1}{1-\beta}}
$$

Firm's labour demand is negatively dependent on the costs for labour $b$ and $\bar{s}$ and positively on labour productivity $A$. The impact of investment in human capital $c$ on labour demand depends on its size: for small levels of investment it is increasing, for a larger $c$ it decreases. This is due to the concavity of the revenue function and the linearity of the cost function with respect to $c$. Hence, there is an optimal investment associated with every combination of the other parameters and variables that maximizes labour demand.

\footnotetext{
${ }^{7}$ The assumption that the frm accepts only a homogeneous labour force with the same wage level and haman capitall endowment is frequently made. The fair wage notion may prevent the firm to pay identical workers difterent remuneration. Compare e.g. the insider-outsider models of Cormuth and Oswald (1987) or Gotifries and Horn (1987).

This stetement is proven in the first appendix of this chapter.
} 


\subsubsection{The Problem of the Workers}

The homogeneous risk-neutral workers optimize their surplus that is defined as their monetary income. If labour demand is smaller than the number of workers in the previous period, then every worker faces the same probability to lose his/her job. This assumption is usual in insider-outsider models. ${ }^{9}$ Investments in human capital always entail elements of sunk costs as they cannot be used when being unemployed. Here, the workers lose their entire investment when they are unemployed, because the outside option is independent of human capital while workers have to invest in human capital before they know if they can keep their job.

In defining the surplus function of the workers, two situations can be distinguished. The first possibility is full employment $(l \geq N)$. The surplus function then reads as:

$$
s=(b c+\bar{s})-(1+r) c^{2}
$$

That is, the workers earn the basic wage in the primary labour market $\bar{s}$ plus the bonus $b$ paid on each unit of human capital investment $c$ with certainty, while they have to subtract the investment in specific human capital. The costs of investment are assumed to be quadratic in the amount of human capital, $c$, with a shift parameter $(1+r)$. Therefore the investment in human capital shows decreasing returns to scale. This is frequently found in empirical studies (see Willis (1986) p. 536 for a survey). Therefore this assumption is widely used in theoretical specifications of the human capital formation function. ${ }^{10}$

The second possibility is unemployment $(l<N)$. We find the following expected surplus function of a risk-neutral worker with job-uncertainty: ${ }^{\text {II }}$

$$
s=\frac{l}{N}\left(b^{\prime} c+\bar{s}\right)+\left(1-\frac{l}{N}\right) \bar{s}-(1+r) c^{2}
$$

\footnotetext{
${ }^{9}$ See also Lindbeck and Snower (1988), p. 172. By assuming that the workers are equal and taking the consequences of their decisions into account, we circumvent the problem that individually rational. decisions may produce inferior solutions in prisoners-dilemme structures (compare eg Vogt (1986)). The main argument in favour of this assumption is the right of the workers to set human capital themselves and therefore being able to directly influence the labour demand of the firm.

${ }^{10}$ Compare e.g. the convex cost function of investment in human capital in Siebert (1985) p. 16 or Hart and Moutos (1995) p. 16. We can also assume that specific human capital investments are made on the concave part of the learning curve, compare e.g. Becker (1983) p. 53. Becker also explicitly points at decreasing returns to scale for human capital investrnents due to limited individual physical and intellectual. capacity, Becker (1983) pp. 98-102

11This is the formulation for the objective functions of workers (unions) most widely spread, compare e.g. Layard, Nickell and Jackman (1991), p. 100 and Carret and Oswald (1987), P. 433.
} 
The basic wage $\bar{s}$ and bonus mark-up $b^{\prime}$ over the outside option is earned with probability $\frac{l}{N}$. The exogeneous outside option-unemployment benefit $\bar{s}$-is earned for sure, while the investment costs have been made before the employment decision under the uncertainty who will be able to keep the job. In the case of unemployment workers lose their investments in human capital. The focus of this chapter is on market power of workers when investment in human capital entails sunk costs. Therefore a distinction between general and specific human capital is beyond the scope here. Virtually all investments in human capital entail elements of sunk costs even if there are other firms that are interested in the worker. ${ }^{12}$ In this model all human capital investments are specific, because the outside option is unemployment and all investment costs are lost in the case of unemployment. It is shown below that this leads to labour market inefficiencies when workers can determine their human capital investments themselves.

We assume that bonus income is taxed to provide a compensation for those who are unemployed in order to have a closed model. This assumption is of course not necessary in the full employment case in equation (3.3). Hence, $b^{t}$ represents bonus premium after taxes.

Since taxes have to be paid to finance unemployment premia, it is clear that $\left(b-b^{\prime}\right) c l=$ $(N-l) \bar{s}$ should hold where $b$ is the net bonus paid by the firm. Substitution in equation (3.4) yields:

$$
s=\frac{l}{N}(b c+\bar{s})-(1+r) c^{2}
$$

which is the relevant surplus function in case of unemployment.

The human capital supply function of the workers under uncertainty $(l<N)$ is derived by maximizing the surplus function (3.5) with respect to human capital:

$$
c=\frac{l b}{2 N(1+r)}
$$

The higher the bonus $b$ and relative labour demand $\frac{l}{N}$ of the firm, the higher the motivation of the workers to invest in human capital. Due to the sunk-cost property of the investment in human capital, the investment declines if the chances to stay in the labour market worsen (i.e. $\frac{1}{N}$ decreases). The investment decreases also when the cost parameter, $1+r$, increases.

\footnotetext{
${ }^{12}$ Compare also Stevens (1994).
} 
The analogous investment reaction function of the workers under certainty is derived from surplus equation (3.3):

$$
c=\frac{b}{2(1+r)}
$$

In the next section the situation is described when the labour force $N$ is split into $n$ insiders and $m$ unemployed outsiders.

\subsubsection{Insiders and Outsiders}

If the homogeneous labour force is split into $n$ insiders and $m$ unemployed outsiders (with $m+n=N$ ), both groups of workers may behave different. Insiders are interested in keeping their jobs, while outsiders may try to join the work force. Insiders and outsiders are assumed to be identical except with respect to their work status.

When labour demand declines below the number of insiders, the risk to lose a job for an insider is relative to the number of insiders. The expected surplus of the insiders does not increase when labour demand is larger than the number of insiders. In this case the full employment surplus (3.3) is valid. Therefore insiders are not interested in absolute labour demand but in relative labour demand with respect to the number of insiders. In the insider-outsider model, insiders' expected surplus under uncertainty is according to equation $(3.5):^{13}$

$$
s=\frac{l}{n}(b c+\bar{s})-(1+r) c^{2}
$$

The investment reaction function of the insiders with uncertainty is therefore analogous to equation (3.6):

$$
c=\frac{l b}{2 n(1+r)}
$$

\footnotetext{
${ }^{13}$ Insiders pay the unemployment benefit for the unemployed outsiders. The underlying surplus with the payment of the firm $b$ before unemployment insurance equals therefore (compare (3.4)):

$$
s=\frac{l}{n}(b c+\bar{s})+\left(\frac{N-l}{n}\right) \bar{s}-(1+r) c^{2}=\frac{l}{n}\left(b c+\bar{s}-\left(\frac{N-l}{l}\right) \bar{s}\right)+\left(\frac{N-l}{n}\right) \bar{s}-(1+r) c^{2}
$$

Notice that the weights $\frac{1}{T_{n}}$ and $\left(\frac{N-1}{H}\right)$ do not add to unity.
} 
Outsiders invest in human capital if this is beneficial to them, i.e. if the expected benefits are higher than the expected costs of investment in human capital. Outsiders earn the outside option $\bar{s}$ if they stay unemployed and do not invest in human capital. The benefit of human capital investment is the bonus $b c$ paid by the firm if the outsider is employed, while the costs are $(1+r) c^{2}$ and the payment for unemployment benefit if not all workers find a job. The outsiders behave- like the insiders-as if a union would coordinate their investment and bonus demand in order to maximize their joint surplus. If outsider outperform the insiders and replace them accordingly, their surplus function is equal to (3.8) and the investment reaction function under uncertainty is equal to (3.7) when $n$ is replaced by $m$ due to the symmetry between both groups of workers.

Outsiders may however also be motivated to invest into human capital when they can not outperform the insiders, but join them in the labour force. This is the case if labour demand indnced by the insiders is large enough that sufficient outsiders can enter the labour market. The outsiders invest in human capital, if their expected surplus is higher than their outside option $\bar{s}$, or if labour demand is at least:

$$
\ell=\frac{m\left(\bar{s}+(1+r) c^{2}\right)}{b c+\bar{s}}+n
$$

Labour demand has to be higher than the number of insiders by at least as much such that the sunk costs in human capital are paid off on average for all outsiders. This minimum labour demand increases with the number of outsiders and the investment costs while it decreases with the bonus paid for human capital. Notice that (3.10) is only valid if outsiders do not outperform insiders, but imitate their bonus and human capital decision.

\subsection{Optimum}

A typical benchmark case is to introduce a social planner that maximizes the total rent from investment in human capital. The objective function of the social planner is defined by:

$$
R=A l^{\beta} c^{1-\beta}-(1+r) l c^{2}+\bar{s}(N-l)
$$

Notice that in the context of the social planmer scenario, $\bar{s}$ indicates the shadow price for labour that is larger or equal to zero. If we take the condition $\partial R / \partial c=0$ into account, one can derive that: 


$$
\frac{\partial R}{\partial l}=\frac{3 \beta-1}{2} A\left(\frac{c}{l}\right)^{1-\beta}-\bar{s}=0
$$

In order to obtain a reasonable social optimum, we have therefore to assume that $3 \beta-1>0$. This rules out under-employment in the optimum and we have instead $l^{*}=N$ and $s>0$.

In the relevant full employment case, total rent is defined as:

$$
R=A N^{\beta} c^{1-\beta}-(1+r) N c^{2}
$$

Efficient investment in human capital $c^{*}$ is found by maximizing equation (3.11) with respect to $c$ :

$$
c^{*}=\left(\frac{(1-\beta) A}{2 N^{1-\beta}(1+r)}\right)^{\frac{1}{1+\beta}}
$$

Efficient investment increases with productivity of human capital $A$ and decreases with the number of workers $N$ and investment costs $1+r$. Substitution of $c^{*}$ in (3.11) then yields the optimal rent $R^{*}$ :

$$
R^{*}=(1+\beta) \Omega^{\frac{1}{1+\beta}} N^{\frac{3 \beta-2}{1+\beta}}
$$

with

$$
\Omega=\frac{A^{2}}{4}\left(\frac{1-\beta}{1+r}\right)^{1-\beta}
$$

This expression will be used frequently in the equations below.

The optimal rent depends positively on the effectiveness of humar capital investment $A_{4}$ and the size of the labour force $N$, while it decreases with higher investment costs $r$. Notice that optimal rent $R^{*}$ and optimal investment in human capital $c^{*}$ are independent of the unemployment benefit $\bar{s}$ since full employment always prevails. In addition also the bonus baid for buman capital investment has no impact on $R^{*}$. This is consistent with the insight that the social planner can choose the bonus level freely in order to distribute the rent between the agents. Therefore rent distribution is independent of rent creation and the social planner can distribute rents between frm and employees as it seems appropriate by determining $b$.

It is obvious that the resulting maximal profit $\pi^{*}$ in this case is defined by 


$$
\pi^{*}=\mathbb{R}^{*}-\bar{s} N
$$

Here the social planner attributes the entire rent to the firm, while workers only earn their outside option $\bar{s}$. Hence maximal profit $\pi^{*}$ is a decreasing function of the outside option. The profit of the firm increases with $N$ due to the assumption $3 \beta>1$.

The aggregate outside option of the workers never can be higher than the optimal rent $R^{*}$, because the workers would then earn less than their unemployment benefit when the firm enjoys part of the rent. This is not possible. The maximal outside option $\widehat{s}$ is therefore defined as:

$$
\widehat{s}=\frac{R^{*}}{N}
$$

It seems reasonable to assume that $\bar{s}<\widehat{s}$ should hold and the ontside option $\bar{s}$ is defined for convenience as share $\varepsilon$ of $\hat{s}$ :

$$
\bar{s}=\epsilon(1+\beta) \Omega^{\frac{1}{1+\beta}} N^{\frac{2 \beta-2}{1+\beta}}
$$

with $\varepsilon \in[0,1]$.

Now the results of the benchmark labour market can be compared to the insideroutsider scenario.

\subsection{Insider-Outsider Scenario}

\subsubsection{Insiders Are Monopolists}

In order to assess labour market inefficiencies caused by insiders, first an insider-outsider scenario is constructed where outsiders are not able to underbid the offer of the insiders. This assumption is made in several insider-outsider models, compare e.g. Blanchard and Summers (1986), Gottfries and Horn (1987) or Carruth and Oswald (1987). Therefore the 7. insiders enjoy a monopolistic market power. In a next step it is shown if the possibility of the outsider to underbid insiders has an impact on employment and labour market performance.

In the monopolistic insiders case without underbidding, outsiders either may imitate the bonus offer and human capital investment of the insiders or do not try to enter at all 
Outsiders only invest, in human capital if this is beneficial to them, i.e. if the chance to get a job is sufficiently large to re-earn the sunk investment costs in human capital.

The monopolistic insiders choose a level of human capital such that they optimize their (expected) surplus without taking the surplus of the outsiders into account. Since the surplus with job uncertainty (3.8) is always smaller than the surplus with certainty (3.3) ${ }^{14}$, the optimal human capital/bonus combination is chosen such that labour demand is at least the number of insiders. It is discussed below if it is in the interest of the monopolistic insiders to increase labour demand above $n$.

Now the surplus and investment in human capital of the monopolistic insiders are derived. If the surplus of the insiders with job certainty (3.3) is maximized with respect to $c$, taking the labour demand of the firm $l(3.2)$ into account, we obtain:

$$
c^{\text {mon }}=\left(\frac{\beta(1-\beta) A}{2(1+r) l^{1-\beta}}\right)^{\frac{1}{1+\beta}}
$$

The investment of the monopolistic workers increases with efficiency parameter $A$ and decreases with the costs of human capital investment $(1+r)$ and the number of workers demanded $l$. When we compare the investment of the monopolistic workers to that in the optimum (3.12), we find investment to be inefficiently high, i.e. $c^{\text {mon }}>c^{*}$, when the number of workers demanded is smaller than a share $\beta^{\frac{1}{1-\beta}}$ of the entire labour force. This is due to the fact that on the one hand the investment of the workers is always biased below with respect to the efficient investment, because the workers do not enjoy the entire surplus created by human capital investments. ${ }^{15}$ This can be seen from the additional $\beta$ in the numerator. On the other hand investment increases when the number of insiders $l$ decreases, because a lower rent-share has to be transferred to the firm in order to obtain a lower labour demand. In this scenario human capital investment is divided by the number of insiders $l$ instead of the entire labour force $N$. The surplus the monopolistic workers enjoy is:

$$
s^{\text {mon }}=(1+\beta) \beta^{\frac{2}{1+\beta}} \Omega^{\frac{1}{1+\beta}} n^{\frac{-2(1-\beta)}{1+\beta}}
$$

Notice that the surplus of the monopolistic insiclers decreases with the number of workers demanded $l$. The monopolistic insiders pay the unemployment benefit for the unernployed outsiders. ${ }^{16}$ Therefore the surplus of the insiders is optimal, when the number of

\footnotetext{
${ }^{14}$ This statement is proven in the second appendix of this chapter.

${ }_{15}$ Compare also MocLeod and Molcomson (1993).

${ }^{16}$ Compare footnote 11 .
} 
workers demanded is minimal without losing job certainty. This is the case when the number of workers demanded is the number of insiders in the previous period, $n$. When the insiders are able to set bonus demand and human capital investment monopolistically such that their surplus is maximal, labour demand is set at $n$ and outsiders are involuntarily unemployed if $s^{\text {inon }}>\bar{s}_{\text {; }}$, because they would work for a lower wage while they cannot underbid the insiders by assumption. Therefore also in equation (3.17) labour demand $l$ has to be substituted by the number of insiders $n$.

Substituting insider investment (3.17) into the profit function of the firm (3.1), with employment equal to $n$, we obtain:

$$
\pi^{\text {mon }}=2(1-\beta) \beta^{\frac{1-\beta}{1+\beta}} \Omega^{\frac{1}{1+\beta}} n^{\frac{3 \beta-1}{1+\beta}}
$$

From equation (3.19) one sees that the profit of the firm is increasing in the number of insiders when the insiders offer the monopolistic bonus/investment combination. The higher the number of insiders seeking ernployment the higher is the rent offered to the firm to induce an adequate labour demand. Therefore also this model derives the familiar result that the costs or rents of specific human capital are divided between firm and workers (compare Becker (1983) pp. 26-37). The sharing decision in this model is however not introduced in order to reduce the likelihood of either party unilaterally terminating the employment relationship and imposing on the other party a loss in return (compare Hashimoto (1981)). Here, insiders grant a part of the rent to the firm in order to make sure that labour demand is sufficient for full employment of insiders.

The social welfare is in the case of monopolistic insiders derived by substituting (3.17) into the social welfare function $R^{\text {man }}=\pi^{\text {mon }}+n s^{\text {mon }}+m \bar{s}$. This yields:

$$
R^{\text {mon }}=\left(\beta^{2}-\beta+2\right) \beta^{\frac{1-\beta}{1+\beta}} \Omega^{\frac{1}{1+\beta}} n^{\frac{3 \beta-1}{1+\beta}}
$$

Notice that $R^{\text {mon }}$ increases in $n$ and that even at full employment (i.e. $n=N$ ) holds $R^{\text {mon }}<$ $R^{*}$ (compare (3.13) and Figure 3.2 below). Therefore social welfare and employment clearly are reduced and labour market inefficiencies caused by the behaviour of the monopolistic insiders. The monopolistic insiders scenario would only generate efficient results, if training would have no impact on productivity $(\beta=1)$ and if there would be no unemployed outsiders $(n=N)$. In the next section it is demonstrated which impact the possibility of outsiders to underbid the insiders has on labour market performance and employment. 


\subsubsection{Insiders Are Contested by Outsiders}

In the previous section it is shown that if outsiders are not able to underbid the offer of the insiders, insiders never voluntarily allow for the entry of outsiders, because this would reduce their rent. In this section, it is argued that the opportunity of outsiders to underbid the insiders may induce the employment of outsiders. Underbidding is however not always sufficient to prevent involuntary unemployment. When the outsiders are not able to offer a high enough profit to the firm, the insiders are still able to skim their monopolistic insider rent $s^{\text {mon }}$ and keep employment at $n$. The necessity to invest in human capital may therefore be sufficient for the insiders to defend their rents against potentially underbidding outsiders and create involuntary unemployment.

Now the identical outsiders underbid the insiders if this grants them a higher rent than the outside option. In order to tackle the question, if the insiders are able to erect barriers against outsiders willing to contest their position with strategic human capital investment, the contestability theory (see e.g. Baumol (1982) or Baumol, Panzar and Willig (1988)) with sunk costs and the limit price theory (see e.g. Dixit (1980)) are applied to the labour market. The results of the labour market are therefore not determined by conjectural variations of the incumbents or bargaining between employers and employees, but by pressures of (potential) entry.

The incumbent workers are not able to react on an entry threat of the unemployed workers by bonus demand reductions. The crucial assumption that quantities are more volatile than prices seems to be more realistic on the labour market with fixed wage contracts for a certain period than on product markets where insiders may adapt prices quicker than production quantities. The insiders" commitment in sunk education costs may give them an advantage, however (compare e.g. Baumol, Panzar and Willig (1988) pp. 29ff, Shepherd (1984) and Stiglitz (1987a)). Sunk costs can create market power in otherwise perfectly competitive markets.

Outsiders are "perfect, competitors for the job" (compare Lindbeck and Snower (1988)) and they underbid the profit offer of the insiders if this grants them a higher rent than staying unemployed without investment in human capital. As the insiders have to pay the unemployment benefit of the outsiders, there is a motivation for the insiders to let some active outsiders into the labour market when the number of outsiders is large. On the other hand, as shown in the section above, the rent share of the workers decreases with 
the number of workers employed.

The symmetrical set-up between the two groups of workers, the lack of turnover costs and because outsiders observe the profit offer of the insiders and react on that imply that the insiders would not be able to acquire rents without the opportunity to invest in human capital. The insiders would have to copy the behaviour of the outsiders in order to be able to keep their jobs. Then the efficient bench-mark scenario would hold, the entire labour force $N$ be employed, the rent be maximized and completely given to the firm. Notice that insiders use here an activity which creates rents in order to erect barriers to entry, while rent is decreased by insiders" activities like harassment, creating turn-over costs or non-cooperation in insider-outsider models á la Lindbeck and Snower (compare the insider-outsider literature survey in chapter two).

The insiders invest in human capital such that they are able to match the potential profit offer of the outsiders, because otherwise the insiders outperform them. The outsiders only invest in human capital, if they have an opportunity to outperform the insiders, enter the labour market and still earn a surplus that at least equals their outside option. The insiders can therefore calculate the threat point $\pi^{\circ}$ of the outsiders that gives the maximal profit offer to the firm while guaranteeing the outsiders just their outside option. The insiders lose their sumk costs if they lose their job, while the outsiders do not invest in human capital when there is no pay-off for the investment.

As the profit of the firm increases with the number of workers, the threat of the outsiders to replace the insiders increases also with their number. The maximal threat point of the outsiders is found when their surplus is set equal to the unemployment compensation, taking into account that from their bonus they have to cover both sunk costs of investment and the unemployment compensation of the former insiders who are then unemployed. As a consequence find that for outsiders" threat point it has to holl (compare workers' surplus function ander uncertainty $(3.5)$ ):

$$
b c+\bar{s}=(1+r) c^{2}+\frac{N}{m} \bar{s}
$$

which implicitly defines the bonus outsiders are willing to accept in order to become employed. Given (3.21) and the number of outsiders $m$, they invest in human capital such that the profit for the firm is maximized. The optimal amount of human capital investment per outsider is: 


$$
c^{\circ}=\left(\frac{(1-\beta) A}{2(1+r) m^{1-\beta}}\right)^{\frac{1}{1+\beta}}
$$

and maximal profits of the firm the outsiders can offer are:

$$
\pi^{0}=(1+\beta) \Omega^{\frac{1}{1+\beta}} m^{\frac{3 \beta-1}{1+\beta}}-\bar{s} N
$$

It is obvious that the profits are increasing with the number of outsiders, and this is the reason that the firm employs all outsiders. ${ }^{17}$ Notice that $\pi^{\circ}=\pi^{*}$ if $m=N$, i.e. the profit of the firm is maximal if there are no insiders (compare also Figure 3.1). The firm skims the entire rent at the threat point $\pi^{\circ}$ of the outsiders while all workers (employed entrants and unemployed former insiders) just earn their outside option. Finally one sees from (3.23) that there is a minimum number of outsiders required to generate a positive profit. The bomus for the employed outsiders has to cover both the sunk costs of investment and the unemployment compensation the outsiders have to pay for the former insiders.

Substitution of the definition of $\bar{s}(3.16)$ in (3.23) shows that the requirenent of positive profits offered by the outsiders implies that the share of insiders at the labour pool is small enough:

$$
\frac{n}{N}<1-\varepsilon^{\frac{1+a}{3 \beta-1}}
$$

The insiders know that they will be replaced by the outsiders, if they do not offer at least $\pi^{\circ}$ to the frm. They have therefore two different options, if they want to stay in the firm: Either they match the profit offer of the outsiders $\pi^{\circ}$ and keep the outsiders out or they cooperate with the outsiders and allow for the entry of outsiders by setting their human capital investment/bonus combination such that labour supply is higher than the number of insiders.

If the profit offered by the insiders in the passive ontsiders scenario $\pi^{\text {mion }}$ is higher than the profit offered by the outsiders $\pi^{\circ}$ insiders do not have to react at all on the presence of potentially underbidding outsiders. The number of outsiders may be so small that they

\footnotetext{
${ }^{17}$ When the outsiders invest $(3.22)$, it might be profitable for the firm to employ less outsiders at the bonus implied by (3.21). However, if the firm would do this, the outsiders would invest not accourding to (3.22), but they would take into account the risk of becoming unemployed. The resulting profit then would be below (3.23). Hence all outsiders are employed.
} 
offer a profit to the firm that is smaller than that the insiders offer when the outsiders are not able to underbid the insiders $\pi^{\text {mon }}$. Then the insiders are able to keep the outsiders from their jobs without changing their monopolistic behaviour, i.e. the insiders' surplus is $s^{\text {mon }}$ and the entry threat of the outsiders is not effective. A situation in which outsiders pose an effective threat requires that $\pi^{\circ}>\pi^{\text {mon }}$. It can be derived from $\pi^{\text {mon }}(3.19)$ and $\pi^{\circ}$ (3.23) that the threat by the outsiders is effective when the number of insiders is smaller than $\widehat{n}$, where $\frac{\widehat{n}}{N}$ is given by: ${ }^{18}$

$$
\frac{\left(1-\frac{\hat{n}}{N}\right)^{\frac{3 \beta-1}{1+\beta}}-\varepsilon}{\left(\frac{\hat{n}}{N}\right)^{\frac{3 \beta-1}{1+\beta}}}>2\left(\frac{1-\beta}{1+\beta}\right) \beta^{\frac{1-\beta}{1+\beta}}
$$

Notice that (3.25) is a stricter restriction than (3.24), which is intuitive because the profit insiders offer to the firm has to be higher than zero in order to have an effective threat. The entry threat of the outsiders is effective, when $n$ is relatively small or the outside option is small (i.e. $\varepsilon$ is small).

If the entry threat is effective, the insiders have to set $b$ and $c$ such that $\pi=\pi^{\circ}$ and $l=n$ are valid simultaneously, ${ }^{19}$ if they want to keep the potential entrants outside. It can be shown that this strategy may give a surplus for the insiders that is higher than $\bar{s}$. This is formally clone by solving labour demand of the firm (3.2) which is set equal to the number of insiders, $n$, for $b$. This function is then substituted in the profit function (3.1) which is set equal to the threat point of the outsiders $\pi^{\circ}$, evaluated at $n$ and solved for $c$ :

$$
c^{i}=\left(\frac{\pi^{0}}{(1-\beta) A n^{\beta}}\right)^{\frac{1}{5-\beta}}
$$

The surplus of the insiders erecting barriers to entry by offering $\pi^{\circ}$ to the firm equals:

$$
s^{i}=\frac{\beta \pi^{\alpha}}{(1-\beta) n}-(1+r)\left(\frac{\pi^{0}}{(1-\beta) A n^{\beta}}\right)^{\frac{2}{1-\beta}}-\frac{m}{n} \bar{s}
$$

\footnotetext{
"The necessary number of inisiders $\hat{n}$ can be calculated explicitly, if the outside option is set equall to
zero $(\varepsilon=0)$ :

$$
\frac{\widehat{n}}{N}<\frac{1}{\left(2(1-\beta)(1+\beta)^{-1} \beta^{\frac{1-\beta}{\beta} \beta}\right)^{\frac{1+\beta}{3 \alpha-1}}+1}
$$

${ }^{19}$ Here, once again the argument applies that (3.5) is always llarger than (3.3), see appendix.
} 
Notice that $s^{i}$ may be larger than $\bar{s}$ and the solution with insiders erecting barriers to entry may therefore be viable. Comparison of equation (3.27) with equation (3.18) and using

$$
s^{\text {mon }}=\beta^{\frac{2}{1+\beta}} \frac{n^{\frac{2(1-\beta)}{1+\beta}}}{m^{\frac{3 \beta-\beta}{1+\beta}}} \pi^{\circ}+\bar{s} N
$$

shows however that the surplus of the insiders with outsiders present is smaller than $s^{\text {mon }} 20$ Therefore an effective entry threat of the outsiders always reduces the surplus of the insiders when barriers to entry are erected.

The insiders have also the second option to cooperate with the outsiders. In this case they set a bonus/human capital investment such that also outsiders are demanded by the firm and the outsiders can imitate them in order to get a job. From the monopolistic workers scenario it is clear that the rent of the insiders decreases with the number of workers demanded exceeding the number of insiders $n$. Therefore it is not in the interest of the insiders to let all outsiders in, but they just allow so many outsiders in that it is in the interest of the outsiders to imitate the insiders and not underbid thern. Minimum labour demand is then determined by equation (3.10) which gives the number of insiders to be hired at least. If outsiders would earn a surplus higher than their outside option when they replace the cooperating insiders, insiders' wage demand has to be lower and total labour demand higher accordingly. In order to see when it is in the interest of the insiders to cooperate and allow for the entry of outsiders instead of blocking the entry, we have to compare insiders' surplus (3.27) with the cooperation surplus. It is clear from the analysis above that the surplus of the insiders decreases with the number of outsiders allowed into the labour market. If it is shown therefore that the surplus of the insiders allowing the entry of all outsiders results in a higher surplus than blocking the entry of all outsiders when the entry threat is effective, it is clear that this is also the case when the insiders allow just the minimal number of outsiders into the labour market. Therefore it is shown below that the surplus with cooperation is higher than the surplus with barriers to entry even if all outsiders are allowed into the labour market.

The surplus of the insiders allowing for full employment is calculated analogously to the monopolistic insiders scenario. The optinal investment in human capital is again equation (3.17), while the labour demand $l$ is now equal to $N$. The cooperative surplus of the insiders (and outsiders) is with full employment:

\footnotetext{
20From (3.18) and (3.19), we see that
} 


$$
s^{c}=(1+\beta) \beta \frac{2}{1+3} \Omega^{\frac{1}{1+2}} N^{\frac{-2(1-\theta)}{1+2}}
$$

where the superscript $c$ stands for cooperation. Here all workers skim the maximum rent that is compatible with full employment. It can be shown that the surplus with cooperation (3.28) is higher than the surplus with barriers to entry when the entry threat of the insiders is effective (confer (3.27)). It is therefore never in the interest of the insiders to block the entry of the outsiders when the outsiders are able to offer a higher profit to the firm than the monopolistic insiders. The real cooperation surplus of the insiders increases when it is sufficient to allow less than all outsiders into the labour market.

Summing up, two cases can be distinguished. If the number of insiders is lower than $\frac{\pi}{N}$ (confer (3.25)), insiders cooperate with the potentially underbidding outsiders, because it is too costly to provide the profit offered by the outsiders to the firm $\pi^{\circ}$ and pay the unemployment benefit to the outsiders. In this case, insiders set a bonus/wage demand that ensures full employment of the insiders and sufficient employment of the outsiders such that the outsiders do not underbid their profit offer. If the number of insiders is larger and outsiders' entry threat is not effective, insiders keep the outsiders out, and enjoy the full surplus they would enjoy when outsiders could not underbid them $\left(s^{\text {mon }}\right)$. Therefore the profit of the firm is maximally $\pi^{\mathrm{c}}$ if the relative number of insiders is smaller than $\frac{\widehat{T}}{N}$ and $\pi^{\text {mon }}$ if there are more insiders. Firm's profit is therefore reduced when there is involuntary unemployment created by the insiders. The profit of the firm in the different scenarios is summarized graphically in Figure 3.1: 


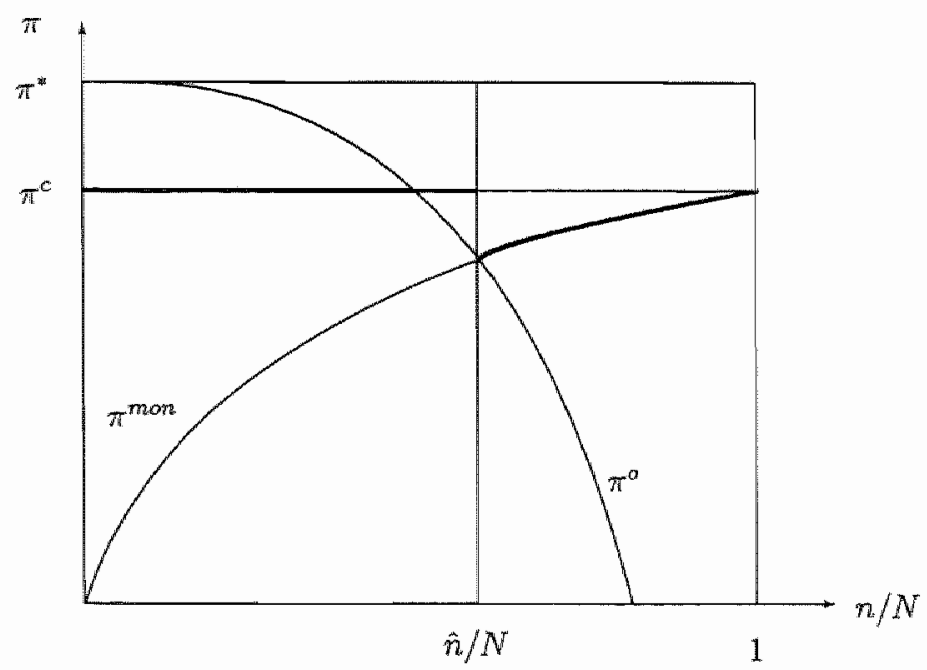

Figure 3.1: Profits in the Insider-Outsider Scenario

The benchmark level of profits $\pi^{*}$ is the level enjoyed by the firm, if human capital investment is efficient, all workers are employed and the surplus of the workers equals their outside option. The share of insiders on the total number of workers does not have an impact on the maximal level of profits for the firm, because all workers are employed. The same applies for the hypothetical cooperation scenario when all outsiders are let in. This is not necessarily the case. If entry of outsiders can be avoided by allowing less than all outsiders into the labour market, firm's profit in the cooperation scenario is smaller. The profit the monopolistic insiders offer to the firm $\pi^{\text {mon }}$ increases with the number of insiders who want to be re-employed $\frac{n}{N}$. If the entire labour force was employed in the previous period, the profit of the firm equals that of the cooperation scenario with full employment. The maximal threat point of the outsiders, $\pi^{\circ}$ increases also with the number of outsiders. When all workers would have been unemployed in the previous period, their maximal profit offer would equal $\pi^{*}$. Notice that a positive number of outsiders is necessary for a positive threat point and necessarily $\pi^{\circ}=\pi^{\text {man }}$ at $\frac{\widehat{n}}{N}$.

Figure 3.2 sums up social welfare in the different insider-outsider scenarios. 


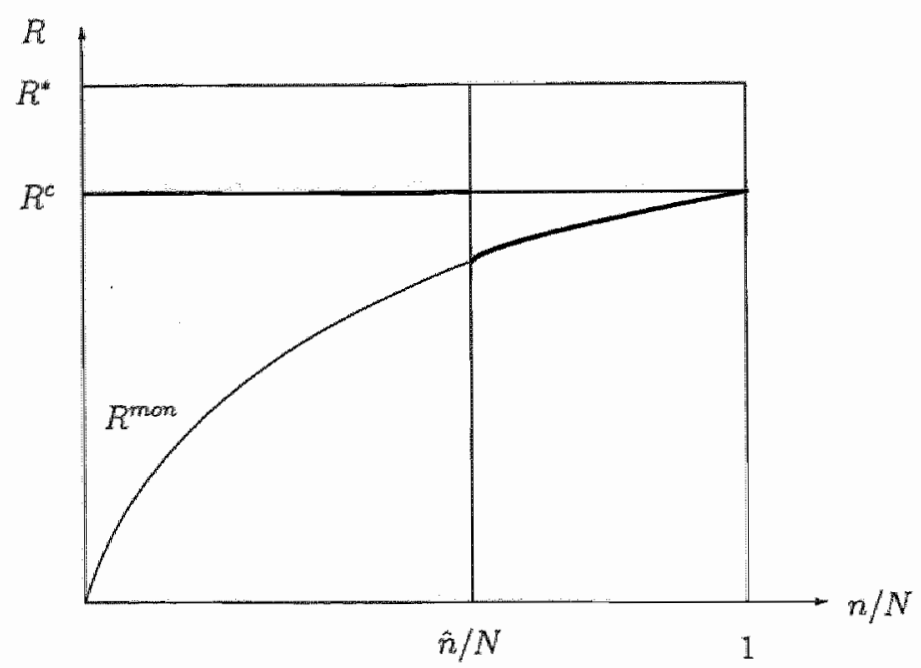

Figure 3.2: Welfare in the Insider-Outsider Scenario ${ }^{21}$

Figure 3.2 clearly indicates the inefficiencies incurred by the possibility of the insiders to set investment in human capital and bonus demand. In the case where the entry threat of the outsiders is not valid (i. e. $\frac{n}{N}>\frac{\hat{i}}{N}$ ), social welfare $R^{\text {mon }}$ is not only biased downwards by the inefficient investment, but also because labour demand is inefficiently low. Social welfare therefore increases with decreasing unemployment, i.e. when $\frac{n}{N}$ approaches 1 . In the case of a valid entry threat, social welfare is maximally at $R^{c}$. It would be equal to $R^{*}$, if human capital investment had no impact on labour productivity $(\beta=1)$. If labour demand induced by the insiders is however lower than full employment, social welfare is still stronger biased downwards with respect to $R^{*}$. Nevertheless an effective entry threat of outsiders improves labour market efficiency and increases employment.

\subsection{Conclusions}

This chapter shows that the necessity of human capital investment is an additional reason for the existence of insider market power and labour market inefficiencies. It leads to the persistence of unemployment even if full employment is efficient and a reduction in social welfare.

\footnotetext{
${ }^{21}$ The bench mark level of social welfare $R^{*}$ is the maximal level obtained in the social planner scenario with full employment.
} 
In the optimum a social planner chooses full employment while maximizing the social rent generated by human capital investments. This gives the efficient employment and human capital investment level.

The insider-outsider scenario shows that involuntary unemployment is created by the necessity to invest in human capital even if we exclude all reasons identified by Lindbeck and Snower and others which give rise to insider market power. Outsiders are perfect competitors for the job and there are no transaction costs or further insider activities that create barriers to entry in other well-known insider-outsider models. Insiders have to pay the unemployment benefit of the outsiders, if they create barriers to entry. Insiders have to commit themselves first, while outsiders freely can underbid thern. Therefore insiders lose their sunk investment costs, if outsiders outperform them. Outsiders only invest in human capital, if this is beneficial for them, knowing the behaviour of the insiders.

First it is demonstrated that irsider human capital investment behaviour causes labour market inefficiencies and involuntary unemployment (monopolistic insider scenario). Here it is assumed that outsiders can not underbid the offer of the insiders. It is advantageous for the monopolistic insiders to keep labour demand at the number of insiders, because a higher labour demand can only be achieved by a higher rent share granted to the firm. Monopolistic insiders invest inefficiently in human capital, because they have to grant part of the rent generated by the investment to the firm in order to secure re-employment. Therefore the possibility of strategic human capital investments induce lower rents to be distributed and a reduction in employment to the number of insiders.

When outsiders have the possibility to underbid the profit offer of the insiders, the insiders have two possibilities. Either they choose an investment/bonus combination such that they can keep their jobs for sure and are able to match the offer of their rivals, or they cooperate with the insiders and allow for a higher labour demand of the firm. Outsiders only pose an effective threat on the insiders, if their number is large enough and the unemployment benefit is low. The entry threat is not effective if the threat point of the outsiders is lower than the profit offer the insiders voluntarily give to the firm in the monopolistic insiders scenario. If the entry threat of the outsiders is not effective, all outsiders are involuntarily unemployed and the insiders enjoy their monopolistic rent.

It is shown that it is always a dominant insiders strategy to cooperate and allow for entry, if the entry threat is effective. Here underbidding of outsiders leads to a reduction in insider rents, an increase of employment and an increase in social welfare and labour 
market efficiency. Nevertheless, cooperative investments of entrants and insiders are inefficient. There may still be involuntarily unemployed outsiders if the insiders can avoid being underbid by allowing only part of the outsiders into the labour market. Then the unlucky outsiders not allowed into the labour market enjoy a smaller surplus than insiders and entrants.

Notice that in this scenario strategic human capital investments alone constitute barriers to entry. Frequently it is argued that insiders can defend their rents, because they have an advantage in human capital endowment. This advantage may originate from learning on the job or inside knowledge of the firm's organization. These arguments of course add to the potential of human capital to create market power of insiders, labour market inefficiencies and unemployment.

\subsection{Appendices}

\subsubsection{Different Demand Elasticities and the Revenue Function}

In this appendix it is shown that different demand elasticities or market power of the firm may be incorporated in the revenue function of the firm in equation (3.1). We assume that goods demand $d$ is defined as:

$$
d=B p^{-n}
$$

with $1<\eta<\infty, p$ product price and $B$ a constant. The elasticity of demand is lower when the consumers are less price elastic and when there is less competition on the market for the product. In order to obtain increasing revenues from production, it is necessary to assume an ellastic demand function $(\eta>1)$.

Then revenue $R=p y$ can be rewritten as:

$$
R=B^{\frac{1}{n}} y^{1-\frac{2}{n}}:=C y^{\kappa}
$$

with $0<\kappa<1$ and $C$ constant.

This can be rewritten if we use the definition of $y=E l^{\alpha} C^{b}$ from equation (3.1):

$$
R=C E^{\kappa \kappa} l^{\kappa \alpha} c^{\kappa \delta}:=A l^{\beta} c^{1-\beta}
$$

with $A$ constant. Therefore different demand elasticities on the goods market can be depicted with the reverne function (3.1). 


\subsubsection{Insiders Prefer Full Employment}

Here it is shown that the surplus of insiders under job certainty (3.3) is always larger than the surplus of the insiders under uncertainty (3.8) if labour demand of the firm (3.2) is taken into account.

Substituting firm's labour demand (3.2) into insider's expected surplus with job uncertainty and maximizing with respect to human capital investment, the optimal $c$ is found:

$$
c=\left(\frac{(1-\beta) l^{\beta} \beta A}{2(1+r) n^{1}}\right)^{\frac{1}{1+\beta}}
$$

The expected surplus under uncertainty is therefore:

$$
s=\frac{l^{\beta} \beta A}{n}\left(\frac{(1-\beta) l^{\beta} \beta A}{2(1+r) n}\right)^{\frac{1-\beta}{1+\beta}}-(1+r)\left(\frac{(1-\beta) l^{\beta} \beta A}{2(1+r) n}\right)^{\frac{2}{1+\beta}}
$$

The same exercise can be done for job certainty. The corresponding human capital investment reads then:

$$
c=\left(\frac{(1-\beta) \beta A}{2(1+r) n^{1-\beta}}\right)^{\frac{1}{1+\beta}}
$$

The expected surplus under certainty is therefore:

$$
s=\frac{\beta A}{n^{1-\beta}}\left(\frac{(1-\beta) l^{\beta} \beta A}{2(1+r) n}\right)^{\frac{1-\beta}{1+\beta}}-(1+r)\left(\frac{(1-\beta) \beta A}{2(1+r) n^{1-\beta}}\right)^{\frac{2}{1+\beta}}
$$

If both surplus levels are compared, it is clear that the surplus under certainty is higher than that under uncertainty. Workers invest more when they can be sure to keep their jobs (compare equation (3.6)), because hurnan capital investment is sunk. The reduction in investment costs due to a lower $c$ cloes not compensate the reduction in revenues due to uncertainty, however. 


\section{Chapter 4}

\section{Human Capital and Wage Incentives}

\subsection{Introduction}

Efficiency wages have two functions, namely to recruit, motivate and retain workers and to determine employment (compare also the literature survey in chapter 2). In addition to familiar reasons like asymmetric information, shirking, fairness and turnover, also the necessity to invest in human capital may give rise to higher than market clearing wages and labour market inefficiencies. This result hinges on the familiar assumption in human capital theory that workers can decide themselves about human capital investments.

The following model shows when firms have to pay wages that are higher than marketclearing in order to motivate the employed workers to invest (more) in training. The extraction of investment in human capital is costly for the frm when employed workers can decide themselves about their investment behaviour. When acquiring skills, workers react, on the reward for training paid by the firm.

The model is based on the same objective functions of workers and the firm as in the preceding chapter. The profit function of the firm is again dependent on the number of workers $l$ and investment in human capital $c$ :

$$
\pi=A l^{\beta} c^{1-\beta}-(b c+\bar{s}) l
$$

with $0<\beta<1$.

The surplus function of the workers with job certainty depends on the bonus payment $b$ for human capital investments $c$, the minimum wage $\bar{s}$ and the human capital investment $\operatorname{costs}(1+r) c^{2}$ :

$$
s=(b c+\bar{s})-(1+r) c^{2}
$$


The surplus function of the workers with job uncertainty is again: ${ }^{1}$

$$
s=\frac{l}{N}(b c+\bar{s})-(1+r) c^{2}
$$

From the surplus functions, the investment reaction functions of the workers can again be derived by differentiating equation (4.2) and (4.3) with respect to $c$. The investment: reaction function under certainty is:

$$
c=\frac{b}{2(1+r)}
$$

and the investment reaction function with uncertainty about a work place is:

$$
c=\frac{l b}{2 N(1+r)}
$$

Uncertainty about a job reduces the expected pay-off of human capital investments and decreases therefore investment, because there is no correlation between human capital investment and unemployment benefits. Investment costs are therefore lost in case of unemployment.

The model in this chapter differs in one crucial respect from the model described in chapter three: the firm sets both - the wage offer and labour demand-while the workers only decide about their human capital investment according to equations (4.4) and (4.5). It: is argued that the firm may choose labour demand below the number of workers although this reduces workers incentives to invest in human capital and is inefficient from a social welfare perspective.

The model in the previous and in this chapter represent therefore the two extreme assumptions about which party (workers or firms) deternines the wages set. This is analogous to the insider-outsider and efficiency wage theory, respectively (compare chapter two).

The surplus of the workers under uncertaingy is again derved from:

$$
s=\frac{l}{N}\left(b^{\prime} c+\bar{s}\right)+\left(1-\frac{l}{N}\right) \bar{s}-(1+r) c^{2}
$$

Here, $b^{\prime}$ is the bomus before unemployment insurance is paid which is used or the expenses for unemployment benefits (compare the previous chapter). 


\subsection{Wages as Incentive to Invest in Human Capital}

The homogeneous workers set their investment in human capital such that their surplus is maximized at the bonus/employment combination determined by the firm, i.e. according to their investment reaction functions (4.4) or (4.5), depending on labour demand. Human capital investment increases with labour demand and the bonus paid for human capital. The workers invest less in human capital, if the investment costs increase. The firm determines bonus offer and labour demand simultaneously such that the profit is maximized taking the investment reaction functions of the workers into account. It turns out that it can be a profit maximizing strategy of the firm to set labour demand $l$ smaller than full employment $N$. Therefore we have to distinguish two cases, wages with full employment (superscript $f$ ) and wages with unemployment (superscript $e$ which stands for efficiency wage). First the case with unemployment is discussed.

\subsubsection{Unemployment}

If the reaction function of the workers under labour uncertainty (4.5) is substituted into the profit function of the firm (4.1) and maximized for labour demand $l^{e}$ and the bonus offer $b^{e}$ simultaneously, we obtain:

$$
\begin{aligned}
& b^{\mathrm{e}}=2 N(1+r)\left(\frac{\bar{s}}{A \beta}\right)^{\frac{1}{1-\beta}} \\
& l^{\mathrm{e}}=\frac{(1-\beta) A}{4 N(1+r)}\left(\frac{A \beta}{\bar{s}}\right)^{\frac{1+\beta}{1-\beta}}
\end{aligned}
$$

The labour demend of the firm is in this scenario smaller than $N$, if the minimum wage $\bar{s}$ is larger than the following expression:

$$
\hat{s}^{e}=4^{\frac{\beta}{1+\beta}} \beta \Omega^{\frac{1}{1+\beta}} N^{-\frac{2(1-\beta)}{1+\beta}}
$$

with $\Omega=\frac{A^{2}}{4}\left(\frac{1-\beta}{1+r}\right)^{1-\beta}$. If $\bar{s}$ is higher than $\widehat{s}^{\circ}$, the firm demands less than $N$ workers. In that case there is unemployment in this scenario. Is this efficient? From the social planner scenario in chapter three, we know that full employment is efficient if $\bar{s}$ is not too high. The threshold for $\bar{s}$ lies at:

$$
\widehat{s}=(1+\beta) \Omega^{\frac{1}{1+\beta}} N^{-\frac{2(1-\beta)}{1+\beta}}
$$


If the outside option equals $\widehat{s}$, the entire rent is distributed to the workers (who all earn their outside option), while the firm earns no rent. The threshold of the unemployment benefit between unemployment and employment in the incentive wage scenario therefore equals $\widehat{s}^{e}=4^{\frac{\beta}{1+\beta}}\left(\frac{\beta}{1+\beta}\right) \hat{s}$. It is clear that $\hat{s}^{e}$ is smaller than $\widehat{s}$. This is not surprising because at $\widehat{s}^{e}$ the entire rent generated by human capital investment is paid to the workers by the social planner. In the incentive wage scenario, the firm gets part of the rent. (this part actually increases with labour demand) and the entire rent is inefficiently low, which is shown below. Therefore both aspects put a downward pressure on $\hat{s}^{\mathrm{e}}$ in comparison. to $\widehat{s}$. The difference between $\widehat{s}^{e}$ and $\widehat{s}$ is larger, if the impact of human capital on labour productivity grows ( $\beta$ decreases), because then the necessity of the firm to stimulate the workers to invest increases in order to obtain a higher labour productivity. Since $\widehat{s}^{3}<\widehat{s}$, there is a range of possible values of the exogeneously given outside option $\bar{s}$ that lead to unemployment in the incentive wage case, while it is efficient to employ the entire labour force as we see in the social planner scenario. This constitutes the result that the attribution of the right to set investment in human capital to the workers can lead to a reduction in labour demand, because firm's bonus payment has to be higher than efficient in order to stimulate the workers to invest.

The investment in specific human capital in this scenario with unemployment can be calculated now:

$$
c^{\mathrm{e}}=\frac{(1-\beta) A}{4 N(\mathbb{1}+r)}\left(\frac{A \beta}{\bar{s}}\right)^{\frac{\beta}{1-\beta}}
$$

We know from the social planner scenario in chapter three that the efficient investment in human capital equals:

$$
c^{*}=\left(\frac{(1-\beta) A}{2 N^{1-\beta}(1+r)}\right)^{\frac{1}{1+\beta}}
$$

It is clear that the workers invest inefficiently little in human capital formation. Investment in this scenario $c^{\mathrm{e}}$ is maximally (i.e. when $\bar{s}=\widehat{s}^{\mathrm{e}}$ ) equal to $\left(\frac{1}{2}\right)^{\frac{1}{1+\beta}} c^{*}$ and even smaller with a higher outside option. Therefore again labour market inefficiencies are caused by the possibility of the workers to decide about human capital investments themselves.

The social welfare for this scenario in the case of unemployment is derived from $t^{\circ}$ and $c^{\mathrm{e}}$ :

$$
R^{e}=\frac{(3+\beta)(1-\beta) A^{2}}{16 N(1+r)}\left(\frac{A \beta}{\bar{s}}\right)^{\frac{2 \beta}{1-\beta}}
$$


A comparison with the efficient social welfare $R^{*}$ derived in chapter three shows that social welfare is inefficiently low here, while the bias increases with the outside option $\bar{s}$, compare also Figure 4.1 and Figure 4.2 below. The well-known Solow-condition is fulfilled in this scenario, i.e. $\frac{\partial c^{a}}{\partial b^{\frac{b}{a}}}=1$. The firm minimizes therefore the labour costs per efficiency unit of labour given the human capital investment reaction function.

Substituting the equations for firm's bonus offer (4.6), labour demand (4.7) and workers' investments (4.8) into the profit function of the firm (4.1) then gives:

$$
\pi^{\mathrm{e}}=\frac{(1-\beta)^{2} A^{2}}{8 N(1+r)}\left(\frac{A \beta}{\bar{s}}\right)^{\frac{2 \beta}{1-\beta}}
$$

It is clear that the profit of the firm decreases in the outside option of the workers $\bar{s}$. Compare Figure 4.1 for an illustration. The surplus the workers enjoy is analogously derived by substituting (4.6), (4.7) and (4.8) into the surplus function of the worker (4.3) with job uncertainty:

$$
s^{e}=\frac{(1+3 \beta)(1-\beta) A^{2}}{16 N^{2}(1+r)}\left(\frac{A \beta}{s}\right)^{\frac{2 \beta}{1-\beta}}
$$

Therefore firm and workers share the rents generated from workers' human capital investments.

Figure 4.1 below depicts social welfare, workers' surplus and firm's profits in this scenario when there is job uncertainty. 


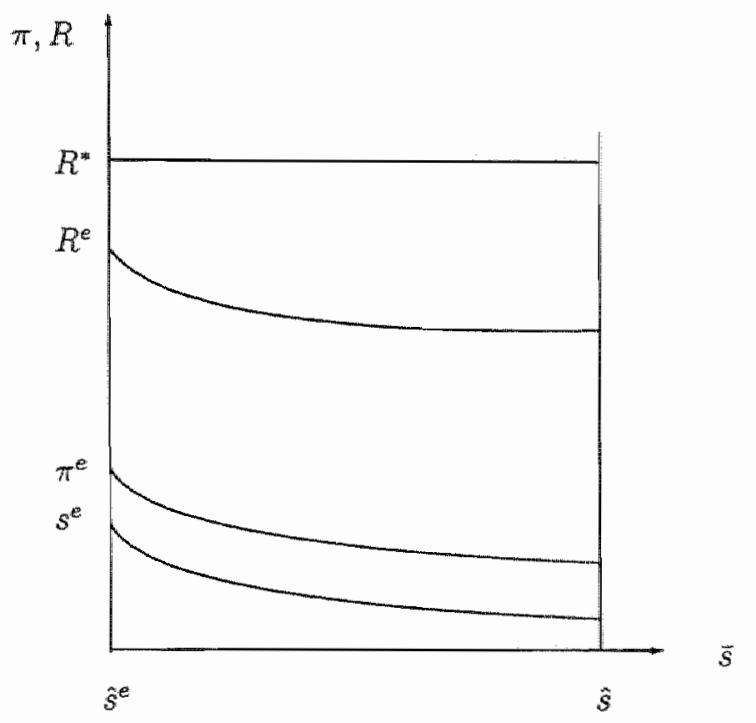

Figure 4.1: The Incentive Wage Scenario with Unemployment ${ }^{2}$

Social welfare is lower than optimal if the workers can determine their investment in human capital themselves, because workers can not skim the entire rent generated by human capital investment. Therefore human capital investment is inefficiently low. The incentive wage scenario with unemployment is only defined for an outside option between $\widehat{s}^{e}$ and $\widehat{s}$. If the outside option is lower than $\widehat{s}^{e}$, labour demand is at least as high as labour supply. If the outside option is above $\widehat{s}$, also in the social planner scenario unemployment is caused by the high unemployment payments that set a minimum surplus level for all workers. We excluded this possibility in the previous chapter in order to have a benchmark with full employment.

\subsubsection{Full Employment}

Now the analogous profit, surplus and welfare level for full employment in the incentive wage scenario are determined. The bonus the firm offers its workers is calculated by optimizing the profit function of the firm (4.1) with respect to $b$, taking the investment reaction function of the workers with job certainty (4.4) into account and setting labour demand exogeneously equal to $N$.

Notice that in Figure 4.1 it is assumed that $(1-\beta)>\frac{1+3 \beta}{2 N}$ and therefore $\pi^{\mathrm{e}}>s^{\mathrm{e}}$ compare equations (4.11) and (4.12). 
Workers investment is in this case equal to: ${ }^{3}$

$$
c^{1}=\left(\frac{A(1-\beta)}{4 N^{1-\beta}(1+r)}\right)^{\frac{1}{1+\beta}}
$$

Notice that $c^{f}=c^{e}$, if $\vec{s}=\widehat{s}^{e}$, i.e. there is no gap at the limit. The investment in the full employment case is inefficiently small, compare $c^{*}(4.9)$. The reason is that not the entire rent from human capital investment is enjoyed by the workers. If the entire rent could be appropriated by the workers, labour demand of the firm would be zero, however. The labour/investment reaction function of the firm increases with the rent share appropriated by the firm, compare (4.7). Rent distribution influences therefore rent creation and labour demand.

In the full employment incentive wage case, the profit level of the firm is:

$$
\pi^{f}=2^{-\frac{1-\beta}{1+\beta}}(1+\beta) \Omega^{\frac{1}{1+\beta}} N^{\frac{3 \beta-1}{1+\beta}}-\bar{s} N
$$

The profit of the firm consists of firm's part of the rent (first term on the right hand side) minus the outside option paid for all workers. There is also no break in profits between the unemployment and full employment case at $\widehat{s}^{e}$, compare $\pi^{e}(4.11)$ and Figure 4.2. The profit of the firm decreases with the outside option.

With full employment, workers' surplus reads as:

$$
s^{\mathrm{f}}=\bar{s}+4^{-\frac{1}{1+\beta}}(1-\beta) \Omega^{\frac{1}{1+\beta}} N^{\frac{2 a-2}{1+\beta}}
$$

Notice that the surplus level of the workers is higher than the outside option $\bar{s}$, i.e. the firm gives part of the rent generated by the investment to the workers. Otherwise the workers would not be motivated to invest.

The welfare level with full employment and wages set by the firm is:

$$
R^{h}=(3+\beta)\left(\frac{(1-\beta)^{2} A^{2} N^{3 \beta-1}}{16(1+r)^{1-\beta}}\right)^{\frac{1}{1+\beta}}
$$

\footnotetext{
${ }^{3}$ Bonus demand is analogously:
}

$$
b^{\vec{t}}=\left(\frac{A(1-\beta)}{2 N^{1-\hat{b}}}\right)^{\frac{1}{1+B}}
$$


Notice that the welfare levels with unemployment and full employment are equal in this scenario, $R^{\mathrm{e}}=R^{\mathrm{f}}$, if $\bar{s}=\widehat{s}^{\mathrm{e}}$ (compare (4.10)), otherwise full employment leads to a higher social welfare level, se Figure 4.2 below. Nevertheless even with the efficient employment level, social welfare is inefficiently small here because investment is inefficiently low.

The profit of the firm $\pi^{\mathrm{e}}$ and $\pi^{\mathrm{f}}$ and workers' surplus $s^{\mathrm{e}}$ and $s^{\mathrm{f}}$ decrease with the size of the pool of workers $N$, whether unemployment prevails or not. With full employment, workers' share of the rent declines when the number of workers increases in order to secure the higher labour supply. With unemployment, the employed workers have to pay more unemployment benefit to the jobless. Both effects decrease the motivation of the workers to invest in human capital and therefore firm's profit and indirectly workers' surplus.

Profits and rents in the incentive wage scenario are summarized in Figure 4.2. Since labour demand $l$ and the number of workers $N$ is given, $R^{*}$ is given, too. However, profits $\pi^{*}$ in the benchmark case decline with $\bar{s}$ (compare chapter three). Figure 4.2 illustrates that the inefficiently low investment and labour demand pushes the social welfare $R^{\mathrm{f}}$ and $R^{\mathrm{e}}$ below the level of the benchmark scenario $R^{*}$. Also the profit of the firm, both $\pi^{\mathrm{f}}$ and $\pi^{\mathrm{e}}$, is lower than in the case where the social planner attributes the entire rent to the firm $\pi^{*}$, if the outside option is not too high. With full employment, i.e. if the unemployment benefit is low enough $\left(\bar{s}<\widehat{s}^{e}\right)$, the profit of the firm, social welfare and employed workers' surplus are higher than with unemployment. In the area between $\widehat{s}^{e}$ and $\widehat{s}$, there is unemployment in the incentive wage scenario while full employment is efficient. The outside option can not be larger than $\widehat{s}$, because then the maximal rent generated is not even sufficient to pay the outside option to all workers. 


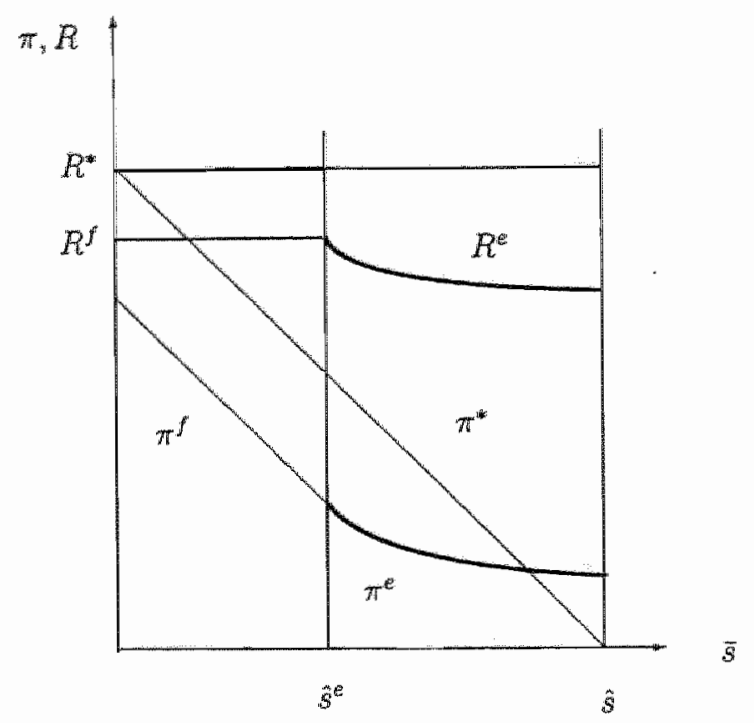

Fugure 4.2: The Incentive Wage Scenario

\subsection{Conclusions}

If we compare this model with well-known efficiency wage models, it is clear that the incentive wage scenario does not assume asymmetric information between principal and agent (see Shapiro and Stiglitz (1984)), uncertainty about effort (see Rasmussen (1994) chapter 7.2), labour transaction costs (see Salop (1979)) ) or fairness notions (see Akerlof (1982)). The model is however closely related to the "morale effects" branch of efficiency wage models (compare Stiglitz (1987) p. 22). The question seems appropriate, why the firm cannot avoid the inefficient investment and the higher bonus by offering an efficient contract that attributes some of the additional rent gained to the workers in exchange to efficient investment. The firm could make a contract that assures efficient investment and gives the workers at least the surplus they would enjoy if they could determine investment themselves, i.e. $s^{f}$ or $s^{e}$, because the firm can observe effort and knows the effort reaction function of the workers.

It is not possible for the firm to construct a complete contract, however, if there is uncertainty about which one of the workers will be unemployed after the investment costs in human capital are sunk, i.e. in the unemployment case where $\bar{s}>\bar{s}^{e}$. Here the workers take 
the risk of unemployment voluntarily and react on it by an inefficiently small investment in human capital. As the firm cannot determine beforehand which workers will be unemployed after having invested in human capital, it cannot force the workers from their investment reaction function (4.5). This is not the case in the scenario with full employment. In this case the argument can be made that a complete contract avoids the inefficiencies implied by incentive wages. Therefore the full employment scenario with incentive wages (and $\pi^{f}$ and $R^{\mathrm{f}}$ in Figure 4.2) is always dominated by the efficient contract and will never be chosen.

This model provides two possible results. If the outside option is smaller than $\widehat{s}^{\mathrm{e}}$, the efficient contract is struck between firm and workers, providing full employment, efficient investment and the optimal social welfare $R^{*}$. If the outside option is larger than $\vec{s}^{\text {w }}$, the employees choose voluntarily a higher wage in exchange for a probability to get unemployed, because the income reduction in case of unemployment is small. Then the investment in human capital and employment is inefficiently small and social welfare declines.

In all versions of the model discussed above, the minimum wage was given even for the social planner. The minimum wage affects the results in the social planner scenario and the incentive wage scenario differently, however, and leads to voluntary unemployment in the incentive wage scenario. It is worthwhile for the workers to take the risk to be unemployed in exchange for a higher wage when they are employed, because the unemployment benefit is rather high. In the insider-outsider scenario, unemployment was involuntary, however, because the workers would like to work for the wage set by the insiders, labour demand is however too low. An obvious policy implication when voluntary unemployment is present and human capital investment is inefficient is of course to lower the minimum wage such that the full employment scenario with its efficient equilibrium is reached. Then the difference between the market wage and the unemployment benefit is large enough to induce the workers to invest sufficiently to ensure their (re-)employment. 


\section{Chapter 5}

\section{Why Do not all Workers Invest in Skills?}

\subsection{Introduction}

Since the begin of the 1980 s skilled workers earn an increasing rent from education. Although non-competitive rents can be earned when investing in skills during more than one decade, nevertheless some workers still decide to stay unskilled. How can this be reconciled with individual rent meximization? In most OECD countries we observe the following:

- Skilled workers enjoy higher wage mark-ups in recent years. ${ }^{1}$

- Skilled workers enjoy lower relative unemployment rates in recent years. ${ }^{2}$

Both stylized facts lead to a non-competitive wage differential to be earned by skilled workers if we assume that investment costs in skills did not increase stronger than the benefits from being skilled."3

Rents from education have found a tremendous interest in the economic profession, especially because the rising wage inequality is associated with increased wage mark-ups on skills, compare e.g. Johnson (1997) and Topel (1997) for recent references. Rising

\footnotetext{
${ }^{1}$ Compare the empirical obserwations in chapter two.

${ }^{2}$ Unemployment rates for unskilled workers are roughly three times higher for unskilled workers than those for skilled workers, compare e.g. Mincer (1991) or the survey in Layard, Nickell and Jackman (1991) pp. 286-292. Sreessens and Shadman-Mehtu (1995) p. 271 present French data while van Ours and Ridder (1997) and van Zon at al (1997) have ewidence for the Netherlands and Germany. Nickell and Bell (1995) show that relative unskilled memployment slightly fell in most OECD countries during the recession in the first years of the 1990 s.

${ }^{3}$ This is certainly the case for the 1980 s, whille the evidence is mixed for recent years, compare e.g. Blackburn et al (1991), p. 8 or Clotfelder (1991) pp. 64-69.
} 
income inequality leads to phenomena such as stratification, working poor and social unrest. Economic research concentrates on the question, how shifts in labour demand or supply and changes in wage setting institutions have caused the observed trend. Economists put forward a broad variety of arguments for increased wage mark-ups for skilled workers. The de-unionization especially in Great Britain and the United States may have an adverse effect on relative wages of unskilled workers (Freeman (1993)). Another argument is skillbiased technological change which reduces the relative labour demand for unskilled workers (compare Bound and Johnson (1992), Katz and Murphy (1992) or Braver and Hickok (1995) for recent data). Immigration of unskilled workers (see Topel (1993)), a slowdown in the rate of growth of the college educated population (Bound and Johnson (1992), Katz and Murphy (1992) or Davis (1992)), a trade deficit for durable goods, i.e. the massive import of goods mainly produced by unskilled labour (Borjas and Ramey (1994)) and internationalization which increased competition for goods that are produced with relatively unskilled labour are mentioned for the US (Murphy and Welch (1989) or Krugman and Lawrence (1993)). Compare also the survey in Borjas (1996) pp. 272-277; he argues that all arguments mentioned in the various studies could explain more than the observed huge increase in wage inequality. In these studies skilled and unskilled labour supply are assumed to be exogeneous or dependent on other non-economic factors like demographic structure or educational policy in order to explain increasing wage inequality. In addition different unemployment levels of skilled and unskilled workers are not taken into account or even assumed away (exceptions are Blockbum et al (1991) and Borjas and Ramey (1994)).

This chapter poses different questions, while it takes the increased skilled wage markup and a higher relative unemployment incidence of unskilled workers as given. In contrast to most other studies, skilled labour supply is treated as endogeneous and being influenced by the benefits and the costs of skills. The main questions are:

1. Which consequences have increased wage mark-ups for skilled workers on the labour market?

2. Why do not all workers invest in skills as a consequence of persistent rents earned by skilled workers?

3. Should we care about the consequences of increased skilled wage mark-ups from a welfare point of view and which are possible remedies? 
In order to answer these questions, a simple closed economic model is constructed including demand and supply for different skills and unskilled labour. If we assume in the tradition of the human capital theory (compare chapter two) that every worker is free to choose a skill, a worker invests in a certain skill as long as a rent is to be earned with this activity. The skilled wage development suggests that skilled workers are increasingly able to charge a higher mark-up for their labour services, i.e. they enjoy market power on the market for their skills. The position of the skilled workers is not uncontested, however. First, unskilled workers can also acquire this skill. Second, the firm can replace on skill group by another for performing a task if the first skill group asks too high a wage. Therefore, we find a situation familiar from the theory of monopolistic competition.

The approach to interpret the labour market as monopolistic competitive is not new. The innovation of this chapter is however to draw the dividing line between skilled and unskilled labour and focus on the education decision. All existing models that interpret the labour market as monopolistically competitive with differentiated skills (see e.g. Snower (1983), Blanchard and Kiyotaki (1987), Nishimura (1989) Nielsen et al (1995), Matsuyama (1995)) entail basically three flaws:

1. All workers enjoy a rent, because the number of workers is assumed to be fixed and there are no unemployed workers underbidding the wage set collectively by the workers of one skill (or their union).

2. Market power on the labour market is assumed to arise because there are different (but symmetric) sorts of labour. There are no costs for skill acquisition, which is not in the tradition of the human capital theory. Therefore all workers are skilled and enjoy market power in these models without investment costs. Rent equalization takes place between different skills groups. Frequently, it is assumed that each worker has a unique skill that distinguishes him or her from all other workers.

3. These models do not distinguish between unemployed and working persons, but assume that the working time of the entire labour force reacts on exogeneous shocks. Therefore unemployment is defined as under-utilization of total working time, while nobody actually gets unemployed by an adverse shock or high wage demands.

The model developed below cures these flaws by explicitly introducing investment costs and two labour markets (skilled and unskilled) without entry-barriers. In addition unem- 
ployment and a rent differential between workers is possible.

The model developed below entails different skills in order to be comparable to the labour market models assuming monopolistic competition cited above. The main results of the model are also obtained, however, if the group of skilled workers is assumed to be homogeneous. In the appendix, a rough sketch of the model is given assuming homogeneous individuals who can decide to acquire one skill or not. ${ }^{4}$

Usually it is assumed that the relationship between lifetime earnings and schooling is such that the supply and demand for workers of each schooling level are equated and no worker wishes to alter his or her schooling level (compare the survey in Willis (1986), p. 527). The data suggest that the first point does not hold. Therefore it is not imposed in this chapter.

If we apply the Chamberlin (1933) model of monopolistic competition to the labour market, we have the following characteristics: ${ }^{5}$

1. Human capital is differentiated in different groups of workers that are no perfect substitutes. The skilled workers are able to take advantage of their relative monopoly situation and determine the wage themselves.

2. The number of different human capital groups is so large that each group ignores its strategic interactions with other groups of workers. The wage setting of one skill group is negligible in the aggregate labour market.

3. Entry on the skilled labour market is unrestricted and takes place until unskilled workers can not earn a rent by investing in human capital. The decision to train is based on a cost/benefit calculation including the relative unemployment rate and the relative wage mark-up (compare also the model in Abowd and Asnenfelter (1981) and Nickell and Bell (1995)). There are no institutional barriers or market imperfections that would hinder one of two equally able persons to educate herself.

Introducing two labour markets with no entry barriers leads to a situation familiar from the theory of compensating wage differentials. It is well known from this theory that there must be a countervailing effect if one group of workers enjoys higher than compensating wages and there is free entry possible for all groups of workers. Disagreeable job characteristics

Whe appendiv is based on a suggestion by Winfried Vagt.

${ }^{5}$ Compare also Benassy (1991) and Matsuyama (1995). 
or different unemployment hazards between industries or skills groups have been identified as possible equilibrium mechanisms (compare e.g. Layard, Nickell and Jackman (1991) p. 303 - 307 or Abowd and Ashenfelter (1981)). If we split the work force between skilled and unskilled workers, however, these arguments can not be applied. ${ }^{6}$

\subsection{Labour Demand}

In this section firm's demand for skilled and unskilled labour is derived. For simplicity, it is assumed that there is a large firm representing the entire labour demand of the economy. The firm dernands workers with different skill specializations and unskilled workers. There are $\kappa$ exogeneously given groups of workers with differentiated abilities (with $\kappa$ large). The labour pool $n$ per ability group is split into $n_{u}$ unskilled and $n_{s}$ skilled workers, while the number of workers choosing to train themselves is determined endogeneously. In equilibrium the entire labour force is made up of $\sum_{u=1}^{\kappa} n_{u}=N_{u}$ unskilled and $\sum_{s=1}^{\kappa} n_{s}=N_{s}$ skilled workers with $N_{u}+N_{s}=N$.

The firm asks for a number of skilled workers $l_{s}$ (with $\sum_{s=1}^{\kappa} l_{s}=L_{s}$ ) in each human capital category of abilities. The demand for unskilled workers is denoted $L_{u}=\sum_{u=1}^{\kappa} l_{u}$ with $l_{u}$ being the unskilled labour demand per ability group.

The profit function is assumed to be analogous to the Spence-Dixit-Stiglitz utility function, that is widely used in models of monopolistic competition: ${ }^{7}$

$$
\pi=g\left[\sum_{u=1}^{\kappa} l_{w},\left(\sum_{s=1}^{\kappa} l_{s}^{p}\right)^{\frac{1}{p}}\right]-\sum_{u=1}^{\kappa} w_{u} l_{u}-\sum_{s=1}^{\kappa} w_{s} l_{s}
$$

with $0<\rho<1$ for concavity and $g$ homothetic in its arguments.

The parameter $w_{s}$ is the wage asked by the skilled workers of ability group $s$. The wage for unskilled labour is fixed due to unions or minimum wage legislation and is assumed to be equal to $w_{u}$. This is the minimum wage that is higher than the outside option (or unemployment benefit) of unskilled workers. The closer $\rho$ is to one, the more substitutable are the different human capital groups, i.e. other skills groups can be used for the same kind of job easily if their wage demand is lower. Every pair of varieties is hereby equally

\footnotetext{
${ }^{6}$ Notice that Layard, Nickell and Jackman (1991) p. 305 assume a less than compensating wage differential for skilled workers in order to obtain a higher equilibrium unemployment rate for umskilled workers. They argue that wage bargaining power of skilled workers does not allow for a compensating wage mark-up.

"Compare e.g. Blanchard and Kiyotaki (1987), Timole (1988), Nishimura (1989) and Matsumama (1995).
} 
well substitutable for each other. Due to $\rho<1$ the firm shows "love of variety," i.e. it employs all $\kappa$ different skills instead of employing all workers from a selected subset of skills. The price of the output is normalized to one. The subprofit function for the differentiated human capital has a symmetrical constant elasticity of substitution (CES) form.

The firm maximizes its profits by deciding how many unskilled workers and how many skilled workers to employ per ability group. Maximizing the profit function (5.1) with respect to $l_{u}$ and $l_{s}$ of one ability group yields demand for skilled and unskilled workers for this group, respectively:

$$
\begin{gathered}
g_{1}=w_{u} \\
g_{2}\left(\sum_{i=1}^{\kappa} l_{s}^{\rho}\right)^{\frac{1-\rho}{\rho}} l_{j}^{\rho-1}=w_{s}, \forall j=1, \ldots, \kappa
\end{gathered}
$$

where $g_{1}$ and $g_{2}$ are the partial derivatives of $g$ with respect to the first and second argument. The marginal (value) product of labour has therefore to be equal to the wage. Usually it is assumed that individual marginal productivity declines with the number of workers who have the same specialization while it is positive over the entire range (i.e. $\left.g_{2}>0\right)$. Therefore labour demand for a specialization decreases, if its wage level increases or the production is strict quasi-concave in all different skilled labour inputs. The same applies to unskilled workers $\left(g_{1}>0\right)$ and consequently for aggregate labour demand. In order to derive the results below, we only need the assumption that labour demand decreases in wages but is always positive. For simplicity and without loss of generality it is assumed that skilled labour demand is only dependent on the skilled wage, while unskilled labour demand is only dependent on unskilled wage, i.e. there are no cross-wage elasticities $\left(\frac{\partial l_{s}}{\partial w_{u}}=0\right.$ and $\left.\frac{\partial u_{w}}{\partial w_{s}}=0\right)$.

\subsection{Workers' Surplus}

All workers have uninhibited access to education. The choice of education is a rational intertemporal decision process under uncertainty. Uncertainty arises because workers do not know at the moment they invest in skills, if they are able to find an adequate skilled job afterwards. As education takes time (frequently several years) skilled workers do not know if they are chosen by the firm when the demand for their skill is lower than the supply. This crucial element can also be captured in a static set-up where all skilled workers face 
the same probability not to get an adequate job when there is an over-supply. Investment. costs are assumed to be sunk, i.e. they can not be recovered if the skilled worker does not find an adequate job.

Workers differ in their education costs." Only if the pay-off of training is higher than training costs, workers decide to train. For the clarity of the argument, we concentrate on a representative ability group with $n$ members that is split up endogeneously into $n_{u}$ unskilled and $n_{s}$ skilled workers. Every ability group is assumed to have an identical education cost distribution. Assume that all workers in the ability group can be ranked by a strictly increasing human capital cost function. For simplicity the investment costs have a special form for the $i$-th worker in the ability group: $c_{i}=\frac{c}{n_{u}^{i}}$ with $n_{u}^{i} \in[1, n-1]$, the number of the remaining unskilled workers in the pool. The worker with the lowest investment costs has therefore costs of $\frac{c}{n-1}$, while $c$ are the highest investment costs. ${ }^{9}$ This human capital costs function has the plausible characteristics that more workers decide not to train when investments costs increase than additional workers decide to train when investment costs decrease by the same amount (ceteris paribus).

Workers invest in human capital if their expected surplus increases hereby. Therefore workers with low investment costs invest in skills while above a certain level of investment costs training is not beneficial. The marginal skilled worker with rank $n_{s}$ has costs of $\frac{c}{r_{0}}=\frac{c}{n-n_{s}}$. This worker is indifferent between education or staying unskilled, all workers with lower investment costs choose for education.

It is assumed that the skilled workers who find no adequate job for their specialization, i.e. the over-qualified workers, are offered unskilled labour jobs. Skilled labour is therefore a perfect substitute for unskilled labour, while skilled workers earn the same wage as unskilled workers in unskilled jobs. ${ }^{10}$ Therefore the wage is paid for performing a function and not for a person with a certain skill. The firm prefers skilled workers to do these unskilled tasks, while the unskilled workers fill the remaining vacancies for unskilled jobs. ${ }^{11}$

\footnotetext{
Snower (1996) constructs a similar model for the supply of skills. He assumes uncertainty about the axailability of skilled vacancies, howewer (compare p. 118).

Notice that the additional costs of education increase from worker to worker. The differences in costs between skilled workers are therefore relatively small in contrast to those between unskilled workers.

${ }^{10}$ The extrene assumption of complete substitutability and zero unemployment for skilled workers is made for simplicity. If some costs would be associated with employing skilled workers in unskilled jobs and skilled workers would face a lower umemployment risk than that of the unskilled workers, the results would not change qualitatively.

"We observe that skilled workers easily substitute unskilled workers. During recessions firms hoard sikilled workers, corapare e.g. Nickell and Bell (1995) p. 41 Saint-Paul (1996) p.12 or van Zon et al (1997).
} 
Therefore there may be two adverse effects on labour demand for unskilled workers. First, unskilled workers may be substituted directly by over-qualified skilled workers. Second, if aggregated labour demand is lower than aggregated labour supply, additional unskilled workers experience unemployment.

Suppose that $n_{s}-l_{s}=o$ skilled workers are over-qualified, i.e. find no adequate skilled job. These skilled workers replace unskilled workers. Then the $n_{u}$ unskilled workers enjoy the following expected surplus:

$$
s_{u}=\frac{l_{u}-o}{n_{u}} w_{u}+\left(1-\frac{l_{u}-o}{n_{u}}\right) \bar{s} \text { if }\left(l_{u}-0\right)>0
$$

That is, each unskilled worker earns the exogeneous labour market wage $w_{u}$ (the minimum wage) with the probability that he or she keeps the job. The outside option $\bar{s}$ (unemployment benefit) is earned by $n-l_{u}-l_{s}=u$ unemployed unskilled workers. Therefore $u$ is the sum of both effects-substitution by over-qualified skilled workers $o$ and reduction in aggregate demand. If $\left(l_{u}-o\right)$ is negative, all unskilled workers are unemployed. For simplicity and without loss of generality, we assume however that the number of skilled workers $n_{s}$ is smaller than total labour demand $l_{s}+l_{u}$ for this ability group, i.e. $l_{u}-o$ is always positive. Therefore over-qualified skilled workers find an unskilled job for sure and unemployment is only experienced by unskilled workers.

Hurnan capital investment in a skill involves sunk costs that are individually different. "Sunk" means in this context that the investment costs can't be re-earned if no adequate job is found. In equilibrium every skilled worker is employed in his or her specialization or in a position that requires no specific skill. Skilled workers of one ability group face the same risk to be over-qualified, if skilled labour demand $l_{5}$ is smaller than labour supply $n_{s}$ for "their" skill.

In order to have a closed model, it is assumed that the skilled workers who work in an adequate skilled job, i.e. the workers who earn more than the minimum wage have to pay an unemployment insurance that is used for the unemployment benefit of the unskilled workers. Skilled workers who find an adequate job in "their" skill enjoy therefore the surplus below if the individual investment cost is $c_{i}$ :

$$
s_{s}^{i}=w_{s}-\frac{\bar{s} u}{l_{s}}-c_{i} \text { with } c_{i}=\frac{c}{n_{u}^{i}} \text { and } n_{u}^{i} \in[1, N]
$$

Here $w_{s}$ is the skilled wage (which is equal for all skilled workers of the ability group who find an adequate job). The unemployment benefit $\bar{s}$ which has to be paid for $u$ unemployed 
unskilled workers is spread on the $l_{s}$ adlequately employed skilled workers. Skilled workers who do not find an adequate job and therefore work in unskilled jobs enjoy this surplus:

$$
s_{s}^{i}=w_{u}-c_{i}
$$

Notice that the surplus of overqualified skilled workers is lower than the surplus employed unskilled workers enjoy. Therefore overqualification may lead to surplus equalization between expected surpluses of skilled and unskilled workers. The skilled workers' expected surplus with investment costs $c_{i}$ is:

$$
\begin{aligned}
& s_{s}^{i}=\frac{l_{s}}{n_{s}}\left(w_{s}-\frac{u}{l_{s}} \bar{s}\right)+\left(1-\frac{l_{s}}{n_{s}}\right) w_{u}-c_{i}, \text { if } l_{s}<n_{s} \\
& s_{s}^{i}=w_{s}-\frac{u}{l_{s}} \bar{s}-c_{i} \text { if } l_{s} \geq n_{s}
\end{aligned}
$$

In this static set-up, it is assumed that before the beginning of the period, skilled workers have to sink costs for a specialization in specific human capital and that at the end of the period, equilibrium is already reached. This assumes complete information on all sides already before the transactions start, i.e. the workers know how many other workers specialize in "their" human capital and there is no convergence process towards the equilibrium. In equilibrium the expected surplus of the marginal skilled worker equals the expected surplus of the unskilled workers.

\subsection{First Best Solution}

The first best solution maximizes the rent $R$ of all market participants which is the sum of workers' rents and firm's profits: $R=\pi+\sum_{u=1}^{\kappa} n_{u} s_{u}+\sum_{i=1}^{n_{s}} \sum_{s=1}^{\kappa} s_{i s}$. Total rent or net output is, assuming symmetry between different skills:

$$
R=g\left[\sum_{u=1}^{\kappa} l_{s u},\left(\sum_{s=1}^{\kappa} l_{s}^{\rho}\right)^{\frac{1}{\rho}}\right]-\kappa \sum_{i=1}^{n_{s}} c_{i}
$$

Notice that the level of wages only influences the distribution of rents between the agents, because the skilled workers pay the unemployment benefit $\bar{s}$ for the unemployed workers, but has no influence on total. rent $R$. In the first best solution which maximizes the rent, 
wages decrease until full and adequate employment is found for every worker. ${ }^{12}$ This is possible because marginal productivity of all workers is positive $\left(g h_{h_{x}}\right.$ and $\left.g l_{s}>0\right)$. Therefore efficient total labour demand equals $l_{s}+l_{w}=L$, the entire labour force. Overqualification is inefficient because human capital investment is costly. The first-best solution is: $l_{s}=n_{s}$ with $l_{s}$ according to (5.3) and $l_{u}=n_{u}$ with $l_{u}$ according to (5.2) for every skill group.

In the first best solution the expected surplus of skilled and unskilled workers in an ability group is changed (compare (5.4) and (5.5)):

$$
\begin{gathered}
s_{u}=w_{u} \\
s_{s}=w_{s}-\frac{c}{n_{u}}
\end{gathered}
$$

where (5.6) is the surplus of all unskilled workers and (5.7) is the surplus of the marginal skilled worker. All other skilled workers enjoy higher rents.

The equilibrium condition for the number of skilled workers requires that the surplus of the marginal skilled worker $s_{s}$ is equal to the surplus of the unskilled workers $s_{0}$, i.e. no additional expected rent can be gained from acquiring a skill. Only then no unskilled workers are attracted to invest into schooling. This is the case here, if:

$$
s_{s}=w_{s}-\frac{c}{n_{u}}=w_{u}=s_{u}
$$

The skilled wage mark-up in (5.8) is called compensating, because the marginal skilled worker re-earns precisely his or her investment costs by the skilled wage premium. All unskilled workers cannot re-earn their investment because their investment costs are higher. All inframarginal skilled workers enjoy a rent which is the difference between their individual investment costs $c_{i}$ and $\frac{c}{r_{4}}$.

In order to obtain full employment, $w_{u}$ has to clecrease such that total labour demand $l_{u}+l_{s}$ is equal to total labour supply $n$ in every ability group, taking (5.8) into account. The competitive unskilled wage that equates aggregate labour demand and supply is called $w_{4 .}^{c}{ }^{13}$ The situation for a representative ability group is shown in Figure 5.1.14

\footnotetext{
${ }^{12}$ Compare Loyard, Nickell and Jackman (1991) p. 319.

13 We have to assume that investment costs $f$ are such that the difference $l_{s}-l_{0}$ equals $\frac{f}{r_{0}}$ at $n_{s}$. This "heroic" assumption is made for the comvenience of presentation and does not have an irmpact on the results derived below.

${ }^{14}$ Compare the analogous Figure 9 in Layard, Nickell and Jackman (1991), p. 320. Labour demand is depicted linearly decreasing for expository purposes.
} 


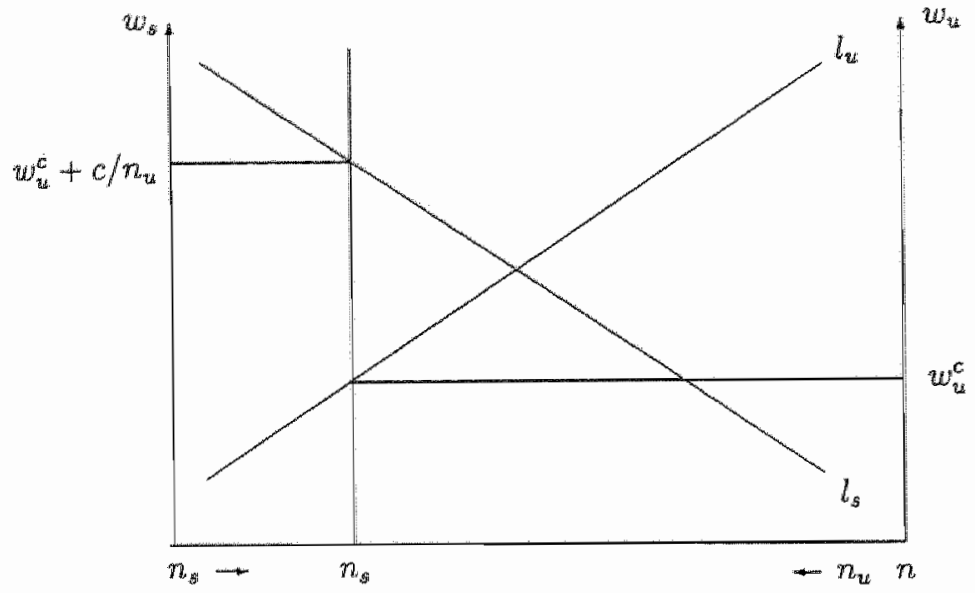

Figure 5.1: First Best Equilibrium

In Figure 5.1 unskilled wages and the skilled wage mark-up are such that skilled and unskilled labour supply $l_{u}$ and $l_{s}$ add up to $n$. In addition all skilled workers $n_{s}$ of the ability group depicted find adequate jobs, i.e. there is no over-supply of skilled workers. In equilibrium the marginal skilled worker with investment costs $\frac{c}{n_{u}}$ earns a net surplus of $w_{u}^{c}$

\subsection{Monopolistic Competition}

Now it is shown that a more than compensating mark-up for skilled wages skilled workers can ask because they have monopolistic market power necessarily leacls to overqualification and a Pareto-inferior solution. Higher wages for skilled workers reduce skilled labour demand and therefore aggregate labour demand. This increases unemployment of unskilled workers and unemployment insurance payments of skilled workers.

It is assumed that all skilled workers are organized in a union that represents the interests of them and sets the monopolistic skilled wage mark-up. ${ }^{15}$ An alternative interpretation is that one large union sets an individual wage for each ability group. 16 We assume hereby -in order to be able to compare both situations-that the wage for unskilled labour is still fixed at the level in the first best scenario $w_{w}^{c}$. This can be motivated

\footnotetext{
1.5 We find this construction e.g. in Snower (1983), Nishimura (1989) and Nielsen et al. (1995).

${ }^{16}$ In this symmetric case, the wage for all different skills is equal. Hence, also the assurnption that one union sets the skilled wage for all different qualifications would do the trick.
} 
with a minimum wage set by unions.

According to the theory of monopolistic competition, it is assumed that the skilled workers only take the demand function for their specialization into account and ignore the effects of their wage demand on aggregate labour demand and labour demand for other skills groups. The basic assumption that skilled workers or their unions do not take into account the shift in their demand function incurred by their wage setting can be motivated from the large number of skills. Here the actual impact of individual wage setting of one skill group indeed has a negligible impact on total demand for labour. Since $n$ and $\kappa$ are large, a change of $l_{s}$ has little effect on total skilled labour demand and therefore little effect on $g_{1}$ and $g_{2}$. Hence it is assumed that all wage demands of the individual workers in an ability group move together and the individually small effects add to a significant amount. The perceived skilled labour demand for the workers of a representative human capital group can be rewritten from (5.3):

$$
l_{s}=\alpha w_{s}^{-\frac{1}{1-p}}
$$

with $\alpha$ being a positive constant. The labour demand for skilled workers of one ability group decreases with the wage demand of that group. This effect is the larger the higher is the elasticity of substitution between the different abilities.

If the perceived demand function for skilled workers of one specialization (5.9) is substituted into the expected surplus function of the skilled workers $s_{s}(5.5)$ and this expression then maximized with respect to $w_{s}$, we obtain skilled wage demand. Unions set wages such that the expected skilled workers" surplus is maximal, taking labour demand (and over-qualification) and unemployment benefit payments into account. This results in the well-known ${ }^{17}$ optimal skilled wage mark-up..18

$$
w_{s}=\frac{w_{t z}^{c}}{\rho}
$$

Notice that the chance to be employed, the shift parameter in the perceived demand function $\alpha$ and the individual sunk costs for the acquisition of skill $c_{i}$ do not play a role in the monopolistic wage mark-up. The wage demanded increases with the outside option/the

\footnotetext{
${ }^{17}$ Compare the identical price setting behawiour in Tirole (1988) equ. (7.19) on p. 299 and Dixit and Stiglitz (1977) equ. (15) on p. 299.

${ }^{18}$ The expression below is only walid for $l_{s}<n_{s}$ or over-qualification. It is shown below that this is the case with a more than compensating monopolistic skilled wage mark-up.
} 
minimum wage $w_{v i}^{c}$ and decreases with the substitutability of the different sorts of human capital. The workers ask a mark-up over their outside option, because it is assumed that $0<\rho<1$. Analogous to other models of monopolistic competition, the necessity to employ workers with different skills ("love of variety") which can not perfectly be substituted by each other gives skilled workers the possibility to demand a monopolistic wage mark-up.

It is not clear, whether the optimal monopolistic wage mark-up is higher or lower than in the first best solution (where $w_{s}=w_{u}^{c}+\frac{c}{n_{u}}$ ). In this chapter the question is central which are the consequences of a higher than compensating skilled wage mark-up and simultaneously increased unemployment of unskilled workers under monopolistic circumstances for skill supply and social welfare. Therefore it is assumed that the monopolistic wage mark-up is higher than the compensating mark-up in the sacial planner scenario. Notice that the assumption of a higher than compensating wage differential between skilled and unskilled wages also implies that unemployment is induced, because the aggregate labour demand decreases in wages. The mark-up of the skilled workers therefore also has to compensate for the unemployment benefit costs $\bar{s}$ adequately employed skilled workers have to pay for the $u$ unemployed unskilled workers. Therefore in the remainder of this paper it is assumed that:

$$
w_{u}^{c}\left(\frac{1-\rho}{\rho}\right)-\frac{u \bar{S}}{n_{s s}}>\frac{c}{n_{u i}}
$$

Notice that equation (5.11) has to apply for all levels of $u$.

The equilibrium number of skilled workers is reached if the unskilled workers in the labour pool for a certain skill are not able to earn a rent by training. The traditional notion of monopolistic competition equilibrium would imply that there is no surplus above the competitive unskilled wage $w_{u}^{c}$ achievable for the skilled workers, i.e. no additional rents from education are enjoyed by the skilled workers. This condition is analogous to the zero-profit condition on the goods market that prohibits the market entry of additional firms.

On the labour market, there is no such zero-profit condition, however, because the surplus of the unskilled workers falls below $w_{u}^{c}$ if unskilled workers face the risk to get unemployed. In this case also the expected equilibrium surplus of all skilled workers decreases and at least the marginal skilled worker enjoys an expected surplus which is lower than $w_{w}^{c}$. 
It is shown below that overqualification is necessary to reach an equilibrium when skilled wage demand is higher than compensating. Skilled and unskilled labour demand $l_{s}$ and $l_{u}$ are directly derived from equations (5.2) and (5.3) dependent on $w_{w}^{c}$ and $\rho$. Overqualification and the number of unskilled workers are deduced from $n_{s}$ and $n$. Notice that a necessary ingredient for this result is the assumption that overqualified skilled workers are not able to underbid their former colleagues in order to price themselves into the skilled labour market again. This follows from the assumption that the firm only employs workers with the same wage demand.

Notice also that an equilibrium is only defined for overqualification ( $O$ is positive or zero), i.e. underqualification is not viable. With underqualification, skilled labour denand is higher than skilled labour supply. Therefore, all skilled workers earn the more than compensating wage differential with certainty, while unskilled workers maximally can earn $w_{u}^{c}$. Therefore all unskilled workers are attracted to obtain skills here and this can not be an equilibrium (except at the corner solution $n_{s}=n$ ).

If we set the expected surplus for the marginal skilled worker equal to the surplus earned by an unskilled worker, the labour market equilibrium condition can be derived from workers' surplus functions (5.4) and (5.5):

$$
\frac{l_{s}}{n_{s}} w_{s}-\frac{u}{n_{s}} \bar{s}+\frac{o}{n_{s}} w_{u}^{c}-\frac{c}{n_{u}}=\frac{l_{u}-o}{n_{u}} w_{u}^{c}+\left(1-\frac{l_{u}-o}{n_{u}}\right) \bar{s}
$$

In order to show that overqualification 0 is necessary for an equilibrium in (5.12), this equation is rewritten such that the effects of $o$ on the surplus of unskilled workers and the marginal skilled worker is clear. The left hand side which is the expected surplus of the marginal skilled worker can also be expressed as:

$$
s_{s}=-\frac{o}{n_{s}}\left(w_{s}+\bar{s}-w_{u}^{c}\right)+w_{s}-\frac{n_{u}-l_{u}}{n_{s}} \bar{s}-\frac{c}{n_{w}}
$$

The surplus of the unskilled workers (the right hand side) can be rewritten as:

$$
s_{u}=-\frac{o}{n_{u}}\left(w_{u}^{c}-\bar{s}\right)+\frac{l_{u}}{n_{u}} w_{u}^{c}+\left(\frac{n_{u}-l_{u}}{n_{u}}\right) \bar{s}
$$

In order to reach an equilibrium, (5.13) has to be equal to (5.14). Suppose there was no overqualification, i.e. the number of skilled workers would decrease symmetrically with the 
decrease in skilled jobs. In this case, equation (5.13) and (5.14) read:

$$
w_{s}-\frac{n_{u}-l_{u}}{n_{s}} \bar{s}-\frac{c}{n_{u}}>\frac{l_{u}}{n_{u}} w_{u}^{c}+\left(\frac{n_{u}-l_{u}}{n_{u}}\right) \bar{s}
$$

As the right hand side is smaller than $w_{u}^{c}$ and the left hand side is larger than $w_{u}^{c}$, this never can be an equilibrium (both sides cannot be equal). Therefore overqualification has to equate both sides. ${ }^{19}$

Overqualification reduces the expected surplus of the skilled workers and of the unskilled workers, compare (5.13) and (5.14). In order to reach an equilibrium, the surplus of the marginal skilled worker (5.13) has to decline faster than that of the unskilled workers (5.14), because the expected surplus of the unskilled workers is already lower than in the optimum due to the unemployment induced by higher skilled wages. In addition the expected surplus of the skilled workers is higher than in the optimum due to the higher skilled wage mark-up. Overqualification reduces the surplus of the marginal skilled worker by the monopolistic wage mark-up above the outside option of the skilled workers minus the payment for an additional unemployed unskilled worker $\frac{1}{\tau_{s}}\left(\frac{w_{u}^{c}}{\rho}+\bar{s}-w_{u}^{c}\right)$. The expected surplus of the unskilled workers is reduced by the difference between the wage in the unskilled labour market and the unemployment benefit $\frac{1}{n_{u}}\left(w_{u}^{c}-\bar{s}\right)$. Therefore we have the following condition for an equilibrium with a more than compensating mark-up:

$$
\frac{n_{s}}{n_{u}}<\frac{1-\rho-\varepsilon \rho}{\rho-\varepsilon \rho}
$$

The unemployment insurance cost burden has to be divided by the number of adequately employed workers. Therefore the share of skilled workers on the work force should not be too large, because otherwise the expected reduction in surplus is relatively too small per person. The larger is the mark-up $\rho$ the smaller has to be the relative share of skilled workers, because only the skilled workers benefit from a higher monopolistic mark-up. ${ }^{20}$

The labour market is brought to equilibrium by the number of workers choosing ed-

${ }^{19}$ Equilibrium overqualification is here equal to:

$$
0=\frac{\frac{n_{0}-l_{0}}{n_{0}}+\frac{l_{0}}{n_{0}} w_{0}^{c}-w_{s}+\frac{n_{0}-l_{0}}{n_{s}}+\frac{c}{n_{0}}}{\frac{w_{0}-\bar{s}}{n_{0}}-\frac{w_{w_{s}}+\bar{s}-w_{0}}{n_{u_{s}}}}
$$

${ }^{20}$ If $p>0.5$, the share of skilled workers has to be smaller smaller than the share of unskilled workers nis $<1$. 
ucation, $n_{s}{ }^{21}$ As we assume a declining skilled labour demand in skilled wages, there is less skilled labour demand in the monopolistic wage scenario than in the optimum. There is zero cross-wage elasticity in labour demand, therefore unskilled labour supply is not affected.

As the skilled labour demand (5.3) is not specified, it is unclear, if $n_{s}$ is higher or lower than in the optimum.

Therefore it is clear that with a more than compensating monopolistic mark-up overqualification has to be induced in order to reach an equilibrium on the labour market. Here labour market power of skilled workers induced by their relative monopoly position causes labour market inefficiencies. The intuition is that if the costs of acquiring a skill are lower than the "additional revenues" being skilled, it is in the interest of the unskilled workers to invest in education even if there is a risk to lose the investment costs because there is an over-supply in their skill. The additional revenues are the mark-up paid for skilled workers and the avoidance of the lower outside option of unskilled workers in case of unemployment. An excess supply of skilled workers occurs therefore, if a low substitutability between skills groups and a low unemployment benefit allows a higher than compensating monopoly mark-up for skilled wages, if the investment costs (and therefore the barriers to enter the skilled labour market) are low or if the minimum wage $w_{u}^{c}$ is high. In addition a high unemployment rate of unskilled workers (i.e. a high wage elasticity of aggregate demand) contributes to the waste of resources induced by overqualification.

Unemployment of unskilled workers reduces in the monopolistic competition equilibrium the expected surplus of unskilled workers below $w_{u}^{c}$. Therefore the expected increase in surplus by skilled workers finding adequate jobs due to the more than compensating mark-up has to be lower than the expected decrease in income of the skilled workers who are forced to work in unskilled jobs. As a consequence of the induced unemployment of unskilled workers, the expected surplus of the skilled workers sinks also below the optimum level in the monopolistic competition labour market equilibrium. The monopolistic wage

\footnotetext{
${ }^{21}$ Equation (5.12) determines the number of skilled workers $n_{s}$ in the market equilibritum with monopolistically competitive wages $w_{s}$ :
}

$$
n_{s}=n\left(\frac{\epsilon u-l_{s}\left(\frac{1-p}{\rho}\right)}{u-l_{s}\left(\frac{1-p}{\rho}\right)-\frac{s}{w i b}}\right)
$$


mark-up is the optimal strategy of skilled workers taking the perceived labour demand curve for "their" skill into account, although it generates an inefficiently low expected surplus for all workers if it is more than compensating. Therefore the lack of a flexible wage coordination mechanism leads to a suboptimal outcome even for the skilled workers, if they have a high market power. It is clear that also the social rent is smaller than in the first. best scenario, because the profit of the firm is reduced by the higher skilled wage and lower employment.

The monopolistic competition situation may be depicted as in Figure 5.2:

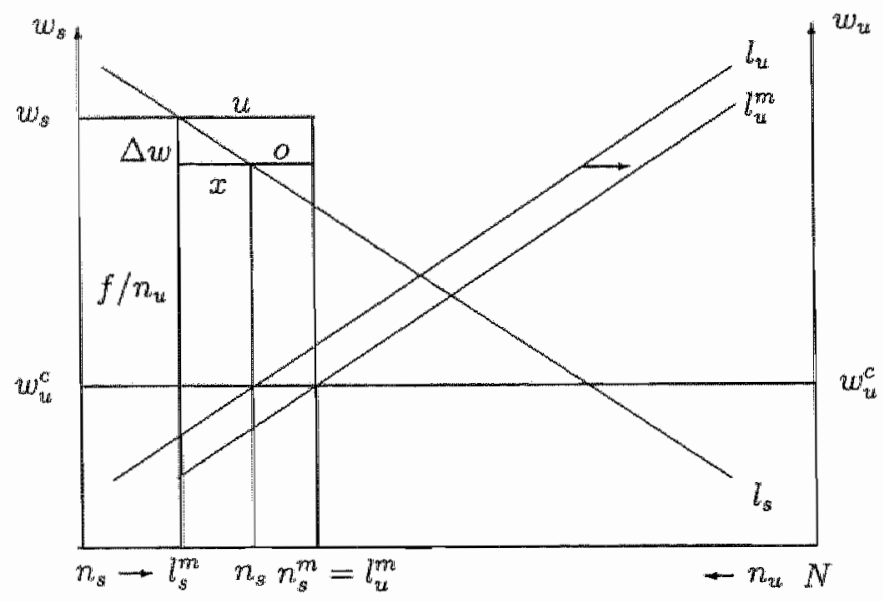

Figure 5.2: Monopolistic Competition

From the analysis above, it is clear that a more than compensating wage mark-up of the slkilled workers leads to overqualification if (5.16) holds. That means that $n_{s}^{m}>l_{s}$ at $w_{s}$. This difference is indicated by o in Figure 5.2. Notice that $w_{s}=w_{\mathrm{u}}^{c}+\frac{n}{n_{u}}+\Delta w$ with $\Delta w$ being the more than compensating part of the skilled wage demand. The labour demand function of unskilled workers shifts to the right by overqualification $o$, because the overqualified skilled workers substitute unskilled workers. In addition, unskilled labour demand also shrinks due to lower aggregated labour demand, which is denoted $x$ in Figure 5.2. Unskilled labour demand is not affected by the higher skilled wage due to the assumption that $\frac{\partial l_{u}}{\partial w_{u}}=0$. We know therefore that $n_{s}^{m}$ is left of the new skilled labour demand $l_{s}^{\mathrm{m}}$, while the difference between $l_{s}^{m}$ and $l_{u}^{m}$ equals the number of unemployed unskilled workers, $u=o+x=n-l_{s}^{m}-l_{u}^{m}$. Figure 5.2 is just one representation of many different possible equilibria in the monopolistic competition labour market. 


\subsection{Remedies}

It is shown now by which measures a social planmer could avoid overqualification $(0=0)$, in the monopolistic competition scenario where the more than compensating mark-up (5.11) is valid. In addition, a social planner solution proposed e.g. by Dixit and Stiglitz (1977) in the unconstrained optimum section and by Tirole (1988) as "first-best benchmark" is applied to this labour market model.

Two obvious possibilities of the social planner to avoid overqualification are to decrease the outside option of the skilled workers $w_{u}$ or to increase investment costs in human capital c. If the social planner has to respect the monopolistic mark-up of the skilled workers and free entry into the skilled labour market, full employment of skilled workers in skilled jobs can be achieved by decreasing the minimum wage $w_{u}$ such that in the labour market equilibrium (5.12) aggregate skilled labour demand equals aggregated skilled labour supply $\left(l_{s}^{m}=n_{s}^{m}\right)$. This is possible because a reduction in $w_{u}$ reduces the expected surplus of the skilled workers more than that of the unskilled workers. This can be seen from equation $(5.12)$ where the term on the left hand side multiplied by $w_{w}^{c}$ is larger than the term on the right hand side which is also multiplied by $w_{w}^{c}$. The difference equals the investment costs in human capital $\frac{c}{N-n_{s}}$. Therefore less workers decide to invest in human capital when the minimum wage decreases.

The solution for the unskilled wage is then:

$$
w_{u}^{p}=\frac{c}{n-n_{s}}\left(\left(\frac{1-\rho}{\rho}\right)-\frac{\left(n_{u}-l_{u}\right)\left(n \varepsilon-n_{s}\right)}{n_{s}\left(n-n_{s}\right)}\right)^{-1}
$$

The level of the minimum wage $w_{u}^{p}$ that is compatible with zero overqualification increases with the education costs and decreases with the mark-up between minimum wage and skilled wage on the one hand and minimum wage and the nnemployment benefit on the other hand. This social planer measure also leads to less unemployment of unskilled work.. ers, because aggregated labour demand increases, due to the falling wages. The number of workers specializing in a certain skill is reduced, because it is less attractive to invest in training. Notice that the social planner solution implies a lower surplus for both groups of workers than in the first best optimum, because $w_{u}^{p}<w_{u}^{c}$. Firm's profits increase in comparison to the monopolistic competition scenario. This measure to reduce minimum wage until overqualification vanishes can be depicted as in Figure 5.3 : 


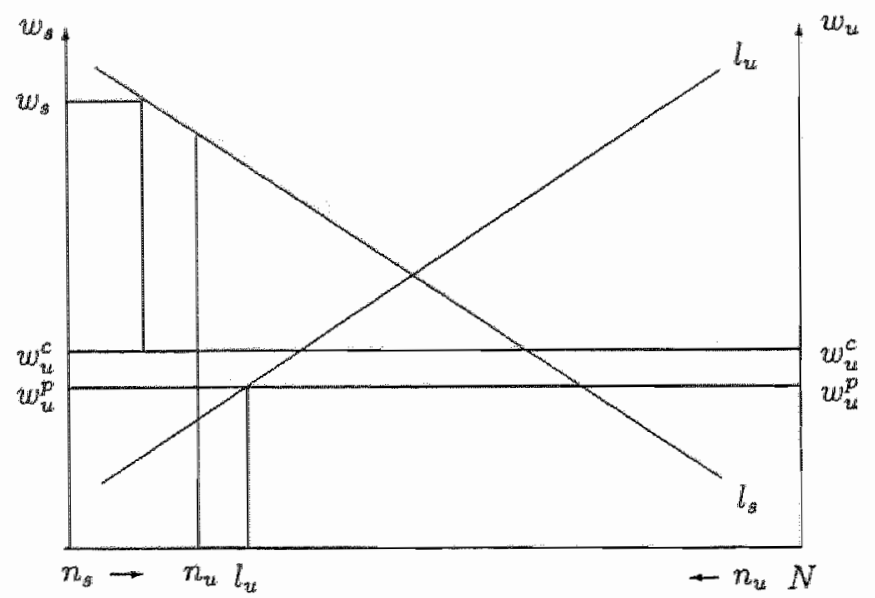

Figure 5.3: Reduction in the Minimum Wage

Here, again, the skilled workers ask the more than compensating mark-up $w_{s}-w_{u}^{p}$. If the minimum wage is decreased, the unskilled labour demand increases to $l_{u}$, while the mumber of unskilled people increases to $n_{u}$. Skilled labour demand increases to $n_{u}$ in Figure 5.3. In the new equilibrium therefore $n_{u}-l_{u}$ workers are unemployed, while all skilled workers find work. No unskilled workers are then replaced by overqualified skilled workers.

An increase in investment costs also reduces the attractiveness of investments in skills. In order to reduce overqualification to zero, the investment costs should be:

$$
c=\left(n-n_{s}\right)\left(\frac{1-\rho}{\rho}\right) w_{u}^{c}-\frac{\left(n_{u}-l_{u}\right)\left(n \varepsilon-n_{s}\right)}{n_{s}}
$$

As education is highly subsidized (compare the figures presented in chapter 2 about public education subsidies), an increase in investment costs could easily be achieved by a reduction in public subsidies e.g. for university education in times of overeducation. The inefficiencies incurred by the monopolistic skilled wage mark-up still reduce the social welfare in this case.

Dixit and Stiglitz (1977) and Tirole (1988) p. 299 propose another social planner solution. Here, the social planner does not allow for the exploitation of monopolistic market power by setting a more than compensating skilled wage demand. The social planner sets wages of skilled workers equal to the minimum level $w_{u}$. In addition, the schooling costs of the skilled workers employed in skilled jobs are borne by the firm. Marginal labour costs are therefore $w_{u}$ for the unskilled jobs and $\left(w_{u}+\frac{n_{2}}{n_{u}}\right)$ for the skilled jobs. The demand 
for workers within the different skills groups $l_{s}$ and the demand for unskilled workers per skills group $l_{u}$ is still determined from the first order conditions of frm's profit function (5.2) and (5.3), while the number of skilled workers $n_{s}$ is again determined by the no-entry condition, i.e. unskilled workers earn no rent when training. Notice that the firm just pays the education costs for the skilled workers accepted, while the skilled workers who do not find an adequate job lose their investment costs. Therefore not all workers are attracted to invest in skills in order to be in the better position also for the unskilled jobs that are first given to skilled workers.

In this case, the ex-post surplus function of the skilled workers is slightly changed. Skilled workers earn the basic wage with certainty (it does not matter, if they work in a skilled or unskilled job), but the education costs are only borne by the firm for those workers who have a job they specialized for. If we assume again that the overqualified skilled workers are chosen randomly, we obtain the following expression for the marginal skilled workers' expected surplus:

$$
s^{\mathrm{r}}=w_{u}-\frac{u \bar{s}}{l_{s}}-\frac{n_{s}-l_{s}}{n_{s}} \frac{c}{n_{u}}
$$

The surplus of the unskilled workers is not changed. They fill the remaining jobs and are paid the basic wage, while the unemployed unskilled workers just earn the outside option $\bar{s}$ (compare (5.4)). If the surplus levels of both groups of workers are set equal, the following condition for the labour market equilibrium is derived instead of (5.12):

$$
w_{u}-\frac{o}{n_{s}\left(n-n_{s}\right)} c-\frac{u}{n_{s}} \bar{s}=\frac{b_{u}-o}{n_{u}} w_{u}+\frac{u}{n_{u}} \bar{s}
$$

From the equilibrium condition above it can be seen immediately that this social planner rule only leads to adequate employment for all skilled workers $(o=0)$, if all unskilled workers find work $\left(n_{u}=l_{u}-o\right)$ or if the outside option of the unskilled workers is equal to the minimum wage $\left(w_{u}=\bar{s}\right)$. Otherwise there is a continuum of equilibria with overqualified workers. The results of this scenario are equal to the first best optimum, if $w_{u}=w_{u}^{c}$ * Therefore the social planner also can reach full adequate employment by giving the firms the right to pay education costs while all workers earn the minimum wage paid in the optimum. Notice that this measure is associated with a different distribution in rents with respect to the optimum. Here the firm earns the entire rent created by the investment in human capital, while in the first best optimum all inframarginal skilled workers enjoy a 
surplus which is higher than the minimum wage $w_{u}^{c}$.

\subsection{Conclusions}

Why do not all workers acquire skills when wage inequality increases, unskilled workers experience an even higher relative unemployment and all skilled workers employed in adequate jobs earn rents as a consequence? This chapter provides two explanations. First, if workers have different education costs, benefits may be lower than costs for workers with high education costs even if skilled workers enjoy rents. Second, if overqualification reduces the expected rents of skilled workers more than that of unskilled workers, overqualification is a surplus-equalizing factor when skilled workers in adequate jobs ask a wage mark-up which is higher than compensating.

This model shows that a more than compensating skilled wage mark-up that is made possible by market power skilled workers enjoy leads to a Pareto-inferior labour market equilibrium. In contrast to comparable models with compensating wage differentials, the monopolistic wage mark-up enjoyred by the skilled workers is not compensated by a higher incidence of unemployment or amenities of this group of workers, but by overqualification. The labour market equilibrium induced by a more than compensating wage differential provides a lower surplus for both groups of workers and reduced profits for the firm. Therefore also skilled workers are on average worse off with their monopolistic wage mark-up, while skilled workers in skilled jobs are better off. This result is obtained because in monopolistic competition models usually it is assumed that skilled workers only take their received labour demand functions into account. Here, workers use skills as a weapon in job competition, which is made possible by easy substitutability of unskilled workers by skilled workers. This induces an additional incentive for overeducation in times of unemployment which makes schooling partially ineffective (compare the theoretical argument in Van Ours and Ridder (1997)).

It is an important question for future research, whether the consequences of increased wage inequality predicted by this model are observed in reality. We should therefore find increasing overeducation at the end of the 1980s and the begin of the 1990s in all countries with large rents for skilled workers (this would also be in line with the cob-web result Richard Freeman predicts for labour markets due to time inconsistency and lags in education. Mincer (1994) estimates the lag between the appearance of rents for schooling 
and a higher incidence of skilled workers at 8 years.

Unfortunately the data basis is rather scanty. All empirical investigations indicate that overeducation is a wide-spread phenomenon on the labour market in recent years (undereducation however as well), compare the survey in Hartog (1985). Borghans and Smits (1997) present evidence for the Netherlands that $22 \%$ of higher vocational school graduates work below their level of education. This is associated with a reduction in wages in comparison to pupils who find adequate jobs. Groot and Maassen van den Brink (1996) present comparable Dutch figures for 1982 (22\% overeducated) and 1995 (24\%). Dekker et al. (1996) p. 13 report an overall overeducation in the Netherlands of $30,6 \%$ with a steep decline in the age of the workers. Beneito et al. (1997) show that $25.6 \%$ of the Spanish labour force is overeducated, while Groot (1996) estimates the figure for the UK at $11 \%$ and Sneessens and Shadman-Mehta (1995) stress that the share of skilled workers is lower than the share of skilled people in France. Büchel and Weißhuhn (1996) show that overeducation is somewhat lower than $20 \%$ in Germany. While it increased in West-Germany between 1984 and 1991 and decreased slightly since then (except for female academics) it still rose in the Eastern part of Germany between 1991 and 1993.

How to measure overeducation properly is still open to debate (compare Hartog (1985)) and studies about the incidence of overeducation over time in different countries are scarce and mainly from the 1970s (compare e.g. Hartag and Oosterbeek (1988) for Dutch evidence). An exception is Kiker et al (1997), who show that overeducation in Portugal increased between 1985 and 1991 from $16.3 \%$ to $25.3 \%$.

This chapter proposes two solutions for the overqualification problem. First, a reduction in unskilled wages leads to full adequate employment of skilled workers, because it makes unskilled work relatively more attractive. The equilibrium surplus of both groups of workers is lower than in the optimum, however. A second step to reduce overqualification is the increase in education costs or a reduction in the substantial public education subsidies.

The social planner can also prohibit the exploitation of skilled workers' market power. Market power of skilled workers can be destroyed by setting the wage of all workers at the unskilled wage level while the firms pay for the education costs of those workers they hire. This solution leads to the first best equilibrium with full and adequate employment for all workers if the unskilled wage is at the market-clearing levell in the first best scenario. Here, the firm earns the entire rent generated by the workers and all workers just earn the minimum wage. In the first best optimum all inframarginal adequately employed skilled 
workers enjoy rents above the minimum wage.

\subsection{Appendix}

In this appendix, a less refined version of the model presented above is given. Here we assume homogeneous workers who can decide to acquire a homogeneous skill or not. In addition, unemployment benefit is not paid by the adequately employed skilled workers, but comes from outside sources.

There are $N$ workers who either can acquire a skill or not. In order to acquire the skill, they have to invest $c$. These investment costs in human capital are sunk, i.e. they can not be re-earned when no skilled job is found after acquiring the skills.

The firm maximizes profits by choosing the optimal number of unskilled workers $L_{u}$ and skilled workers $L_{s}$. Both groups of workers are needed for production. Skilled wage $w_{s}$ and unskilled wage $w_{u}$ are given for the firm. The profit function is defined now as follows:

$$
\pi=g\left(L_{u}\right)+L_{s}^{P}-w_{u} L_{t u}-w_{s} L_{s}
$$

with $0<\rho<1$ and $g^{\prime}>0$ and $g^{\prime}<0$. Skilled and unskilled labour demand are derived from the following first-order conditions:

$$
\begin{aligned}
& g\left(L_{u}\right)=w_{u} \\
& \rho L_{s}^{\rho-1}=w_{s}
\end{aligned}
$$

The workers have uninhibited access to education again. The expected surplus of those $N_{u}$ workers who stay unskilled is again (compare (5.4)):

$$
s_{u}=\frac{L_{u}-0}{N_{u}} w_{u}+\left(1-\frac{L_{u}-0}{N_{u}}\right) \bar{s} \text { if }\left(L_{u}-0\right)>0
$$

if $N_{s}-L_{s}=0$ skilled workers are over-qualified.

The expected surplus of the $N_{s}$ skilled workers is then:

$$
s_{s}=\frac{L_{s}}{N_{s}} w_{s}+\left(1-\frac{L_{s}}{N_{s}}\right) w_{u}-c
$$


if $L_{s}<N_{s}$. Notice that skilled workers do not have to pay the unemployment benefit here and earn $w_{u}$ when they are over-qualified and replace unskilled workers in unskilled jobs.

The rent $R=\pi+N_{s} s_{s}+N_{u} s_{u}$ is maximized again and the labour market is in equilibrium when $w_{s}-c=w_{u}$ and $w_{u}$ (taking $w_{s}$ into account) is set such that $L_{s}+L_{u}=N$. Here all workers are adequately employed and enjoy the same surplus. As all workers are indifferent if they are skilled or not, because the skilled wage mark-np equals the costs for acquiring skills, we can assume that only the required number of workers invests in education and no workers are over-qualified. Figure 5.1 applies again when the notation is adapted.

If the skilled workers enjoy the possibility to set their wage $w_{s}$, they set it in a monopolistic manner such that $s_{s}(5.21)$ is maximized taking into account skilled labour demand (5.19). The corresponding skilled wage is again $w_{s}=w_{u} / \rho$, compare (5.10). Hence the expected income of a skilled worker is:

$$
s_{s}=w_{u}+\frac{1-\rho}{\rho} \frac{L_{s}}{N_{s}} w_{u s}-c
$$

The surplus of the unskilled workers is unchanged and equal to (5.20). An equilibrium requires that $s_{s}=s_{u}$ due to free entry for unskilled workers. One solution is therefore $(1-\rho) w_{u}=\rho c$ and $L_{s}=N_{s}$. If the elasticity of skilled labour demand $\rho$ is however larger and $(1-\rho) w_{w}>\rho c$, then again over-qualification has to be induced in order to bring the labour market to equilibrium (i.e. $L_{s}<N_{s}$ ).

In order to reach an equilibrium with over-qualification, the surplus of unskilled workers has to decrease less than the surplus of the skilled workers again. The surplus of the unskilled workers decreases with over-qualification by the difference between the wage in the unskilled labour market and the unemployment benefit $\frac{1}{N_{u}}\left(w_{u}-\bar{s}\right)$, while over-qualification reduces the surplus of the skilled workers by the difference between skilled and unskilled wage $\frac{1}{N_{s}}\left(w_{s}-w_{u}\right)$ due to the assumption that the skilled workers do not have to pay the unemployment benefit of the unskilled workers. Therefore the analogous condition for an equilibrium with over-qualification is here (compare (5.16)):

$$
\frac{N_{s}}{N_{u}}<\frac{1-\rho}{\rho-\varepsilon \rho}
$$

Figure 5.2 applies for the monopolistic skilled workers situation (with the adapted notation). 
Therefore we can derive the same result of the monopolistic competition model, i.e. that higher than compensating skilled wages cause over-qualification also in a framework with only one skill and homogeneous workers. 


\section{Chapter 6}

\section{Human Capital in a Neo-Keynesian Model}

\subsection{Introduction}

Does employment recover according to the traditional Neo-Keynesian model with fixed wages, if one adds the necessity to invest in human capital? In order to answer this question a simple aggregate labour market model is presented that accounts for the necessity to invest continuously in human capital. In addition the impact of an exogeneous contractional shock upon employment, real compensation and unemployment is discussed within this context. This chapter is therefore a first investigation into the correlation between human capital formation, aggregate shocks and employment. The fundamental mechanisms explained in the chapters based on individual and rational decisions such as the sunk cost nature of human capital formation and the necessity to invest in human capital in order to preserve labour productivity are also used here. The chapter shows that the inclusion of human capital formation in a standard Neo-Keynesian macro model leads to a lower equilibrium employment level and to a slower adoption path in the wake of an aggregate demand shock. ${ }^{1}$

The formal model in this chapter is based on the models developed in a series of papers by William Darity and Arthur Goldsmith (see e.g. Goldsmith and Darity (1992) and Darity and Goldsmith (1996)). The authors argue that exposure to unemployment negatively affects the psychological well-being of the people laid off by teaching a feeling of

\footnotetext{
${ }^{1}$ The argument that human capital formation leads to unemployment persiatience is not new, compere e.g. the overview in Franz (1990). This model presents several arguments in a unified, simple frame work, however.
} 
helplessness that impairs motivation as well as learning and may yield unpleasant emotional disturbances. In a second step evidence is given that also those who are underemployed and those who see that their fellow workers become unemployed suffer psychological damage as well due to feelings of guilt, poor concentration, efforts to seek alternative employment and insecurity. This leads to a worse job performance and reduced labour productivity. Darity and Goldsmith point out that psychological health affects the portion of effective human capital that is actually realized and as a consequence labour productivity of the entire labour pool declines after a period of high unemployment.

In this chapter it is argued that also the (as Darity and Goldsmith call it) "conventional" skill-based aspect of human capital in addition to psychological health and emotional wellbeing may be negatively affected by increased unemployment. The skill-based aspect of human capital is the capacity to initiate and complete tasks by previously acquired skills (human capital investrment). This argument is based on three stylized facts.

1. It is assumed that exogeneous technical progress makes necessary a continuous learning process of the workers.

2. The acquisition of the necessary skills is costly for the workers and includes for a large part also sunk costs, i.e. costs that can not be recovered when the employment relation is terminated, while the increased labour productivity associated with those skills is (partly) lost.

3. Training-on-the-job is necessary for all workers. While employees enjoy it "automatically" during their work, entrants have to be trained first before they can perform their tasks adequately. This is costly.

Like Darity and Goldsmith, for expository purposes, the focus is on the impact of human capital on labour demand and supply and all other factors like the social psychological state of the labour force, capital stock and technology are suppressed.

First a standard Neo-Keynesian labour market model with wage rigidity in the short run (compare Goldsmith and Darity (1992)) is developed. In a next step, the necessity to invest in human capital is introduced. 


\subsection{A Traditional Neo-Keynesian Model}

Here the typical Neo-Keynesian labour market story is given without taking into account human capital. The profit function of the firm is simplified to the following:

$$
\pi=\theta g(l)-w l
$$

with $g^{\prime}(\cdot)>0, g^{\prime \prime}(\cdot) \leq 0, l$ is the number of workers demanded by the firm and $\theta$ the goods price indicating the state of the economy (e.g. goods demand, government expenditures, exports etc.) with upper and lower bounds $\theta \in[\underline{\theta} ; \bar{\theta}]$ with $\underline{\theta} ; \bar{\theta} \in R^{+}$. Capital is assumed to be fixed. Labour demand of the firm is given by the condition that the marginal revenue product of labour equals the nominal wage $\theta g^{\prime}=w$. This results in a falling $D$ curve which is depicted linearly for convenience in Figure 6.1.

Every worker can decide to offer his or her labour power or not, therefore there is no decision about working hours. A workers supplies labour if the wage is higher than her or his reservation wage. The reservation wage depends on labour disutility that differs between individuals. When the wage is higher than the reservation wage, the worker voluntarily stays out of the labour market, if it is lower, he or she tries to get a job. At the reservation wage the worker is indifferent between working or not, i.e. the expected surplus when working has to be equal to the certain unemployment benefit $\bar{s}$. The easiest formulation for workers' utility is to reduce the argument to monetary units and assume risk-neutrality. Then worker $i$ has the following expected utility depending on his/her disutility of work $h_{i}$ :

$$
s_{i}=\frac{l}{N} w+\left(\frac{N-l}{N}\right) \bar{s}-\frac{l}{N} h_{i}
$$

If labour demand $l$ is smaller than labour supply $N$, workers lose their jobs randomly and earn the market wage $w$ with probability $\frac{l}{N}$, while they earn the outside option $\bar{s}$ otherwise. If we set the (monetary) utility of the unemployed worker equal to the outside option $s_{i}=\bar{s}$, we obtain the following expression for the reservation wage $w^{r}$ which is at. least necessary to give workers an incentive to work:

$$
w_{i}^{r}=\bar{s}+h_{i}
$$

That is, when $w>w_{i}^{r}$ labour is supplied by individual $i$. Therefore it is clear that the probability to be unemployed does not affect the reservation wage and aggregate labour 
supply only depends on the distribution of the monetary disutilities to work. At the market wage, the marginal employed worker with the highest work disutility is indifferent between working and being unemployed, while all infra-marginal workers enjoy a rent.

If the wage decreases, workers with high reservation wages leave the firm. Workers' expectations about being unemployed do not play a role and only the distribution of $h_{i}$ is decisive for the exit decision. As more workers decide to quit their job when the wage decreases, we get an increasing supply function of labour $S$. The function $S$ is also depicted linearly in Figure 6.1 for convenience.

Let us look at a short-run equilibrium, where capital stock, price, state of technology and wealth are treated as given. The labour market is cleared by the wage level. Neither the firm nor the workers have market power and are therefore not able to push the ather side from the surplus or profit maximizing reaction function. Market clearing establishes a common wage paid to employed workers, and existing unemployment is considered both frictional and woluntary. ${ }^{2}$ Workers participate at the labour market and the firm maximizes profit on static calculations. All agents do not take the future into account.

The sequence of events when time elapses can be summarized as in the following diagram:

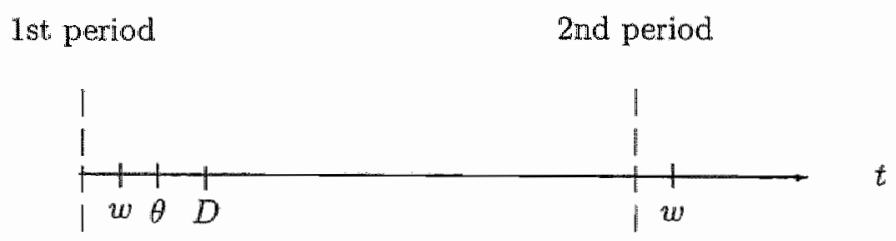

\section{Diagram 6.1: Sequence of Events}

First the wage rate $w$ adapts to the labour market conditions, then a disturbance may occur that changes $\theta$. As a consequence labour demand $D$ changes. Wages adapt to the new situation only at the beginning of the next period if we accept the Keynesian assumption of fixed wages in the short run.

The aggregate labour market equilibrium is in the beginning at point $A$ in Figure 6.1 with a market clearing wage of $w_{A}$. Labour demand falls from $D_{1}$ to $D_{2}$ when the economy experiences an exogeneous negative aggregate shock ( $\theta_{1}$ decreases to $\theta_{2}$ ), while marginal labour productivity decreases to $\theta_{2} g^{\prime}-w$. Assuming in the Neo-Keynesian tradition that

\footnotetext{
${ }^{2}$ Compare Goldsmith and Darity (1992), p. 450
} 
wages are sticky in the short run at $w_{A}$, labour demand is reduced and the distance $N_{A}-N_{Z}$ indicates the number of forced lay-offs. Therefore, $N_{A}-N_{Z}$ workers are involuntarily unemployed in the short run. In Neo-Keynesian models it is argued that wages adjust over time to $w_{B}$ when wage contracts expire or the employers become convinced that the negative shock is permanent. Therefore at the beginning of the second period the wage adapts to the new labour market situation and clears at point $w_{B}$. Therefore the negative supply shock leads to a lower employment level $N_{B}$. The involuntary unemployment gap is closed at a lower level of employment while the wage level decreases. In the traditional Neo-Keynesian model the short-term experience of unemployment has no effect on the productivity of the workers and their reservation wage. The additional workers hired when the wage declines have the same characteristics as the employed workers.

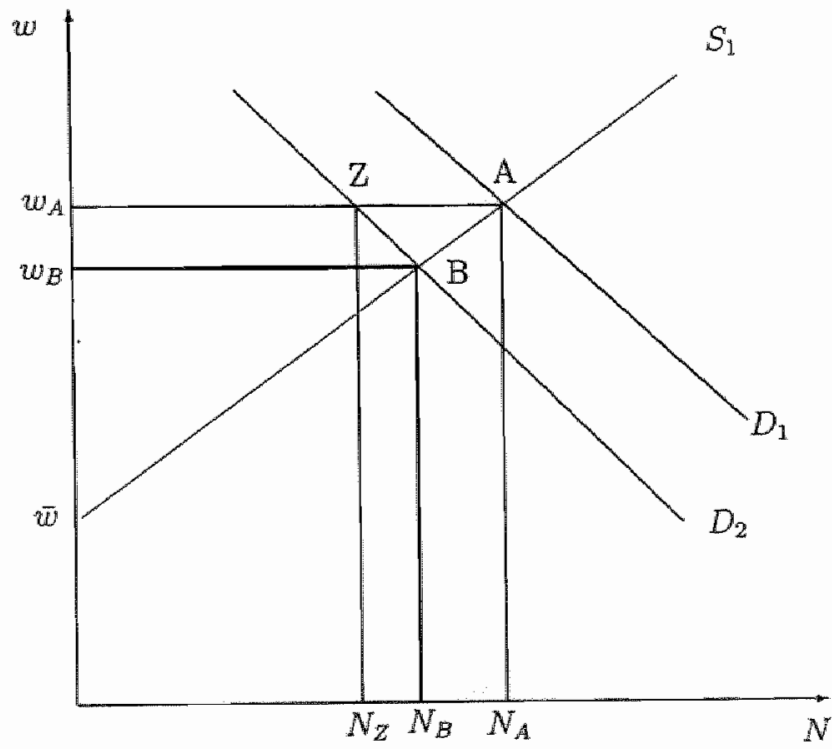

Figure 6.1: The Aggregate Neo-Keynesian Labour Market

\subsection{A Model with Human Capital}

Now assume that workers have to invest in human capital in order to be eligible for a job. Skills have to be up-dated in order to adapt to new and different technologies evolving with 
an exogeneously given and constant rate..$^{3}$ Therefore labour productivity is dependent on recent education $c$ that provides the worker with the possibility to handle new technologies. For simplicity it is assumed that this "skills update" is necessary at the beginning of every period for every worker who wants to find or keep a job.

In addition all entrants need additional training $t$, i.e. familiarity with firm's organization and the daily working routine when they start working at a firm. The underlying assumption is that the firm needs a homogeneous labour force. While the workers "costless" enjoy training-on-the-job, because they interact with colleagues, entrants have to be tanght this knowledge in order to enable them to catch up quickly. Unemployed workers lose the opportunity to maintain and update their skills by working. ${ }^{4}$ Speciall human capital investment $c$ is therefore necessary for all workers and on-the-job training for entrants only. The firm exclusively employs workers who have invested in the necessary human capital formation and on-the-job training and pays the same wage for all workers.

In order to keep the analysis simple, optimal training and skill update are exogeneous. Therefore in contrast to the models in the previous chapters, workers just can decide if to invest or not, but not about the size of investments. Another simplification is that unemployment benefits are paid from "outside" sources and not by employed workers. Therefore this model is not closed.

The model with human capital formation is set up such that it is identical to the traditional Neo-Keynesian model as long as there is no decline in output price $\theta$. Only if there is a negative shock on $\theta$, the human capital effects have an impact on the results.

The sequence of events in the model with human capital formation can be summarized in the following diagram:

1st period 2nd period

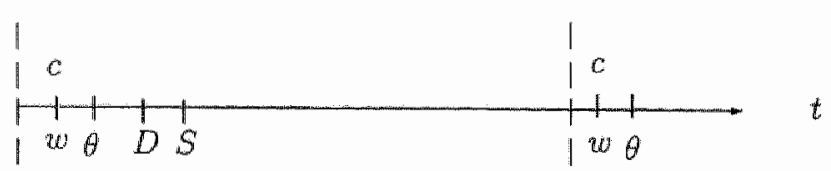

Diagram 6.2: Sequence of Events in the Human Capital Model

In the beginning of every period, all workers who want to join the work force have to

\footnotetext{
${ }^{3}$ Compare e.g. Hargreaves Heap (1980) p. 613.

${ }^{4}$ See Blanchand and Summers (1986) p. 28.
} 
invest $c$ in skills update. In addition to the reaction of labour demand $D$ on a decline in $\theta$, also labour supply $S$ changes. Labour supply changes when employment is uncertain, because the necessity to update skills forces wrorkers to sink human capital investment with uncertain pay-off. Labour demand changes when entrants have to be trained, because the firm has to pay for the training costs. Both effects are described in turn before the new labour market equilibrium is presented.

\subsubsection{Training Costs}

Now entrants need extra training in order to get acquainted with the working routine at the firm. Costs for on-the-job training $t$ are assumed to be fixed and equal for all entrants. The firm pays for it. The falling aggregate labour demand curve depicts again the marginal productivity of labour. The firm myopically maximizes profits at the current period. The simplest formulation of firm's profits is now:

$$
\pi=\theta g(l)-w l-e t
$$

Here, $e$ is the number of entrants who cost an extra $t$ to the firm. This means that marginal productivity of e new workers from the pool of unemployed has to be equal to their higher labour costs $\theta g^{\prime}=t+w$. For the experienced $l-e$ workers marginal productivity still equals $\theta g^{\prime}=w$. If $e$ entrants are hired, labour dernand is such that the higher marginal costs of the new workers are equal to their marginal labour productivity. This leads to a reduction in additional labour demand when entrants are hired. Pissarides (1992) describes a similar phenomenon when firm's labour demand decreases due to a loss of skill during umemployment. Then reduced additional labour demand increases the unemployment spells and therefore reduces average human capital of the unemployed further (thin market externality). This leads to cyclical persistence if the externality is large.

The increasing supply function of labour can be motivated again by workers having different monetary disutilities of work. If the wage increases, labour market participation increases.

Now, we can analyze the impact of a negative aggregated demand shock on unemployment and wages including training costs (compare Figure 6.2). A regative shock reducing product price $\theta_{1}$ to $\theta_{2}$ reduces labour demand again from $N_{A}$ to $N_{Z}$ assuming fixed wages in the short run. The labour demand functions $D_{1}$ and $D_{2}$ and marginal labour productivity 
are unchanged as long as only experienced workers are present in the firm. The introduction of training casts for entrants changes the results from the traditional Neo-Keynesian model. The $N_{A}-N_{Z}$ workers involuntarily set free in the recession do not enjoy the necessary training-on-the-job $t$ and have therefore a lower productivity. As a consequence, the labour demand curve shifts further to the left from $D_{2}$ to $D_{3}$ for all employment levels higher than $N_{x}$, i.e. when the firm hires new workers reacting on decreasing wages. If entrants are hired, their marginal productivity has to be equal to the increased marginal labour costs, $\theta_{2} g^{\prime}=t+w$. Hence the vertical distance between $D_{2}$ and $D_{3}$ equals $t$.

For simplicity, it is assumed that the firm is myopic with respect to the additional costs of entrants when firing workers. If the firm would take the training-on-the-job costs into account, an higher labour stock would be hoarded after the negative shock in the first period. The number of hoarded workers would be such that the reduction in marginal profits in the first period equals the increase in marginal profits in the second period because entry costs are lower, ${ }^{5}$ i.e. $\theta_{2} g^{\prime}\left(l^{*}\right)-w=-t$ where $l^{*}$ is the new market-clearing employment which is higher than $N_{Z}$. This changes the final employment equilibrium, because $D_{2}$ does not shift as far to the left as in the analysis with a myopic firm and $D_{3}$ is just a parallel shift with width $t$ to the right of $N=l^{*}$. Therefore the new employment equilibrium is only to the left of $N_{B}$, if the entry costs are small enough.

An assumption to avoid the introduction of myopic firms is to attribute the burden of entry costs to the entrants. In this case the labour supply curve of entrants is shifted further to the left, while the labour demand curve stays at $D_{2}$. This effect is discussed below in detail.

The model with training costs can be depicted like in Figure 6.2:

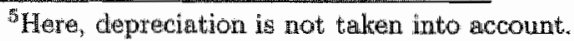




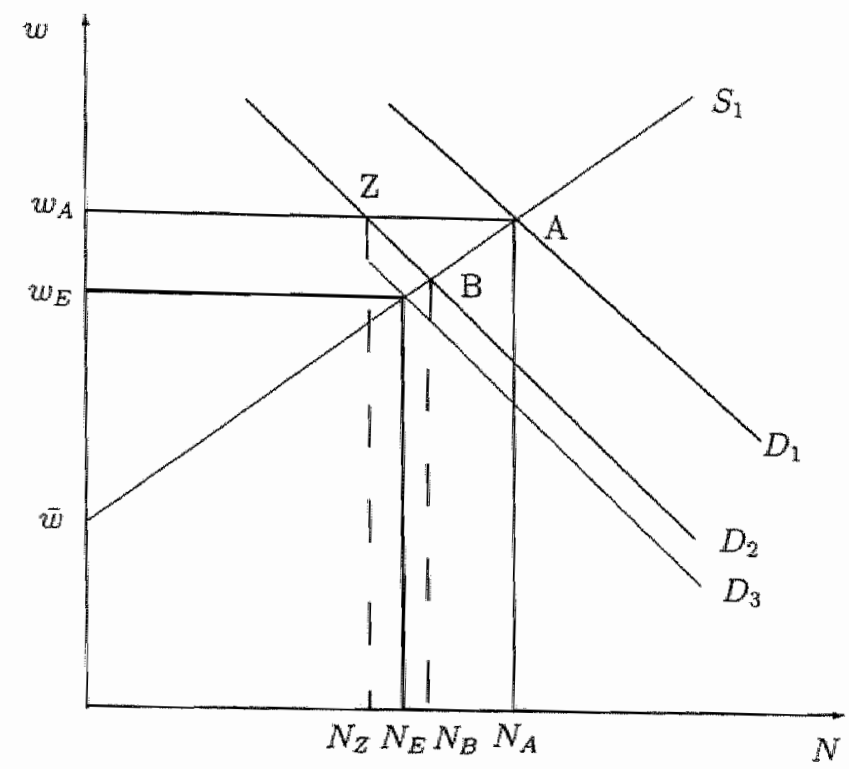

Figure 6.2: The Aggregate Labour Market with Training Costs

The new employment equilibrium with training casts in the beginning of the second period is at $N_{E}$, which is lower than the employment level in the traditional Neo-Keynesian model, $N_{B}$. The lower labour demand function $D_{3}$ is valid for all increases in employment in the future. Therefore a temporary shock has a permanent negative impact on employment.

\subsubsection{Skills Update}

Now it is assumed in addition to the training costs $t$, that all workers have to invest in skills update $c$ in order to be eligible to work at the firm. This may be due to technological developments that make it necessary that workers get acquainted with new technologies on a regular basis (here at the beginning of every period). Workers have to pay for their investment in human capital themselves. The human capital costs $c$ are sunk, i.e. do not yield a pay off when the worker loses his or her job. When the workers accept the wage and invest in human capital, they do not know, if they will be employed afterwards or not, because the realization of $\theta$ in the same period is unknown. In addition the firm fires workers randomly if labour demand decreases due to a decrease in $\theta$. 
The ex-post surplus of the workers who invest in human capital in order to have the possibility to enter the labour market is:

$$
\begin{aligned}
& s_{i}=w-\hat{h}_{i}-c_{y} \text { if employed } \\
& s_{i}=\bar{s}-c_{s} \text { if unemployed }
\end{aligned}
$$

The employed workers earn the market wage $w$ and have to deduct disutility of work and investment costs in human capital. In order to be able to compare the scenario with human capital investments with the bench-mark. Neo-Keynesian scenario, we assume a different scaling of the monetary disutility of work such that with full employment both scenarios are equal, i.e. disutility of work is now $\widehat{h}_{i}=h_{i}-c$. Therefore labour supply is unchanged if all workers keep their jobs.

As it is not certain if the worker stays employed in the period he or she applies for a job, expectations about the chance to stay employed have to be introduced. In order to give a general argument, the expectation about labour demand in period $t$ is called $t_{t}$, while labour supply in this period is called $N_{t}$.

The expected utility of individual $i$ in period $t$ is therefore:

$$
s_{t}^{i}=\frac{l_{t}}{N_{t}} w+\left(1-\frac{l_{t}}{N_{t}}\right) \bar{s}-\frac{l_{t}}{N_{t}} \widehat{h}_{i}-c
$$

or:

$$
s_{t}^{i}=\frac{l_{t}}{N_{t}} w+\left(1-\frac{l_{t}}{N_{t}}\right) \bar{s}-\frac{l_{t}}{N_{i}} h_{i}-\left(1-\frac{l_{t}}{N_{t}}\right) c
$$

The utility $s_{i}^{i}$ of accepting a job is dependent on the chance to stay employed in period $t$. Due to the uncertainty about $\theta$, the workers have to form expectations about the probability to stay employed. It is assumed that workers expect that the rate of involuntary unemployment share in period $t, \frac{N_{t}-l_{t}}{N_{t}}$, is related to the rate of the involuntary unemployment share in the last period with $\frac{N_{t}-l_{t}}{N_{t}}=\lambda \frac{N_{t-1}-t_{t-1}}{N_{t-1}}$ and $\lambda \in[0,1]$. One motivation for this assumption is that deviation of real economic aggregates from the trend are serially correlated (compare e.g. Pissarides (1992) p. 1371) and therefore lay-offs are experienced in waves.

A high $\lambda$ implies that workers think that the increase in involuntary unemployment is strongly related between both periods and that the relative number of workers fired is comparable to that in the previous period. A $\lambda$ of zero implies that workers do not expect 
Q to decrease further. As the workers are fired randomily, this expectation is equal for all workers independent of the senionity of the worker. All workers ask therefore for a risk premium in the period that follows a recession dependent on the share of unemployed in the previous period if $\lambda$ is positive. The reservation wage of individual is now:

$$
w_{t, i}^{\tau}=\bar{s}+h_{\bar{i}}+\left(\frac{N_{t}-l_{t}}{N_{t}}\right) c=\bar{s}+h_{i}+\lambda \frac{N_{t}}{l_{t}}\left(\frac{N_{t-1}-l_{t-1}}{N_{t-1}}\right) c
$$

It is clear that the necessary wage in order to attract a certain number of workers is now higher than in the bench-mark scenario when $l_{t-1}<N_{t-1}$ and it is increasing with the involuntary unemployment rate in the previous period $\left(N_{A}-N_{Z}\right.$ in Figure 6.1 or Figure 6.2 for example) and the expected umemployment correlation coefficient $\lambda$. The risk premium shifts the entire labour supply curve to the left in a parallel fashion in the period after an aggregate demand shock incurring involuntary unemployment, because the workers and entrants demand a risk premium. Workers only enter the labour market if the wage level compensates for their disutility of work and their expected risk to lose their job in the period and the associated loss in sunk human capital investments.

In order to keep the model simple and because this chapter is about the effects of a negative shock on employment, it is assumed that if there was no involuntary unemployment in the last period, workers do not expect it in this period. A reduction of the labour force in the future is therefore only expected when there was involuntary unemployment in the previous period.

In the first period, a change from $\theta_{1}$ to $\theta_{2}$ causes again $N_{A}-N_{Z}$ inwoluntary unemployed workers. While labour dernand increases with a reduction in wages at the beginning of period 2, labour supply decreases because workers charge a risk mark-up $(\lambda>0)$. Labour supply shifts to the left from $S_{1}$ to $S_{2}$ in Figure 6.3 . Due to the assumption of adaptive expectations, workers calculate with a probability of $\frac{N_{2}-l_{2}}{N_{2}}=\lambda \frac{N_{1}-l_{1}}{N_{1}}=\lambda \frac{N_{A}-N_{2}}{N_{A}}$ to keep their job in the second period and the reservation wage increases accordingly. The shilt from $S_{1}$ to $S_{2}$ in Figure 6.3 can therefore be interpreted as a risk mark up of the labour force if in the previous period a high number of workers was fired. This reduces the number of workers investing in human capital at a given wage rate. Notice that employed and wnemployed workers have the same reservation wage depending on $\lambda$ and individual work disutility $h_{i}$. When the reservation wage increases, only the part of the fired workers with a low disutility of work invests again in human capital in the next period.

The model with human capital up-date and training costs can be depicted like in Figrure 


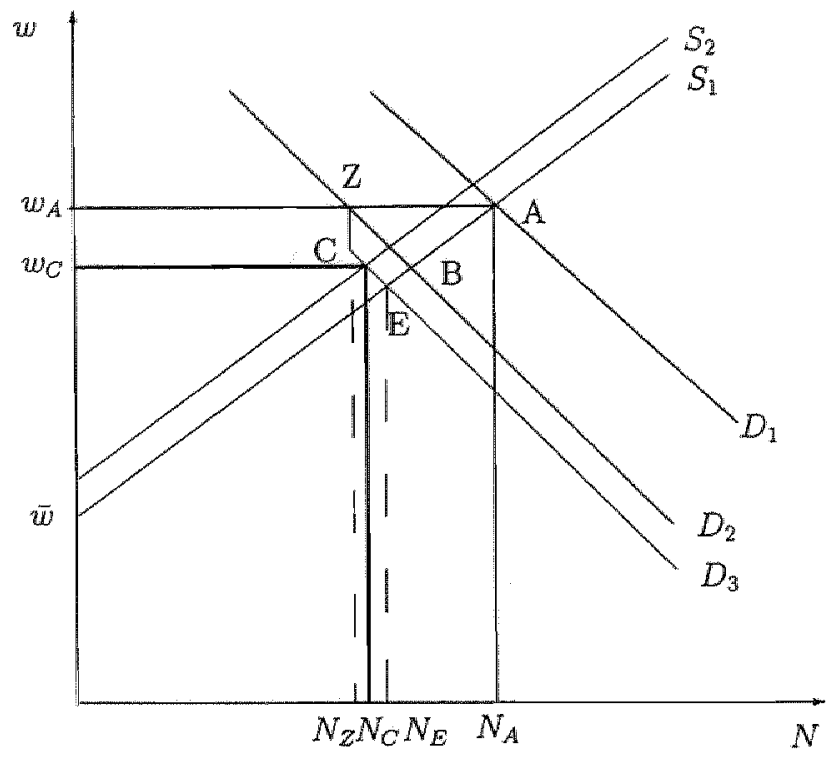

Figure 6.3: The Aggregate Labour Market with Human Capital Formation

In the short run there is again involuntary unemployment $N_{A}-N_{Z}$. This induces the labour supply function to shift from $S_{1}$ to $S_{2}$. If we take into account the shift in labour demand to $D_{3}$ due to training costs, then the equilibrium wage in period 2 is $w_{C}$ instead of $w_{B}$ which implies lowser employment $N_{C}$ than in the traditional Neo-Keynesian model.

If the output price is unchanged in period two, the employment increases to $N_{E}$ at the beginning of period 3 due to the reduced risk perception of the workers. Then the reservation wage equals $\bar{s}+h_{i}$ again with adaptive labour demand expectations. Therefore the second effect (skill update) is only of a temporary nature and labour supply shifts back to $S_{1}$ after one period if no new inwoluntary unemployment occurs.

In order to avoid the assumption of a myopic firm, we can also assume that the burden of training costs has to be born by the entrants themselves. In this case the labour supply curve shifts to the left by an additional $\lambda \frac{N_{t}}{t_{t}}\left(\frac{N_{t-1}-l_{t-1}}{l_{t \rightarrow 1}}\right) t$ at all employment levels higher than $N_{Z}$ in order to compensate for the additional training costs all new entrants have

\footnotetext{
"Goldsmith and Darity (1992) derive a comparable figure with a dominant "distancing" effect, compare Figure 1 on page 464 .
} 
to pay. Training costs have the same sunk cost quality for the entrants as skill up date costs. This also leads to a lower employment equilibrium than point $N_{B}$. If entrants pay the necessary training costs themselves, the labour market equilibrium at the beginning of the second period is at $N_{C}$ as depicted in Figure 6.4:

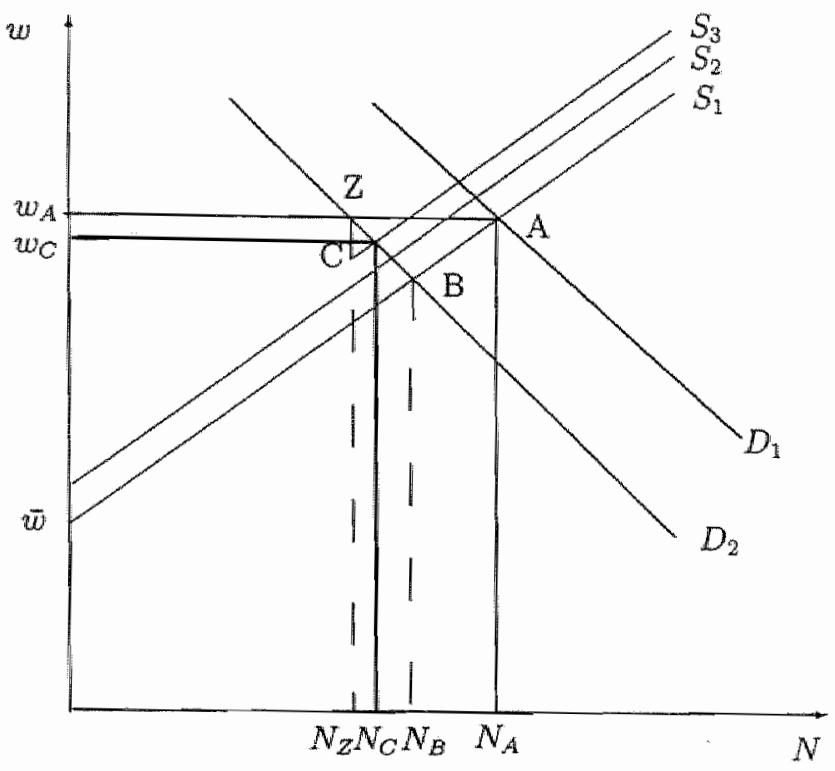

Figure 6.4: Workers Pay for Training Costs and Skills Update

The additional training costs for entrants shift labour supply further to the left to $S_{3}$, while labour demand is at $D_{2}$ at the beginning of period 2 .

\subsection{Conclusions}

In this chapter it is shown in this chapter that with straight-forward arguments including the necessity to invest in human capital, we can reach the similar conclusion as in Darity and Goldsmith's papers that the traditional Neo-Keynesian description of the labour market leads to overly optimistic employment results. The necessity to give entrants onthe-job training reduces average labour productivity forever after a negative demand shock. In addition the reservation wage of the workers increases temporarily in times of job insecurity due to their aversion to lose their sunk and necessary human capital investment. 
Both effects reduce employment level and the increase in employment after involuntary unemployment spells with respect to the traditionall Neo-Keynesian model.

The model presented in this chapter is a straight-forward extension of the main themes of this dissertation-sunk cost property of human capital formation and the necessity to invest in human capital in order to preserve labour productivity - to a model with the Neo-Keynesian assumption of sticky wages in the short run. This allows us to describe the consequences of human capital formation on the adoption path towards a new equilibrium after a negative aggregate shock causing involuntary unemployment. A richer and more realistic picture can be derived when the restrictive assumptions made on the possibilities of the workers and firms to decide about the amount of training and skill update investments are relaxed. In addition the function of workers' expectation formation and firms' myopic behaviour may be further explored. Finally unemployment benefit payments may be endogenized like in the previous chapters. This is subject to future research. 


\section{Chapter 7}

\section{Incomplete Labour Contracts Lead to Worker Rents}

\subsection{Introduction}

How pervasive are market forces on a labour market with incomplete contracts? Contracts on a labour market are incomplete if not all details of a labour relation are determined beforehand. Labour contracts are necessarily incomplete, because not all future events can be anticipated. Labour contracts that have to react on all future events would be extremely complex and involve high transaction costs. When labour markets are incomplete, agents have implicit expectations about the behaviour of the other party in specific situations, however. ${ }^{1}$ Here, trust that the agent indeed acts according to these expectations becomes important. We will argue below that the necessity of trust and the incompleteress of labour contracts lead to market power of workers in otherwise competitive labour markets. The link between the incompleteness of labour contracts, trust and wage demand can be found already in the work of Adam Smith (1937) p. 105: "the wages of labour vary according to the small or great trust which must be reposed in the workman. (...). We trust our health to the physician; our fortune and sometimes our life and reputation to the lawyer and attorney. Such confidence could not safely be reposed in people of a very mean or low condition."

The idea that incomplete labour markets lead to persistent rents in competitive environments is not new. In efficiency wage experiments it was shown that the incompleteness of labour contracts may force firms to pay higher than market clearing wages in order to

\footnotetext{
${ }^{1}$ Compare Fehr and Gächter (1996) pp. $17-18$.
} 
induce an adequate effort. ${ }^{2}$

Some results of an insider-outsider experiment with incomplete contracts that sheds light on the labour market outcomes with incomplete contracts are reported in this chapter. It is necessary to conduct experiments on this issue, because nature does not provide controlled observations here. The essence of an incomplete labour contract is that breaking the implicit rulles cannot be proved in court. In addition expectations about the behaviour of agents in specific situations can not be measured in the field. The main goal of the experiment is to show that workers are able to skim a rent on a perfectly competitive labour market when labour contracts are incomplete. "The experiment demonstrates that the wage mechanism that according to neoclassical theory clears the labour market is decisively weakened by uncertainty about the effort delivered. Moreover workers earn a rent and a labour ower-supply does not lead to a reduction in these rents. The rent earned by the workers implies that wages are higher than necessary and therefore aggregate labour demand is lower than efficient. This provides the link to unemployment. Higher than market clearing wages, workers can ask because labour contracts are incomplete, lead to a reduction in labour demand.

The experiments are based on several salient features of the labour market. First, labour contracts are not complete as argued above. In our experiment the labour contract does not specify the actual level of effort the worker exerts, but only a promised level of effort and the wage (compare e.g. Fehr, Gächter and Kirchsteiger (1997), and Fehr and Gächter (1996)). Here again the Marxian difference between labour and labour power is made (compare the efficiency wage literature survey in chapter two). An employer that: "buys" a worker only receives his or her labour power but has no guarantee that this labour power is indeed translated into labour.

Second, the worler makes a take-it-or-leave-it wage offer which the firm can refuse or accept. This is, for simplicity, frequently assumed in insider-outsider models and contestability models (compare e.g. Lindbeck and Snower (1988 and 1990) or Baumol (1982)).

Third, there is an over-supply of workers and therefore insiders are threatened to be outperformed by unemployed outsiders. These outsiders are perfect competitors for the job as it, is assumed in contestability theory. Outsiders have the possibility to outperform the insiders whenever this is possible.

\footnotetext{
${ }^{2}$ See e.g. Fehr, Göhter and Kirchsteiger (1997), Fehr and Gächter (1996), and Falk and Fehr (1996) who use comparable objective functions of workers and firms and similar effort costs functions.
} 
Fourth, the firm knows, whether there was a difference between promised and actual effort of the insiders, while the behaviour of the outsider is unknown when he or she applies for a job. The firm has the opportunity to punish shirking insiders by switching to the outsider in the next period.

The innovation of the experimental design used here is three-fold.

1. The experiment introduces perfect contestability into experimental structures wellknown from lemon market and principal agent experiments (compare e.g. Holt and Sherman (1990), Lynch et al (1986) and Darns and Holt (1994)). In Iemon market and principal agent experiments the contracts are incomplete, because the quality of the product or the effort of the agent are unknown at the moment of purchase. All experiments mentioned above allow however for reputation (it will be demonstrated below how reputation effects can develop in these experimental designs). Reputation is however a notorious factor that might weaken market forces decisively. ${ }^{3}$ Therefore rents can be created in these experiments by strategic behaviour of agents and by informational asymmetry. The argument that incomplete contracts lead to workers' or sellers' rents can accordingly not be separated from the reputation argument. If we exclude the possibility to create reputation and give the market forces full power in this respect, we can show that the introduction of incomplete markets alone leads to rents in otherwise perfectly competitive markets.

2. The experiment adds incomplete contracts to a perfect contestable market experiment (compare e.g. Coursey et al. (1984) and Harrison (1987)). Harrison describes an experiment that is based on the contestability theory developed by Baumol and others. ${ }^{4}$ The contestable market experiment leads to rapid market clearing and a reduction in rents of the contested market side to zero. This confirms the contestable market theory. Harrison's set-up is taken over. The only difference between bis perfect contestable experiment design and the design presented here is that contracts are incomplete. It is shown that labour contract incompleteness decreases the pervasiveness of outsiders' entry threat and leads to rents for outsiders and insiders.

3. The concept of trust (compare e.g. Luhmann (1973) and Frank (1988) pp.12-14) is introduced into the contestability framework with incomplete contracts. Trust

3. Compare e.g. Frank (1988) pp. 71-96.

¿ Compare e.g. Banmol (1982). 
potentially plays a decisive role in insider-firm relationships and may be an additional source of workers' rents. Insiders frequently can prove that they are trustworthy if they voluntarily do not shirk. Outsiders lack this opportunity. In one treatment, we demonstrate that insiders use this advantage with respect to the outsiders in a stunning way. Insiders' actual efforts frequently even surpassed the promised effort level although this decisively reduced their instant rents.

After explaining the experimental design and the game theoretic predictions derived from the treatment design, some results are presented.

\subsection{Experimental Design}

The economic experiment comprises a main treatment and a trust treatment. Both treatments are repeated 6 times in order to see if the behaviour changes over time due to learning effects and if the decisions are stable. Every repetition is called round. One round comprises one or two periods (see below) and each period has different stages. Here is a summary of the different sequence levels:

Treatment $\longrightarrow$ Round $\longrightarrow$ Period $\longrightarrow$ Stage

The participants are attributed to their "roles" by a random procedure. There are 8 firms, 8 insiders and 8 outsiders in each treatment. As the firm can only employ one workers per period there is a fixed over-supply of workers when insiders and outsiders compete for the job.

\subsubsection{Main Treatment}

The main treatment consists of one period that comprises four stages. In this period one insider and one outsider compete for one job. Insiders have to commit themselves to an offer before the potential entrants can make their offer. The outsiders know the offer of the insiders when they make their offer. The insiders can not react to the offer of the potential entrants. The firm knows both offers and chooses the insider or the outsider on the basis of them. After the decision of the firm the accepted worker realizes the actual effort, while the rejected worker earns the outside option. The firm has to indicate which actual value of effort it expects from the accepted worker. Finally the own pay-off and that of their market partner are revealed to the market participants. 
Table 7.1 below gives an overview about the sequence of events in the main treatment:

\begin{tabular}{|l|l|}
\hline period & action \\
\hline \hline stage 1 & effort promise $f$ and wage demand $w$ is made by insider \\
\hline stage 2 & outsider determines $w$ and $f$ knowing the offer of the insider \\
\hline stage 3 & frm accepts offer of insider or outsider \\
\hline stage 4 & accepted worker determines $f$ and pay-offs are revealed \\
\hline
\end{tabular}

Table 7.1: Sequence of Events in the Main Treatment

We have a perfect strangers design, i.e. every firm is matched only once with the same insider and with the same outsider. Moreover, the identity of the other players is unknown to all agents in all periods. The accepted worker knows therefore that if he or she shirks, this does not have any consequence in the next round. The reason is (i) he or she is matched with another firm and (ii) the fact of shirking is only revealed to the firm that has accepted him or her. In addition, collusion between insiders and outsiders is impossible, because every insider is matched with another outsider in every round.

The workers can determine their posted-bid wage demand, their effort promise and, if they are accepted by the firm, their actual effort. In order to introduce an incomplete labour market, the firm has to accept or reject the wage demand of the worker knowing only the promised effort, while the actual effort is determined by the worker after the labour contract is signed. The workers can give a non-binding indication of the effort they promise to invest after the labour contract is made. The indication of effort is cheap talk and not enforceable if it is above the minimum level. After the worker is accepted the firm can not punish the worker any more when the actual effort of the worker is lower than the promised effort level, i.e. the worker shirks, because the firm is never matched twice with the same insider or ontsider.

Specifically the workers post an incomplete labour contract which consists of a wage demand and a promised effort level. Wages have to be integers between 0 and the redemption value of labour. The available effort levels are between 0.1 and 1 with increments of 0.1 (see Table 7.2). Efforts are associated with a cost function $k(f)$. This effort cost function is common knowledge. If the labour contract is accepted, the worker determines the actual effort level. As the promised effort level is not enforceable, the worker is free to choose any effort level after being accepted by the firm.

The cost function is defined as follows: 


\begin{tabular}{|l|l|l|l|l|l|l|l|l|l|l|}
\hline effort $f$ & 0.1 & 0.2 & 0.3 & 0.4 & 0.5 & 0.6 & 0.7 & 0.8 & 0.9 & 1 \\
\hline costs of effort $k(f)$ & 0 & 1 & 2 & 4 & 6 & 8 & 10 & 12 & 15 & 18 \\
\hline
\end{tabular}

Table 7.2: Effort Levels $f$ and Costs of Effort $k(f)$

It is costly for the accepted worker to exert more than the minimal (enforceable) effort level, while the profit of the firm increases with the effort level of the accepted worker. Therefore a promised effort level higher than the minimum has an important signalling function for trust. The firm can judge the actual effort level of the insider always relative to the promised effort level and considers a lower actual effort level than promised as shirking or an abuse of trust. Although a higher than minimal promised effort level is not enforceable, it can function as an anchor function to judge the trustworthiness of the worker.

The choice variable of a firm is to accept the offer of one of the workers or none. In order to measure the trust between the firm and the accepted worker, the firm has to indicate which effort it expects after knowing the promised effort level but before learning the actual effort level. The worker does not know the expected effort of course. The difference between the expectied actual effort level and the promised effort level is a geruine measure for trust between firm and the accepted worker if the expected effort level is higher than minimal. If the firm expects a higher than minimal actual effort, it puts trust into the worker that he or she keeps the promise to invest more than the enforceable effort level.

The pay-off functions are common knowledge to all agents and the same for all workers and firms. The profit $\pi$ of the firm at the end of the first period is given by:

$$
\begin{gathered}
\pi=2 f-w f \text {, if a labour contract is accepted } \\
\pi=0 \text {, if no labour contract is accepted }
\end{gathered}
$$

The variable $w$ is the wage demanded by the worker, while $Z$ is the redemption value of labour. The redemption value $Z$ is always equal to 100 points. The parameter $f$ is the actual effort. This pay-off function of the firm is chosen primarily in order to avoid the possibility that the firm can experience losses that result from shirking. Otherwise an interaction between loss aversion and trust could arise. It would then not be possible to distinguish whether the firm declines an offer because it does not trust the offer or because it wants to avoid $a_{\text {loss. }}^{5}$

\footnotetext{
${ }^{5}$ Another straightforward formulation of the profit function is $\pi=Z f-w$. Compare also the discussion of this issue in Falk and Fehr (1997) p. 8 .
} 
The surplus of all workers is defined as the following:

$$
\begin{gathered}
s=w-k(f), \text { if employed } \\
s=0, \text { if unemployed }
\end{gathered}
$$

The accepted worker earns the market wage $w$, minus the effort costs $k(f)$. The effort levels and the costs of effort are defined in Table 7.2. The minimum wage demand increases from a with $f=0.1$ untill 18 with $f=1$. The maximum wage is always the redemption value 100. The worker can decline to make an offer. In this case the earning is the outside option 0 .

\subsubsection{Trust Treatment}

In the trust treatment, all profit, costs and surplus functions are the same. The only difference to the main treatment is the number of periods. The trust treatment starts with an additional period. In this first period, insiders are in a monopolistic situation, i.e. outsiders are passive. After the first period, outsiders compete for the job of the insider in a second period which is analogously to the main treatment. The sequence of events in the first period of the trust treatment is:

\begin{tabular}{|l|l|}
\hline period 1 & action \\
\hline \hline stage 1 & effort promise $f$ and wage demand $w$ are made by insider \\
\hline stage 2 & frms decides if to accept promised $f$ and $w$ or not \\
\hline stage 3 & accepted worker determines actual $f$ and pay-offs are revealed \\
\hline
\end{tabular}

Table 7.3: Sequence of Events in Period 1 of the Trust Treatment

The sequence of events in the second period of the trust treatment is analogous to the sequence of events in the main treatment depicted in Table 7.1.

\subsection{Predictions}

The experiment is designed to show the power of perfect contestability to reduce workers ${ }^{3}$ rents when incomplete contracts are present. In addition a treatment with trust between insiders and firms is added in order to see the impact of trust on workers' rents. The constituent game is in both treatments one round. This is a consequence from the perfect stranger design that avoids reputation effects and collusion between rounds. Therefore, 
although every treatment has seweral rounds, no repeated game is played here and the predictions are the same in each round.

\subsubsection{Game Theoretic Predictions}

The experimental design allows some game theoretic hypotheses about the behaviour of the agents assuming rationality and selfishness.

\section{- Trust Treatment}

In the first period of the trust treatment the insider has absolute monopoly power, while in the second period her or his position is perfectly contestable.

Second period: the firm assumes that both workers choose the minimal effort $f=0.1$ in order to maximize their surplus, irrespective of the promised effort. This is their dominant strategy being accepted by the firm, while the firm has no opportunity to retaliate. Notice that this assumption turns the incomplete contract into a complete one, because the firm knows that the sure actual effort is the lowest enforceable one. Therefore the firm chooses the worker with the lower wage offer, because a promised effort above 0.1 in combination with a higher wage demand is not credible. The outsider always underbids the wage offer of the insider he or she is matched with, if there is a rent to be earned with $f=0.1$ (i.e. $w$ is higher than the outside option). The neoclassical prediction for the second period is therefore: $f=0.1$ and $w=0$. The rent for the insider is then equal to the outside option. In this case, the profit of the firm is 10 , while both workers earn a surplus of zero. This is the lemons market result with price at the competitive level for the lowest quality and actual quality at the lowest level (compare Akerlof (1970) and for an economic experiment e.g. Holt and Shermon (1990) or Lynch et al (1986)).

First period: It is clear that the insider is not able to earn a surplus in the second period, because there is perfect contestability. Therefore, there is no scope for building up a reputation for truthfulness or cooperation in the first period, because there is no pay-off for this voluntary reduction in rents. As the insider can determine both, effort and wage demand, he or she can reduce the rent enjoyed by the firm to (almost) its outside option (compare the game theoretic predictions in the ultimatum games, see e.g. Güth et al (1982). The insider therefore maximizes the surplus in period 1 by setting actual effort equal to 0.1 (irrespective of the promised effort level) and wage equal to 99 , because the frrm still accepts a wage that is higher than its outside option zero. In this period, the 
insider's rent is 99 , while the profit of the firm is 0.1 . This is an extreme monopolistic outcome with the insider skimming the entire rent and the profit of the firm being almost reduced to its outside option.

Potential and actual entry decreases the wage asked from the firm (and therefore worker's part of the rent), but does not have a positive impact on the choice of effort (and therefore firm's profit) of the workers accepted. Potential entry in the second period does not have an impact on insiders' behaviour in the first period.

We can summarize the game theoretic predictions for the trust treatment:

1. In the first period, the monopolistic insiders choose an actual effort of 0.1 , while they ask for a wage of 99 .

2. In the second period, the contested insiders choose an actual effort of 0.1 , while they ask for a wage of zero.

3. Outsiders offer a higher profit to the firm if this is possible.

4. Firms always accept the worker who asks for a lower wage assuming that the actual effort is 0.1 anyhow independent of the promised eflort.

Let us turm to the game theoretic predictions for the main treatment.

- Main Treatment

The main treatment only consists of the second period of the trust treatment. This setting allows to test if the addition of the first period where uncontested insiders can prove their trustworthiness increases workers' rentis in the trust treatment with respect to the main treatment.

In the main treatment, neoclassical theory predicts that the insiders know that the outsiders will underbid them when they ask for a wage higher than their reservation wage. The frm accepts the worker with the lower wage demand, because it assumes that the actual effort is 0.1 anyhow. Therefore the market equilibrium is: Insider asks a wage $w=0$ and effort is $f=0.1$. Due to perfect contestability, insiders do not have a possibility to create trust between them and the firm and are therefore not hired if they ask a mark-up above the outside option of zero. Hence there should be no difference between the results in the second period of the trust treatment and the main treatment. The introduction of 
the first period in the main treatment should have no influence on the behaviour of the agents. In addition incomplete markets should not have an impact on workers' rents. The rents should vanish due to competition and the so-called insiders in this treatment have indeed a first movers disadvantage, because they have to commit themselves before the so-called outsiders can decide about their profit offer to the firm.

The game theoretic prediction is therefore:

5. In the main treatment, insiders choose an actual effort of 0.1 , while they ask for a wage of zero.

\subsubsection{Behavioural Predictions}

Trust may have an impact on the behaviour of the agents that is not accounted for in the game theoretic predictions. According to Luhmann, trustworthiness implies that the accepted worker has to keep his or her effort promise although a break of the announcement would be in the own interest (confer Luhmann (1973) pp. 40-50). This is the case if the promised eftort is higher than minimal. In the first period of the trust treatment, the firm does not know the insider and therefore has to guess how "an insider" behaves in the given situation (the same applies for the outsiders in the second period of the trust treatment). Assume the firm would reject the proposed labour contract if it knew for sure that the worker will deliver the minimal work effort. Here, trust that the worker exerts more than the minimal effort level (which would be the cheapest alternative) as promised leads to the acceptance of the labour contract. Therefore trust is necessary for accepting the incomplete labour contract when the promised effort is higher than the enforceable minimal effort and if the firm would not accept the offer when it was known for sure that the actual effort level is minimal. Notice that in the game theoretic predictions the firm indeed assumes that actual effort is never higher than 0.1 .

The mutual beneficial acceptance of the labour contract may therefore be based on trust. It is important that the firm also has an opportunity to sanction insider's abuse of trust (i.e. shirking) by switching in the second period to the outsider. This possibility is another crucial element of a trust relationship (switch-to-punish strategy). This strategy is frequentily observed in economic experiments, compare e.g. Davis and Holt (1994).

Why should the firm decline an offer of the worker that grants itself a positive pay-off only because a higher part of the rent is skimmed by the worker? According to the game 
theoretic predictions the firm accepts even the most uneven split in rents as long as the profit is positive in the transaction. Here, fairness enters the stage. Frank defines fairness as follows: "A fair transaction is one in which the surplus is divided (approximately) equally. The transaction becomes increasingly unfair as the division increasingly deviates form equality." If agents have a notion of fairness and this is reflected in their behaviour, two deviations from the game theoretic predictions should be observed. First firms should reject unfair offers even if this is costly to them. Güth, Schmittberger and Schwarze report this behaviour in their so-called ultimatum games. ${ }^{7}$ Here, one party rejects the part of a cake attributed by another party even though both parties get then nothing when the division is conceived as being unfair. In those experiments, unfair offers were rejected if this rejection was not too costly. On the other hand, offers were considerably fairer than predicted by game theory. Kahneman, Knetsch and Thaler (1986) stress that this behaviour is primarily a consequence of the urge to punish agents who offer seemingly unfair transactions. Notice that in our experiments the rents can be calculated easily. As the reservation pay-offs for all agents are zero, the entire positive pay-off is pure rent. Therefore the division in the first period of the trust treatment predicted by game theory is highly unfair and easy to detect by the firms.

The second deviation of the game theoretic predictions caused by fairness may be that workers voluntarily do not offer unfair divisions of the rent even if they can expect that they can come away with it without punishment. Here the feeling to treat the firm unfairly causes negative emotions that withhold the workers to make full use of their favourable position. Therefore workers voluntarily grant a higher part of the rent to the firm than necessary, i.e., (i) they do not shirk fully and offer a higher than minimal effort level and (ii) insiders do not ask for the maximum wage 99 that grants the firm just the minimal rent above its outside option, compare also chapter nine in Frank (1988).

The main behavioural predictions are therefore:

6. Insiders build up trust by not shirking in the first period of the trust treatment.

7. Firms punish shirking of the insiders in the first period of the trust treatment by switching to the outsider in the second period.

\footnotetext{
${ }^{6}$ See Frank (1988), p. 165.

7Compare e.g. Guth, Schmitberger and Schwarze (1982).
} 
8. Firms decline offers that grant only a small share of the rent to them although this reduces their overall profit.

9. Workers behave fair, i.e. give a considerable share of the rent to the firm although they can not be punished for unfair behaviour once they are accepted by the firm.

\subsection{Results}

The economic experiment was conducted November 26th 1997 at the IEW in Ziirich. The volunteers were mainly students from the universities in Zürich from various faculties excluding economics. Two distinct groups were invited for the two treatments in order to have independent observations. The experiment was framed in neutral terms, i.e., subjects acted in the roles of buyers and sellers. Some effort was put into avoiding to invite students who knew each other and students who participated in comparable experiments before. In both treatments, there where 8 "firms, insiders and outsiders," and each treatment was repeated 6 times. Therefore 48 possible trades could take place in the main treatment and 96 trades were possible in the trust treatment.

Firms and workers earned a show-up fee of 10 Swiss Francs. As it is not possible to lose in any period, all workers earn at least zero points in all periods which are translated into real money according to a fixed exchange rate which is equal and known to all agents. The exchange rate between points earned and Swiss Francs was 13 Rappen $^{8}$ per point (this is roughly 0.2 Dutch Guilders). All students earned more than their usual opportunity costs (they earned on average 23 Swiss Francs which was payed in cash directly after the experiment for an experiment that took less than 2 hours).

The participants received a sheet with pay-offs for firms and accepted workers. Therefore workers consciously could determine the rent share when choosing the actual effort; while firms easily could see how much they would earn with different actual effort levels. In addition at the end of the instructions all agents were asked to solve some pay-off calculations for all agents involved in hypothetical market transactions in order to make sure that everybody was able to calculate all pay-offs. The experiment was only started when all questions were answered correctly.

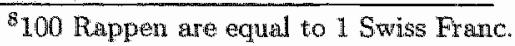




\subsubsection{Main Treatment}

The main finding of this experiment is that in a perfectly contestable labour market with incomplete contracts considerable and stable rents are eamed by the workers (see Figure 7.1).

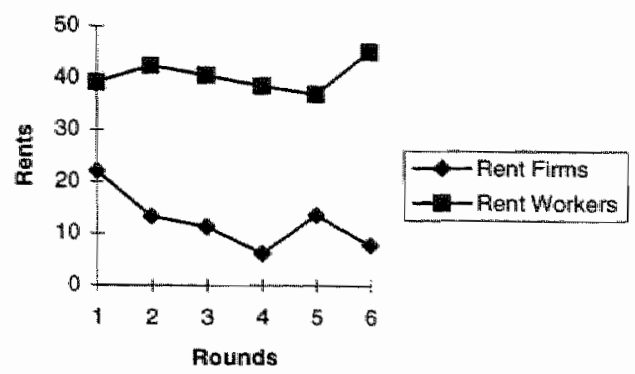

Figure 7.1: Firm and Worker Rents

This is in contrast to contestable market experiments using the same sequence of events but assuming complete contracts. In these experiments, markets quickly converge to the competitive equilibrium (compare e.g. Horrison (1987)) reducing the rents earned by the agents in the contested market to (almost) zero while the ather parties earned the entire rent. The experimental design in Harrison allowed for collusion between insiders and outsider, because their identities were known and insiders and outsiders were matched for several periods. Collusion lead in one session to higher than competitive rents for incumbent and entrant in Harrison's experiment. Collusion is exciuded in the perfect contestability treatment due to the perfect stranger design. This leaves only incomplete contracts as a potential explanation for workers' rents.

Promised profits of outsiders are on average $29 \%$ higher than those of insiders and in all transactions outsiders offer a higher profit than the insiders. This is the expected underbidding behaviour of the outsiders (compare hypothesis three). Therefore all accepted insiders offer a lower promised profit than the outsiders. All but two outsiders demand a lower wage than the insiders. The outsiders demanding a higher wage are not accepted by the firm which is consistent with prediction four. Almost half of the workers accepted are insiders, however ( 20 insiders and 21 outsiders were accepted, compare Tabie 7.4 below). 
This is in clear contrast to the game theoretic prediction (prediction four) that firms choose always the worker that offers a lower wage. Firms do not systematically choose the underbidding outsiders. In every period some insiders have been accepted. The minimal share of insiders at the workers accepted is $37.5 \%$, while in 4 of the 6 rounds insiders are at least half of the accepted workforce, compare also the data in the appendix. Insiders have therefore no incentive to reduce their wage demands in order to stay in the labour market. They take the risk either to earn considerable rents when being accepted and the outside option when being not accepted. The pay-off of this strategy is higher than being accepted for sure by the firm when the wage demand is only little above the outside option zero.

This allows also the outsiders to earn rents even when they underbid the offer of the insiders. The average rents of insiders and outsiders and firms can be seen from the following Table 7.4 while within brackets the number of workers accepted is indicated.

\begin{tabular}{|l||l|l|l|l|l|l|}
\hline Round & 1 & 2 & 3 & 4 & 5 & 6 \\
\hline \hline Average Rent Firms & 22 & 13.3 & 11.3 & 6.2 & 13.6 & 7.8 \\
\hline Average Rent Insiders & $44(3)$ & $42.4(5)$ & $36.5(4)$ & $46.7(3)$ & $36.5(2)$ & $54.3(3)$ \\
\hline Average Rent Outisiders & $35.5(4)$ & $42.3(3)$ & $44.8(4)$ & $33.6(5)$ & $37.5(2)$ & $36.3(3)$ \\
\hline
\end{tabular}

Table 7.4: Rents and Number of Workers Accepted

One clue to the problem why firms do accept insiders although they systematically ask for higher wages than outsiders are expectations of actual efforts. Firms systematically expect higher actual efforts from insiders than from outsiders (compare the overview table at the end of this chapter). Probably firms expect a certain gratefulness of the insiders, because they did not accept the outsiders who had the possibility to underbid the offer of the insiders.

As can be seen from Figure 7.2, rents are distributed quite unfairly between firms and workers. While insiders skim on average $75 \%$ of the rents, outsiders even treat themselves to $81 \%$ of the total rent to be distributed while there is no clear trend in the distribution of rents. Nevertheless shirking is less than predicted by game theory (compare prediction five that states that actual effort is 0.1 with the data appendix).

The unfair distribution of rents leads to reactions of the firms. Firms reject the offers of both agents in 7 cases (almost $15 \%$ of all possible transactions). These rejections especially occur in period 4 ( 4 rejections) and 5 ( 2 rejections). It is remarkable that punishing is not a direct reaction on unfair wage demands of the workers punished. The wage demands of the 


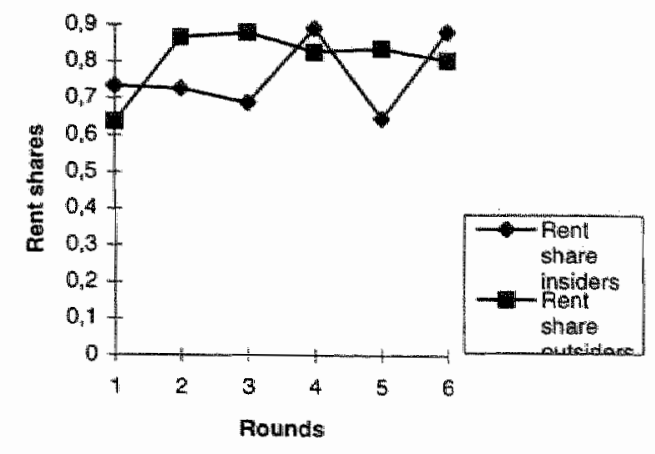

Figure 7.2: Rent Shares in Perfect Contestability

workers rejected are roughly the same for insiders and for outsiders as those of the workers accepted by the firms. Firms react however to an unfair rent division in the previous period (here the workers skimmed on average $84 \%$ of the rent). Therefore the pumishment is rather indirect, because firms punish different workers than those who offer an unfair rent share in the previous period. In addition the firms know that if they pumish an insider and an outsider in this period by rejecting both offers, they will be confronted with a different pair of workers in the next period. Another firm may reap a fairer behaviour induced by the punishment and therefore the punishment is clearly a public good.

Firms might have two different motivations for declining both offers. First, rejections are intended to punish especially unfair offers in the previous period (compare behavioural. prediction eight). Here the emotional gain in punishing an unfair treatment outweighs the material loss. Second, the rejections might be attempts to reduce shirking by workers in general. It does not make sense to punish the workers in the last period, because this can not induce a change in behaviour any more. Therefore firms try to induce a fairer treatment by rejecting both offers although they know that another firm profits from the fairer treatment. This might explain why rejections of both offers do not occur too often although the rent distribution is highly unfair and favours the workers.

In the main treatment shirking is considerable. While the insiders promise on average an effort of 0.71 , actual effort is 0.26 , while the actual effort of the outsiders is at 0.17 with a promised effort of 0.86 (compare the Figures 7.3 and 7.4 ). Outsiders even come close to 
the game theoretic predictions of the actual effort (see appendix).

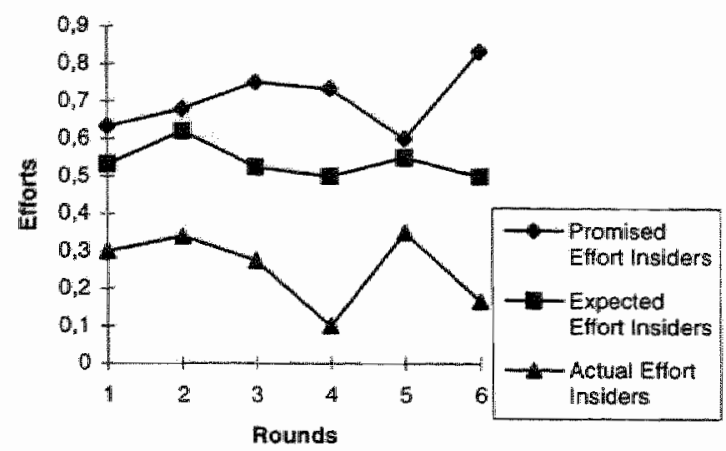

Figure 7.3: Effort Insiders

The firms demonstrate considerable trust in the workers accepted. Although they experience always on average a lower actual effort than promised, expected efforts are considerably higher than 0.1 . The average expected effort for the insiders is 0.55 and quite stable, while the average expected effort of the outsiders is 0.47 and decreases as a reaction of actual efforts. Therefore firms structurally overestimate the actual efforts of the workers, i.e. they assume that the behaviour of the accepted workers would be fairer. This might be another reason for the high acceptance rate of ex-post unfair labour contracts.

At this point it is useful to compare our results with the lemon market and principal agent experiments. Those experiments use comparable incomplete contracts, allow for reputation, however.

\section{Related experiments}

The design of the main treatment is comparable to lemon markets and principal agents experiments, however the results and some assumptions which are relevant for workers' rents deviate considerably. Holt and Sherman (1990) find that when sellers can determine price and quality and buyers learn only the price, in half of the experiments "lemon" results occur. In some experiments with incomplete markets an even higher than efficient actual quality level was offered. A "lemons" result is defined as sellers selling the lowest quality, while buyers only accept the competitive price for the lowest quality. In this case, sellers 


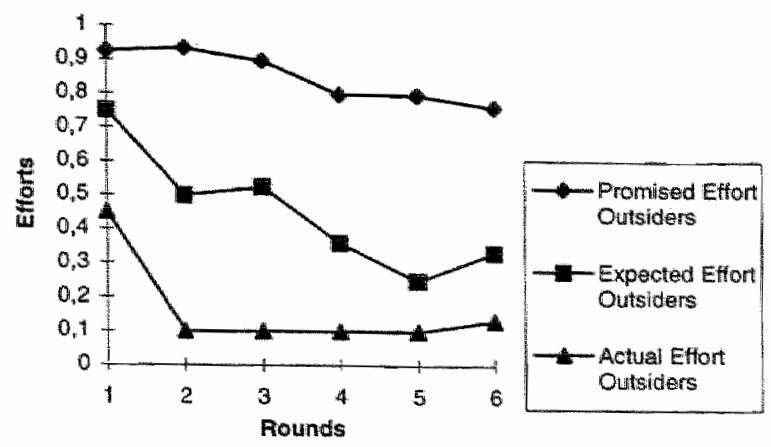

Figure 7.4: Effort Outsiders

do not make a profit on their product although quality is unknown. In Holt and Sherman (1990), quality was not announced. Buyers experienced losses on average, i.e. prices asked were higher than market clearing for the actual quality offered. A problematic procedure in Holt and Sherman (1990) seems to be that at the beginning some rounds are played with full information. Buyers may therefore build some expectations about the quality offered from these rounds especially because the identity of sellers is known and buyers could choose sellers they contracted with in the full information periods. It is not surprising that quality was quite high in the rounds with full information, because sellers wanted to attract buyers. Afterwards buyers were fooled, because then quality considerably declined. In addition over-supply of goods was only moderate. Buyers had a good chance to sell at least one of their two goods, because market demand was set at 4 , while there were 3 sellers offering 2 goods. This small over-supply of goods reduces the market pressures and may induce additional rents. The last element of the experimental design which could lead to sellers" rents in addition to incomplete contracts is that sellers announced their price demands simultaneously. Harrison (1987) points out that the assumption of the incumbent being committed to the offer when the entrant decides about his or her offer is crucial to ensure perfect contestability results.

Lynch et al (1986) demonstrate how pervasive lemon market results are when quality of the product is uncertain at the time of purchase. With quality uncertainty, $96 \%$ of all goods were of low quality and prices were scattered around the equilibrium price for 
low quality generating a clear 'lemons' result. When quality was known (even when the truthful revelation of quality was optional) almost all goods delivered were of high quality and prices were scattered in a narrow range below the equilibrium price for high quality. Therefore sellers were not able to skim a high rent in these experiments although product quality was unknown. Only the possibility to develop a reputation by identifying the sellers and repeating the game increased the incidence of high quality goods sold when quality was unknown, while prices were scattered around the equilibrium price for high quality after the first periods. With reputation sellers' rents were therefore positive. The possibility to develop a reputation is excluded in our experiment design, however.

Also De Jong et al. (1985) found shirking in a principal-agent relationship. They allowed however also for the development of reputation, because there where 32 rounds and the sellers could be identified. Not surprisingly, shirking was not as complete as in other experiments and workers were able to set higher than market-clearing prices. In addition there were 4 sellers and 3 buyers which allowed buyers to keep identities of sellers transparent and did not give market forces a big chance.

From these results we can conclude that the lemon markets and principal agent experiments found in the literature did not give the market forces the full chances (their focus was different) and therefore obtained also some rents for workers and some shirking. If we implement a perfect contestability experiment where the only reason for workers' rents are incomplete contracts, we observe also high and persistent workers' rents. What can be mechanisms behind firms not systematically choosing underbidding outsiders and therefore allowing for high and persistent workers' rents while suffering from an highly unfair rent distribution? One reason could be quality assuring prices. Here firms expect that those workers demanding a higher wage would also invest more in effort. However this expectation is wrong in this treatment. A one-sided Spearman-Rank test which tests the hypothesis that there is a positive relationship between wages and actual efforts for insiders and outsiders rejects this hypothesis. ${ }^{9}$

Reciprocity between insiders and firms could also be a reason for firms to choose insiders instead of underbidding outsiders. Here insiders could be grateful that the firm chooses them instead of the outsiders. This reasoning is not valid, however, because the insiders could only guess if the outsiders had promised a higher rent. Nevertheless, insiders offer

\footnotetext{
${ }^{9}$ The Spearman-Rank value for insiders given is -0.142 which implies a significance level of 0.275 , while the value for the outsiders is 0.11 and the associated significance level is 0.31 .
} 
consistently higher actual efforts and higher rent shares than outsiders. Firms expect a higher actual effort from insiders than from outsiders and therefore anticipate the actual results (compare the data appendix). Obviously there is a higher motivation for insiders to be fair, that is to voluntarily grant a higher share of the rent to the firm and to shirk less than for the outsiders. This leads firms to choose insiders although outsiders promise higher profits.

\subsubsection{Trust Treatment}

Our experimental design allows us to see whether the introduction of trust between insiders and firms has an impact on workers' rents. In addition it can be seen if the threat of entry and actual entry in the second period has a negative impact on workers' rents as predicted in game theory (compare predictions one and two). In the first round of the contestability with trust treatment, 2 contracts by the insider are rejected by the firms. In the second period the firms never reject both offers of the workers. Although rent shares are not higher than in the main treatment, firms clearly decide not to "punish" the workers for an "unfair" offer which is in contrast to the main treatment and prediction eight. In the second period we observe therefore 48 transactions, while in the first period there are 46 insiders accepted.

\section{First Period}

In the first period of this treatment the insiders clearly do not use their monopoly situation in order to maximize their surplus. Remember that the game theoretic prediction is that the insiders skim (almost) the entire rent by setting actual effort equal to 0.1 and wage demand at 99 (prediction one). Instead, the insiders consistently try to create trust by investing a much higher than minimal actual effort and demanding a lower than maximal wage. Contrary to the game theoretic prediction, insiders do not cheat on the firm, but even on average surpass their own promised effort level (compare Figure 7.5).

While the promised effort level is on average at 0.69 (which is already quite high), the actual effort level is at 0.73 on average. This is a stunning deviation from the game theoretic predictions and supports prediction six. The firms on average correctly assess the actual effort by expecting 0.75 on average. Therefore the firm trusts the insiders and anticipates that they do not to shirk on their effort promise. Only in 8 of 48 contracts, insiders shirk in the first periods. The actual rent share offered by the insiders is $43 \%$, i.e. 


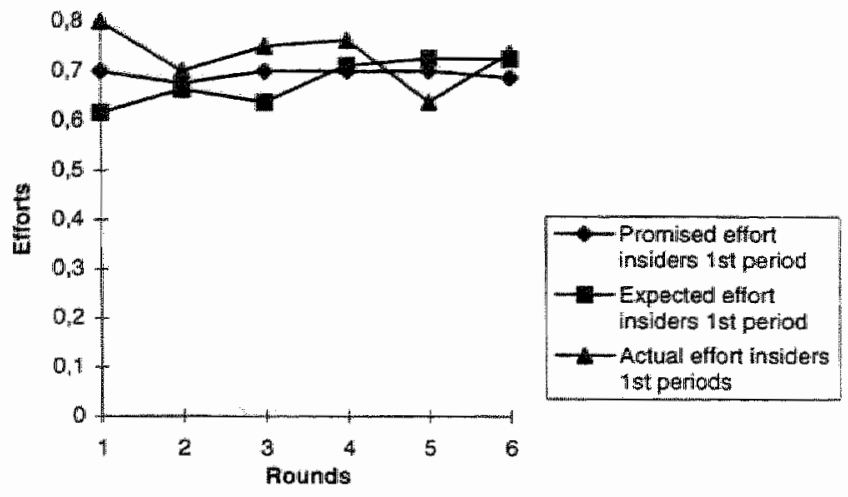

Figure 7.5: Effort Insiders First Periods

the insiders voluntarily give almost half of the rent generated to the firm (which is quite the opposite of the rent distribution predicted in prediction two and supports more the behavioural prediction nine). Insiders earn an average rent of 41,6 (confer to the appendix for the average figures per round). Do we observe this fair behaviour of insiders also in the second period of the trust treatment?

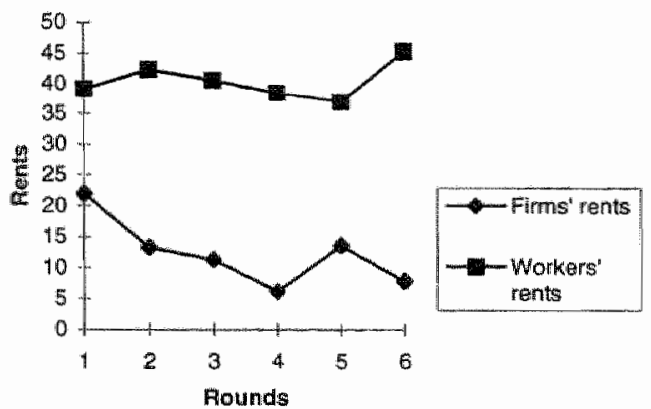

Figure 7.6: Second Period Rents 


\section{Secand Period}

In the second period again outsiders are perfect competitors for the position of the insiders. If we compare the results of the second period of the main treatment with the trust treatment, we see whether the addition of the first period where insiders proved that they are trustworthy has an impact on the rents of the workers and the probability that insiders are accepted. The rents are strikingly similar in both treatments (compare Table 7.4 with Table 7.3 and Figure 7.6 with Figure 7.1). While insiders promise on average an effort level of 0.83 and give 0.31 , firms expect 0.55 . Therefore insiders shirk on a comparable scale as in the main treatment although different people are involved. The fair non-shirking behaviour of the first periods does not have an impact on insiders' shirking behaviour in the second periods. Outsiders promise an effort of 0.85 and give 0.24 , while the firm expects 0.44. Again, we observe that insiders shirk more than outsiders: Here 16 of the 22 accepted insiders and 24 of 26 accepted outsiders shirk. The expected efforts in the main treatment are almost identical to those in the trust treatment (compare the overview in the appendix). Therefore the signalling of the insiders in the first period that they are trustworthy has no impact on average expected effort levels in the second period. That means the firm is not "fooled" by the fairness of the insiders in the first period. In the first round the firms expect on average an effort of 0.63 from the insiders. The expected effort decreases however quickly in the following periods when firms experience the actual efforts the insiders provide and the shirking behaviour of the insiders (compare the Figure 7.7).

The actual effort provided by the outsiders is systematically overestimated. The firms therefore do not anticipate the unfair treatment by the outsiders. Compare Figure 7.8.

Insiders are chosen again by their firm, although outsiders ontperform them by promising a higher profit. Although in the second period 42 out of 48 outsiders promise a higher rent to the firm (this is according to prediction three), 22 insiders are accepted by the firm and 26 outsiders (this again contradicts prediction four). The average profit promised by the outsiders is $15 \%$ higher than that promised by the insiders. This mark-up is lower than in the main treatment, but nevertheless sufficient to attract a comparable number of firms to accept outsiders.

The actual rent share offered by the insiders to the firm in the second period is $25 \%$, while it is $26 \%$ for the outsiders. Both shares are considerable lower than those offered by the insiders in the first periods and only slightly higher than the rent shares offered in the 


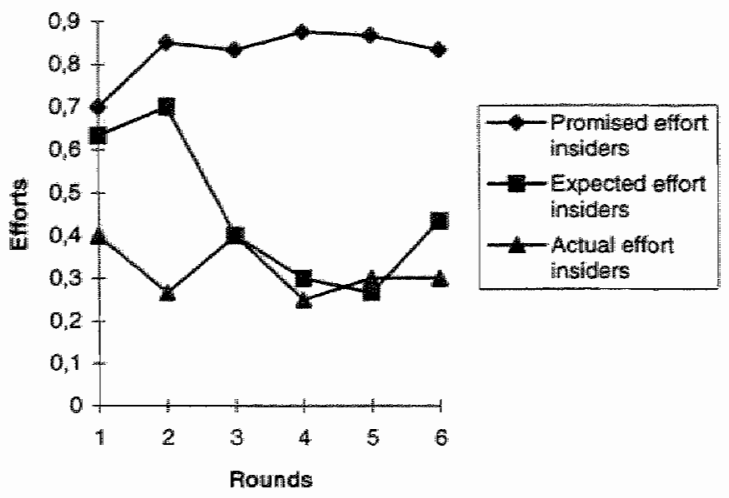

Figure 7.7: Effort Insiders Second Periods

main treatment (see appendix).

\begin{tabular}{|l||l|l|l|l|l|l|}
\hline Round & 1 & 2 & 3 & 4 & 5 & 6 \\
\hline Average Rent Firms & 17.4 & 13.5 & 17.1 & 14 & 13.1 & 13.8 \\
\hline Average Rent Insiders & $52(3)$ & $46.5(6)$ & $52(3)$ & $46.3(4)$ & $30(3)$ & $30.3(3)$ \\
\hline Average Rent Outsiders & $38.6(5)$ & $33(2)$ & $38(5)$ & $42.5(4)$ & $37.2(5)$ & $32.2(5)$ \\
\hline
\end{tabular}

Table 7.5: Rents and Number of Workers Accepted

From the 8 insiders who shirk in the first period, only 2 are accepted in the second period (in both cases, their actual effort level is not lower than the effort level expected by the firm). Therefore the firm clearly pursues a switch-to-punish strategy (prediction seven). This strategy is also reported e.g. in Davis and Holt (1994). They showed that the possibility for sellers to build up a reputation can be a cure for the shirking problem. In Daris and Holt however less shirking is only found if the experiment had 10 rounds and agents' identities were known. In the one period and two period treatments cooperation rates were low and did not differ much. In our experiment however insiders did not shirk in the first period although their reputation not to shirk could only be of use in one period. In the trust treatment, insiders clearly expect that not to shirk and offering a high profit share in the first period is a good strategy to be chosen again in the next period even if the rent asked is then considerable and outsiders may outperform the insiders. A $\chi^{2}$ - test reveals that there is a positive relationship between the amount of shirking of insiders in 


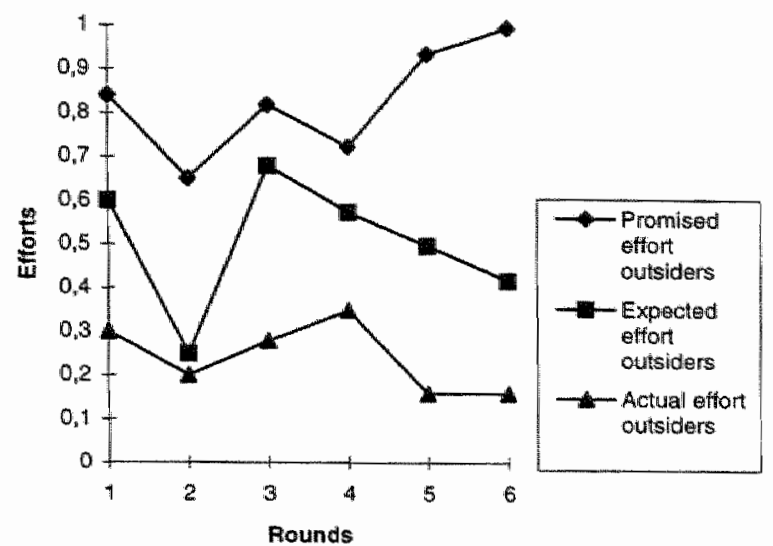

Figure 7.8: Effort Outsiders Second Periods

the first period and their acceptance in the second period. The significance level is however only at $10 \%$ which might be due to the small sample. Nevertheless from those 40 workers who do not shirk or even provide a higher effort than promised, 20 are not accepted in period 2 by the firm. The firm obviously prefers here the outsider who offers a higher promised profit or asks for a lower wage. This is due to the assessment that the insiders do not have a reason not to shirk in the second period even if they proved to be trustworthy in the first period. A $\chi^{2}$ - test reveals again that there is a significant positive relationship at the $5 \%$ level between the size of the promised profit mark-up of the outsiders with respect. to the promised profits of the insiders and the acceptance of those ontsiders. ${ }^{10}$ Therefore the firms are sensitive to the profit mark-up outsiders offer, but do not accept outsiders who offer too little more.

In the trust treatment, insiders try to induce the believe of a quality assuring price. In the first period, a Spearman Rank test shows is a clear positive relationship between wages and actual efforts. Ironically, outsiders also have a significantly positive relationship between wages and efforts in the second period, while insiders do not show a positive relationship between their effort choices and the wage demand in the second period. There-

\footnotetext{
${ }^{10}$ The significance level is at $2 \%$, while the average mark-up of those outsiders not accepted is 4 and the mark-up of the accepted outsiders is 8.3 .
} 
fore the strategy to make firms believe in a quality assuring price in the second period is misleading and firms are not (or only partly) "fooled" by it.

\section{Market Efficiency}

Market efficiency is not improved by perfect contestability, which is in blatant contrast to the game theoretic prediction. Insiders' rents even increase slightly from 41.6 in the first period to 43.5 in the second period (compare the Figure 7.9 and the appendix). Also contrary to predictions one and two, workers" share of the rents in the second periods of the trust treatment are much higher than those of the firm in the second periods: Workers earn on average 40.1 , while the firms only earn 14.8 on average and see their rents decrease from 31.1 in the first periods. Therefore the paradoxical result is obtained that the workers earn a smaller rent when they are threatened by outsiders (if they are accepted by the firm of course), while the rents of the firms decrease dramatically although they are in a better position and can choose between two applicants for the job.

Several tests ${ }^{11}$ show that the wage demand of the insiders in the first period is higher than the wage demand of the workers in the second period on a $5 \%$ significance level. Also the wage demand of the outsiders is significantly lower than the wage demand of the insiders in the first period. Therefore wage demands decrease considerably from the monopoly of insiders in the first period to labour market competition in the second period. The reductions in rents associated with the decrease in wages are however (more than) compensated by higher shirking which increases workers' rents.

Rents are strikingly equal in the second period of the main treatment and the trust. treatment (although two different groups of people participated). The difference between average insiders rents is 0.2 , between average outsider rents is 0.9 and between firm's rents is 2.6 (compare Table 7.5 with Table 7.4 and the appendix for rents in different rounds). Therefore we can not conclude that insiders' efforts to create trust in the first periods had a considerable impact on their (and outsiders') rents in the second period.

Although the rents for insiders and outsiders accepted by the firm are remarkably similar in both treatments, total rent for workers (and firms) is higher in the second period of the trust treatment than in the main treatment. Insiders' rents actually increase by $10.5 \%$, outsiders see their total rents rise by $20.8 \%$, while firms even experience a rent

\footnotetext{
"A Wilcoxon Matched-Pairs Signed-Ranks Test and a t-test for paired samples both show that the wage demand in the first periods are higher than in the second periods at a significance level of $1 \%$.
} 


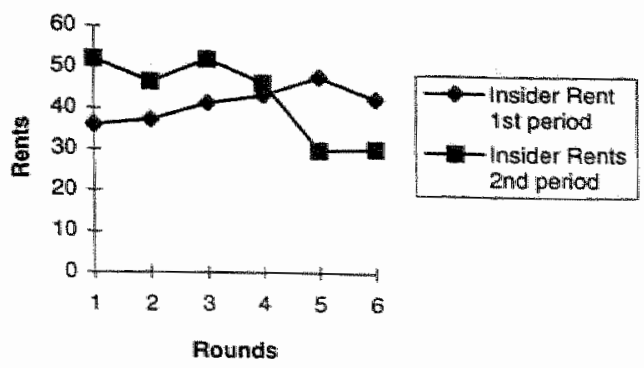

Figure 7.9: Insider Rents

increase of $41.9 \%$. In the trust treatment all possible transactions are made, while in the main treatment 7 labour market contracts are rejected by the firms. Therefore we can see indirectly the size of the sacrifice made by the firms in order to punish unfair behaviour in the main treatment.

Both experiments just lead to 8 independent observations per group. This basis is much too small to draw definite conclusions. Therefore it is planned to conduct several additional experiments in order to assess the stability of the results and have a broader data basis for econometric testing. The prospects of result stability are quite high, because almost all results were qualitatively found in a pre-test conducted at the IEW on June 25th 1997. The conditions in this pre-test were comparable to the contestability with trust treatment. Two additional control treatments may shed light on these puzzles. First, the main treatment may be repeated with complete contracts, i.e. the effort promise of the workers is binding. This allows us to draw conclusions how high the mark-up in worker rents is due to incomplete labour contracts. Second, one may add the first periods (monopolistic insiders) of the trust treatment separately as a control treatment. This allows us to see if the threat of market contestability in the second period of the main treatment has an impact on the behaviour of the insiders in the first period of the main treatment. The hypothesis here is that insiders skim a higher rent than in the control treatment presented here when they do not fear a switch-to-punish strategy of the firms in the second period. 


\subsection{Conclusions}

This experiment shows that workers earn persistent rents in an insider-outsider model with perfect competition when labour effort can be determined after the labour contract is struck. These rents can be created because firms do not systematically choose the underbidding outsider and force therefore the insiders to reduce their demanded rent. Outsiders try to outperform insiders by promising higher rents and asking for lower wages. This is predicted in game-theoretic prediction 3. Firms are sensitive to the amount of underbidding, but do not accept all underbidding outsiders. Workers do not behave completely unfair (which contradicts the game theoretic predictions that actual effort is always equal to 0.1). They voluntarily constrain themselves in shirking and thereby give a higher share of the rent to the firm although they can not be punished for unfair behaviour once they are accepted by the firm. Insiders shirk less than outsiders and firms anticipate that. Firms pumish especially unfair transactions by rejecting both workers in the next period. 'This matches the behavioural prediction eight. Firms' rejections reduce firms' rents more than workers' rents. Firms may also try to increase fairness by rejecting both offers although they will be confronted with other workers in the next period. These workers might not have been punished for unfair behaviour by other firms.

The impact of a first period which allows insiders to build up trust has no significant impact on average worker rents and only a small impact on worker total rents. This is the case although insiders invest considerably in their reputation by providing an actual effort that even is higher than the already impressive promised effort. This is predicted in behavioural prediction six. The firms also expect the insiders in the first period not to shirk. Shirking insiders are punished by switching to the outsider in the second period (prediction seven). Firms do not expect a higher effort in the second period of the trust treatment than in the main treatment on average. Therefore firms recognize the strategy of the insiders not to shirk in the first period in order to build up trust in the first period and to shirk in the second period.

It. is still puzzling why workers are able to skim rents in the contestability periods. Firms correctly expect insiders to behave less unfair than outsiders. In addition it is not clear why workers give up considerable rents in the first periods of the trust treatment although this does not lead to higher rents than in the main treatment.

Summing up we may conclude that all behavional predictions stated in section 7.3 .2 
are found in the insider-outsider experiment. The game theoretic prediction three that outsiders always underbid insiders is also confirmed in this experiment. The other game theoretic predictions about the extreme monopoly and competition outcomes seem to be dominated by faimess and trust behaviour of the agents. 


\subsection{Appendix}

Here an overview is given about the average values in the six rounds of key parameters in the main and trust treatment.

- Main Treatment

\begin{tabular}{|l||l|l|l|l|l|l|}
\hline Raund & 1 & 2 & 3 & 4 & 5 & 6 \\
\hline \hline Rent Firms & 22 & 13.3 & 11.3 & 6.2 & 13.6 & 7.8 \\
\hline Rent Insiders & 44 & 42.4 & 36.5 & 46.7 & 36.5 & 54.3 \\
\hline Rent Outsiders & 35.5 & 42.3 & 44.8 & 33.6 & 37.5 & 36.3 \\
\hline Wage Demand Insiders & 46.67 & 46 & 38.75 & 46.67 & 46 & 55 \\
\hline Wage Demand Outsiders & 42 & 42.33 & 44.75 & 33.6 & 37.5 & 36.67 \\
\hline Promised Effort Insiders & 0.63 & 0.68 & 0.75 & 0.73 & 0.6 & 0.83 \\
\hline Promised Effort Outsiders & 0.93 & 0.93 & 0.9 & 0.8 & 0.8 & 0.77 \\
\hline Expected Effort Insiders & 0.53 & 0.62 & 0.53 & 0.5 & 0.55 & 0.5 \\
\hline Expected Effort Outsiders & 0.75 & 0.5 & 0.53 & 0.36 & 0.25 & 0.33 \\
\hline Actual Effort Insiders & 0.3 & 0.34 & 0.28 & 0.1 & 0.35 & 0.17 \\
\hline Actual Effort Outsiders & 0.45 & 0.1 & 0.1 & 0.1 & 0.1 & 0.13 \\
\hline Insiders Accepted & 3 & 5 & 4 & 3 & 2 & 3 \\
\hline Outsiders Accepted & 4 & 3 & 4 & 5 & 2 & 3 \\
\hline
\end{tabular}


- Trust Treatment

\begin{tabular}{|l||l|l|l|l|l|l|}
\hline Round & 1 & 2 & 3 & 4 & 5 & 6 \\
\hline \hline Rent Firms & 39.27 & 33.11 & 31.2 & 30.1 & 24.21 & 30.48 \\
\hline Rent Insiders & 36 & 37.25 & 41.38 & 43.25 & 47.75 & 42.63 \\
\hline Wage Insiders & 49 & 48.5 & 53.38 & 55.5 & 57.5 & 54.13 \\
\hline Promised Effort Insiders & 0.7 & 0.68 & 0.7 & 0.7 & 0.7 & 0.69 \\
\hline Expected Effort Insiders & 0.62 & 0.66 & 0.64 & 0.71 & 0.73 & 0.73 \\
\hline Actual Effort Insiders & 0.8 & 0.7 & 0.75 & 0.76 & 0.64 & 0.74 \\
\hline \hline Rent Firms & 17.4 & 13.5 & 17.1 & 14 & 13.1 & 13.8 \\
\hline Rent Insiders & 52 & 46.5 & 52 & 46.3 & 30 & 30.3 \\
\hline Rent Outsiders & 38.6 & 33 & 38 & 42.5 & 37.2 & 32.2 \\
\hline Wage Demand Insiders & 56.67 & 48.83 & 56.67 & 48.75 & 33.33 & 33.67 \\
\hline Wage Demand Outsiders & 41.6 & 34 & 40.4 & 46 & 37.8 & 32.8 \\
\hline Promised Effort Insiders & 0.7 & 0.85 & 0.83 & 0.88 & 0.87 & 0.83 \\
\hline Promised Effort Outsiders & 0.84 & 0.65 & 0.82 & 0.73 & 0.94 & 1 \\
\hline Expected Effort Insiders & 0.63 & 0.7 & 0.4 & 0.3 & 0.27 & 0.43 \\
\hline Expected Effort Outsiders & 0.6 & 0.25 & 0.68 & 0.58 & 0.5 & 0.42 \\
\hline Actual Effort Insiders & 0.4 & 0.27 & 0.4 & 0.25 & 0.3 & 0.3 \\
\hline Actual Effort Outsiders & 0.3 & 0.2 & 0.28 & 0.35 & 0.16 & 0.16 \\
\hline Insiders Accepted & 3 & 6 & 3 & 4 & 3 & 3 \\
\hline Outsiders Accepted & 5 & 2 & 5 & 4 & 5 & 5 \\
\hline
\end{tabular}

Notice that the results in the first six rows are from the first periods of the trust treatment while the other results stem from the second periods. 


\section{Chapter 8}

\section{Conclusions}

Human capital investments cause labour market inefficiencies. Some of these inefficiencies are results of the nature of human capital investments and the labour market. This thesis argues for example that human capital investments always entail sunk costs for a certain degree or create rents that have to be distributed on some way or another. Workers determine their human capital investments themselves (even if it would be a Pareto-improvement if the firm would determine it) and labour contracts are inherently incomplete. These "natural" ineficiencies are out of the reach of public policy.

Other inefficiencies are caused by myopic behaviour, imperfect information, market power or restrictions. These deviations from the perfect competition conditions have an impact on the rational individual maximization behaviour and the efficiency of the labour market outcome. Frequently policy measures are meaningful here, because they can improve the performance of the labour market and increase employment.

Before some policy implications and policy dilemmas can be sketched, some provisos have to be made. The models of this thesis are based on neoclassical assumptions and do not take into account legal, institutional, psychological or sociological factors. Workers entail economic capital, i.e. knowledge that produces an economic rent. Social capital, such as cormmunicative skills or cultural capital, i.e. inspiration and the capability to give sense to the work are ignored (compare Klamer et al. (1997) p. 26f). Chapter seven is an example of how factors such as trust, fairness, behaviour under uncertainty and switchto-punish behaviour can influence the outcomes of economic interactions and also how far away from the neoclassical predictions are "real life" markets (even when these markets are simulated in an economic experiment which allows for controlling several factors).

All models in this thesis assume that work is experienced as something for which a 
compensation is neecied in order not to substitute it with the good leisure. This ignores of course the dread associated with unemployment. Unemployment negatively affects happiness of those out of work (compare Clark and Oswald (1994) and Gerlach and Stephan (1996)). In addition it negatively affects the psychological well-being of workers dismissed and of workers who "survived" a restructuring wave in a firm setting free several of their colleagues (compare Darity and Goldsmith (1996) and Goldsmith and Darity (1992)). In addition the risk to get unemployed already may have negative effects on work motivation, commitment towards the employer and emotional well-being. Especially in times of high unemployment and rapid job turn-over where a growing share of the work force feels job insecurity (compare OECD (1997) pp. 129-160), these effects have a tremendous impact. Taking these elements which usually are excluded in neoclassical models into account would certainly reduce the voluntary unemployment predicted by the models presented in this thesis. Here the workers only consider the income reduction caused by unemployment, while unemployment per se is not experienced as frightful.

A last proviso is the attitude towards human capital investments assumed in the models described in this thesis. Workers invest in human capital in order to increase their labour productivity or improve their position in job competition. "Consumptive" aspects of human capital investments like satisfaction from acquiring knowledge, social status and reputation of students or the pressure of social environments to attain certain education grades do not play a role here. Compare also the discussion in chapter two why these aspects may be neglected as a first approximation.

All these restrictions should be borne in mind when judging the lessons for political inference which can be drawn from the models above and the problems labour market policy faces. In addition the implications of the proposed policy measures are frecuently beyond the scope of the models presented and to a certain degree based on subjective value judgements.

The policy advice that can be derived from chapter three with insiders and outsiders is that the market power of insiders that arises due to strategic investment in human capital should be reduced. This can be done e.g. by providing publicly financed courses for unemployed or even mandatory training for people on the dole. These courses should provide outsiders with topical skills that makes them more attractive for firms. Better trained unemployed are a stronger threat for insider rents. Topical skills make outsiders" entry threat more credible and lead to cooperative behaviour of the insiders which allows 
for the employment of at least some outsiders. Credible entry threats reduce the scope of strategic human capital investments of insiders in order to erect barriers to entry.

Chapters three to six propose that the possibility of workers to determine their investment in human capital themselves is detrimental for social welfare. The core problem is that workers have to concede part of the rent generated by human capital investments to the firm in order to induce sufficient labour demand. This causes an externality that induces too little investment. Workers are not motivated to invest efficiently in human capital if they can not skim the entire rent arising from this activity. Therefore it would be more efficient, if the firm could require human capital investment of its workers and hereby internalize this external effect. That means that in the labour contract a passage is added that the firm can decide how much and what education and training is needed for a worker. The firm can then ask the worker to follow this training as part of his or her labour contract duties.

In chapter five, workers invest in human capital even if they run a risk to be overqualified and lose their investments. Rents earned by skilled workers in adequate jobs and a better position in the competition for unskilled jobs attracts unskilled workers with high human capital costs to skill themselves and risk overqualification. Overqualification can be prevented by numeri clausi in study tracks or skills education on the basis of expected labour demand. History teaches however that the state is not an effective regulator of scarce study places. In addition a decrease in unskilled wages or an increase in education costs make overqualification less attractive. This is demonstrated in chapter five.

Skilled workers" rents arise because skilled workers enjoy market power. They can not be replaced easily by other skilled workers and not at all by unskilled workers. The problem of skilled workers' rents can be avoided by letting the firms pay for the education of their workers and having the same remuneration for all workers irrespective if they are skilled or not. This measure indirectly deprives skilled workers form exerting monopoly market power and attributes the entire rent from human capital investment to the firm. Equal wages for all workers are quite egalitarian and may interfere with work motivation for higher educated workers. Therefore a mixture between both evils, skilled workers" market power and lack of work motivation seems the best solution. This leaves politicians with the dilemma how to weigh both evils of course.

The macroeconomic model in chapter six includes two lessons for labour market policy. First, training costs reduce labour demand in the boom after a period of high unemploy- 
ment. Especially in situations with rapid technological changes and economic turbulence training costs tend to be high, because even short spells of unemployment reduce the value of human capital dramatically. Therefore it might be advisable to subsidize training costs for firms that hire unemployed workers, even taking into account the inefficiencies incurred by an increased tax load. " In addition, perceived unemployment risk is detrimental for employment. The government should therefore be cautious in overstating the general unemployment risk or in admitting that a certain ambitious unemployment reduction goal seems not realistic any more, because this only leads to higher reservation wages and less investment in human capital by unemployed workers. This effect increases with the necessary human capital up-date costs and risk aversion of the workers. Therefore also subsidies for human capital investments in times of job uncertainty reduce the reservation wage and hereby increase additional employment created after a spell of involuntary unemployment.

Job security legislation enhances the motivation to invest in human capital. This improves the efficiency of the economy if continuous upgrading of skills is needed. In chapter three to five it was shown that unemployment has a negative impact on the willingness of the workers to invest in human capital because they risk to lose the sunk costs. If workers with high investment costs in human capital perceive high job insecurity in chapter six, they are not willing to invest in human capital at a given wage. Although it might be in the interest of the individual firm to have a flexible working scheme, there are welfare benefits from workers' (perceived) job security.

From chapter seven only an indirect policy advice can be drawn. The incompleteness of the work contract gives rise to workers' rents even when there is an oversupply of workers. Therefore rents for workers and higher than market-clearing wages are observed under experimental circumstances when neoclassical theory predicts that all rents would vanish due to the market forces. Work contracts can never be complete (although some work contracts have book length in some countries), legal instructions to avoid the most important risks of the employers caused by workers' behaviour could at least reduce the scope of fairness and trust towards the worker.

It is an intriguing question for future research whether the patterns found in the models can be detected in empirical studies. As mentioned in the introduction, the literature does not provide too many studies about human capital and employment incidence. One of the fundamental problems is the measurement of skills and frequently rather rough

"The proof of this proposition is beyond the scope of this thesis. 
instruments have to be used as an approximation. The efficiency wage model in the third chapter predicts that higher than market clearing wages are paid in industries with a large impact of permanent training on labour productivity. The impact of training on labour productivity is difficult to measure, however. An adequate empirical study should be comparable to those of Krueger (1991) or Rebitzer (1995) who take one branch (fast food restaurants and maintenance in the petrochemical industry) and compare different supervision methods in the same branch (compare also the literature survey in chapter two). Chapter five indicates that the increase in education rents from the beginning of the 1990s goes hand in hand with an increasing number of overeducated workers. The scanty empirical evidence is reviewed in chapter five. Chapter six suggests that the recovery in employment after a period of involuntary unemployment is slower in industries with a lot of skilled workers than in industries where skilled workers have a smaller share on the labour force. Here again the matching of industries using different skill levels seems to be the main problem. According to chapter seven we can expect that workers' rents are higher in industries where labour contracts are necessarily incomplete and where this incompleteness has a high impact on labour productivity. In addition high wage mark-ups should be observed in firms where workers are not intrinsically motivated not to shirk, e.g. because they do not feel an obligation not to free-ride to their firm or their co-workers. In contrast to an economic experiment in a laboratory, reality does not provide so many controlled experiments, however. Especially the measurement of worker rents seems to be a difficult task. 


\section{References}

John Abowd and Orley Ashenfelter. "Anticipated Unemployment, Temporary Layoffs, And Compensating Wage Differentials, in: "Studies in Labor Markets," Sherwin Rosen (ed.), Chicago: The University of Chicago Press, 1981

Jonas Agell and Kjell Lommerud: "Minimum Wages and the Incentives for Skill Formation," in: Journal of Public Economics, 64, pp. 25-40, 1997

George Akerlof. "The market for 'Lemons': Quality-Uncertainty and the Market Mechanism," in: Quarterly Journal of Economics, 85, pp. 488-500, 1970

George Akerlof: "Labor Contracts as Partial Gift Exchange," in: Quarterly Journal of Economics, 97, pp. 543-569, 1982

George Akerlof. "Gift Exchange and Efficiency-Wage Theory: Four Views," in: American Economic Review, 74 (P\&P), pp.79-83, 1984

George Akerlof and Janet Yellen: "Introduction," in: "Efficiency Wage Models of the Labour Market," Akerlof and Yellen (ed.) Cambridge: Carnbridge University Press, pp. $1-21,1986$

George Akerlof and Janet Yellen: "Faimess and Unemployment," in: American Economic Review, 78, pp. 44-49, 1988

George Alogoskoufis, Charles Bean, Guiseppe Bertola, Daniel Cohen, Juan Dolado, Gilles Saint-Paul: "Unemployment: Choices for Europe," CEPR, London, 1995

Orley Ashenfelter and Alan Krueger. "Estimates of the Economic Return to Schooling from a New Sample of Twins," in: American Economic Review, 84, pp. 11571173,1994 
Costas Azariadis and Joseph Stiglitz: "Implicit Contracts and Fixed-Price Equilibria," in: Quarterly Journal of Economics, Supplement, pp. 1-22, 1983

William Baumol: "Contestable Markets: An Up-rising in the Theory of Industrial Structure," in: American Economic Review, 72, pp. 1-15, 1982

William Baumol, John Panzar and Robert Willig: "Contestable Markets and the Theory of Industry Structure," San Diego: Harcourt Brace Jovanovich, 1988

Charles Bean: "European Unemployment: A Survey," in: Journal of Economic Literature, 32, pp. 573-619, 1994

Gary Becker: "Human Capital," Chicago: The University of Chicago Press, 2nd edition, 1983

Jean-Pascal Benassy: "Monopolistic Competition" in: "Handbook of Mathematical Economics," Vol. IV, Werner Hildenbrand and Hugo Sonnenschein (eds.), NorthHolland: Amsterdam, 1991

P. Beneito, J. Ferri, M. Moltó and E. Uriel: "Over/under-education and Specific Training in Spain: Complementary or Substitute Components of Human Capital?," paper presented at 57th Applied Econometrics Association Conference in Maastricht, May 14-16th, 1997

McKinley Blackbum, David Bloom and Richard Freeman: "Changes in Earnings Differentials in the 1980s: Concordance, Convergence, Causes, and Consequences," NBER Working Paper Series No. 3901, 1991

Olivier Blanchard and Nobuhiro Kiyotaki: "Monopolistic Competition and the Effect of Aggregate Demand," in: American Economic Review, 77, pp. 647-666, 1987

Olivier Blanchard and Lawrence Summers: "Hysteresis and the European Unemployment Problem," in: NBER Macroeconomic Annuals, Stanley Fischer (ed.), Cambridge, Mass.: MIT Press, pp. 23-78, 1986

David Blanchflower, Andrew Oswald and Mario Garrett: "Insider Power in Wage Determination," in: Economica, 57, pp. 143-170, 1990 
Lex Borghans and Wendy Smits: "Overeducation and Earnings of Graduates from Higher Vocational Education," paper presented at 57 th Applied Econometrics Association Conference in Maastricht, May 14-16th, 1997

George Borjas: "Labor Economics," N.Y.: Mc Graw-Hill, 1996

George Borjas and Valerie Ramey: "Time-Series Evidence on the Source of Trends in Wage Inequality," American Economic Review, 84, PP, pp. 10-16, 1994

John Bound and George Johnson: "Changes in the Structure of Wages in the 1980s: An Evaluation of Alternative Explanations," in: American Economic Review, 82, pp.371-392, 1992

Samuel Bowles: "The Production Process in a Competitive Economy: Walrasian, NeoHobbesian, and Marxian Models," in: American Economic Review, 75, pp. 1636,1985

Felix Büchel and Gernot Weißhuhn: "Ausbildungsinadäquate Beschäftigung der Absolventen des Bildungssystems," Diskussionspapier 1996/09, Technische Universität Berlin, 1996

David Brauer and Susan Hickok: "Explaining the Growing Inequality in Wages across Skill Levels," in: Economic Policy Review, 1, pp. 61-75, 1995

Jeremy Bulow and Lawrence Summers: "A. Theory of Dual Labor Markets with Application to Industrial Policy, Discrimination, and Keynesian Unemployment,", in: Journal of Labor Economics, 4, pp. 376-414, 1986

Alan Carruth and Andrew Oswald: "On Union Preferences and Labour Market Models: Insiders and Outsiders," in: Economic Journal, 97, pp, 431-445, 1987

Edward Chamberlin: "The theory of monopolistic competition," Cambridge, Mass.: Harvard University Press, 1933

A. Clark and Andrew Oswald: "Unhappiness and Unemployment"" in: The Economic Journal, 104, pp. 648-659, 1994 
Charles Clotfelter. "Demand for Undergraduate Education," in: "Economic Challenges in Higher Education," Charles Clotfelter, Ronald Ehrenberg, Malcolm Getz and John Siegfried (eds.), Chicago: The University of Chicago Press, pp. 19-142, 1991

Don Coursey, Marc Isaac, Margaret Luke, Vernon Smith: "Market contestability in the presence of sunk (entry) costs," in: Rand Journal, 15, pp. 69-84, 1984

Vincent Crawford: "Relationship-Specific Investment," in: Quarterly Journal of Economics, 105, pp. 561-574, 1990

William Darity and Arthur Goldsmith: "Social Psychology, Unemployment and Macroeconomics," in: Journal of Economic Perspectives, 10, pp. 121-140, 1996

Douglas Davis and Charles Holt: "Equilibrium Co-operation in Three-Person, Choiceof-Partner Games," in: Games and Economic Behaviour, 7, pp. 39-53, 1994

Steven Davis: "Cross-Country Patterns of Change in Relative Wages," in: NBER Macroeconomics Annual, Olivier Blanchard and Stanley Fischer (eds.), Cambridge, Mass.: MIT Press, 1992

Ron Dekker, Andries de Grip and Hans Heijke: "The Effects of Training and Overeducation on Career Mobility in a Segmented Labour Market," mimeo, Researchcentrum voor Onderwijs en Arbeidsmarkt ROA-RM-1996/4E, 1996

W. Dickens and Lawrence Katz: "Inter-industry Wage Differences and Industry Characteristics," in: K. Lang and J.Leonhard (eds.): "Unemployment and the Structure of Labor Markete," New York: Basil Blackwell, 1987

Avinash Dixit: "The Role of Investment in Entry-Deterrence," The Economic Journal, 90, pp. 95-106, 1980

Avinash Dixit and Joseph Stiglitz: "Monopolistic Competition and Optimum Product Diversity," in: American Economic Review, 67, pp. 297-308, 1977

Peter Doeringer and Michael Piore: "Internal Labor Markets and Manpower Analysis," D.C. Heath, 1971 
Richard Edwonds: "Contested Terrain - The Transformation of the Workplace in the Twentieth Century;" New York, Basic Books, 1979

Armin Falk and Ernst Fehr. "Wage Rigidities in a Competitive Incomplete Contract Market - An Experimental Investigation," mimeo Universität Z"urich, 1996

Ernst Fehr and Simon Gächter. "Soziale Kräfte und Lohnbildung: Einsichten aus der experimentellen Arbeitsmarktforschung," in: Ökonomie und Gesellschaft, Jahrbuch 14, Frankfurt/M.: Campus Verlag, pp. 11-52, 1996

Ernst Fehr, Simon Gächter and Georg Kirchsteiger: "Reciprocity as a Contract Enforcement Device: Experimental Evidence," in: Econometrica, 65, pp. 833-860, 1997

Ernst Fehr and Georg Kirchsteiger: "Insider Power, Wage Discrimination and Fairness," in: Economic Journal, 104, pp. 571-583, 1994

Ernst. Fehr, Georg Kirchsteiger and Arno Riedl: "Involuntary Unemployment and NonCompensating Wage Differentials in an Experimental Efficiency Wage Market," forthcoming in: Economic Journal, 1995

Robert Frank: "Passions within Reason-The Strategic Role of Emotions," New York: Norton, $\mathbb{1 9 8 8}$

Wolfgang Franz: "Hysteresis in Economic Relationships: An Overview," in: "Hysteresis Effects in Economic Models," Wolfgang Franz (ed.), Heidelberg: Physica-Verlag, 1990

Richard Freeman: "Demand for Education," in: Handbook of Labor Economics, Orley Ashenfelter and Richard Layard (eds.), Amsterdam: North-Holland, pp. 357-386, 1986 
Richard Freman: "How much has De-Unionization Contributed to the Rise in Male Earnings Inequality?" in: Sheldon Danziger and Peter Gottschalk, eds., "Uneven Tides," N.Y.: Russell Sage, pp.133-163, 1993

Knut Gerlach and Gesine Stephan: "A Paper on Unhappiness and Unemployment in Germany" im: Economics Letters, 52, pp. 325-330, 1996

Arthur Goldsmith and William Darity: "Social Psychology, Unemployment Exposure and Equilibrium Unemployment," in: Journal of Economic Psychology, 13, pp. 449471,1992

Nils Gottfries and Henrik Horn: "Wage Formation and the Persistence of Unemployment," in: Economic Journal, 97, pp. 877-884, 1987

Wim Groot: "The Incidence of, and Returns to Overeducation in the UK," in: Applied Economics, 28, pp.1345-1350, 1996

Wim Groot and Henriëtte Maassen van den Brink "Overscholing en verdringing op de arbeidsmarkt," in: Economisch-Statistische Berichten, 81, pp. 74-77, 1996

Werner Güth, Rolf Schmittberger and Bernd Schwarze: "An Experimental Analysis of Ultimatum Bargaining," in: Journal of Economic Behavior and Organization, 3, pp. $367-388,1982$

S. Hargreaves Heap: "Choosing the Wrong 'Natural' Rate: Accelerating Inflation or Decelerating Employment and Growth?," in: The Economic Journal, 90, pp. 611-620, 1980

Glenn Harrison: "Experimental Evaluation of the Contestable Markets Hypothesis," in: "Public Regulation ed. Elizabeth Bailey," Cambridge, Mass.: MTT Press, pp. 191225,1987 
Robert Hart and Thomas Moutos: "Human Capital, Employment and Bargaining," Cambridge: Cambridge University Press, 1995

Joop Hartog: "Overscholing?," in: Economisch-Statistische Berichten, 70, pp.152156,1985

Joop Hartog and Hessel Oosterbeek: "Education, Allocation and Earnings in the Netherlands: Overschooling?," in: Economics of Education Review, 7, pp. 185-194, 1988

Masanori Hashimoto: "Firm-Specific Human Capital as a Shared Investment," in: American Economic Review, 71, pp. 475-482, 1981

Bertil Holmhnd and Johnny Zetterberg. "Insider Effects in Wage DeterminationEvidence from five countries," in: European Economic Review, 35, pp. 10091034,1991

Charles Holt and Roger Sherman: "Advertising and Product Quality in Posted-Offer Experiments," in: Economic Inquiry, 28, pp. 39-56, 1990

Frederic Huzzinga and F. Schiantarelli: "Dynamics and Asymmetric Adjustment in Insider-Outsider Models," in: Economic Journal, 102, pp. 1451-1466, 1992

Douglas De Jong, Robert Forsythe and Russell Lundholm: "Ripoffs, Lemons, and Reputiation Formation in Agency Relationships: A. Laboratory Market Study," in: Journal of Finance, 40, pp. $809-820,1985$

George Johnson: "Changes in Earnings Inequality: The Role of Demand Shifts," in: Journal of Economic Perspectives, 11, pp. 41-54, 1997

Chinhui Juhn, Kevin Murphy and Brooks Pierce, "Wage Inequality and the Rise in Returns to Skill," in: Journal of Political Economy, 101, pp. 410-442, 1993 
Daniel Kahneman, Jack Knetsch and Richard Thaler. "Fairness as a Constraint on Profit Seeking: Entitlements in the Market," in: American Economic Review, 76, pp. $728-741,1986$

Lawrence Katz: "Efficiency Wage Theories: A Partial Evaluation," in: NBER Macroeconomics Annual 1986, Stanley Fischer (ed) Cambridge, MA: The MIT Press, 1986

Lawrence Katz and Kevin Murphy: "Changes in Relative Wages, 1963-1987: Supply and Demand Factors," in: Quarterly Journal of Economics, 107, pp. 35-78, 1992

Lawrence Katz and Lawrence Summers: "Industry Rents: Evidence and Implications," in: Brookings Papers on Economic Activity, pp. 209-290, 1989

John Keynes: "The General Theory of Employment Interest and Money", London: MacMillan, 1936

B. Kiker, Maria Santos and Mendes de Oliveira: "Overeducation and Undereducation: Evidence for Portugal," in: Economics of Education Review, 16, pp. 111-125, 1997

Arjo Klamer, L. van der Laan and J. Prij: "De illusie van de volledige werkgelegenheid," Assen: Van Gorcum, 1997

Benjamin Klein and Keith Leffler: "The Role of Market Forces in Assuring Contractual Performance," in: Journal of Political Economy, 89, pp. 615-641, 1981

Alan Krueger: "Ownership. Agency, and Wages: An Examination of Franchising in the Fast Food Industry," in: Quarterly Journal of Economics, 106, pp. 75-101, 1991

Allan Krueger and Laurence Summers: "Efficiency Wages and the Inter-Industry Wage Structure," in: Econometrica, Vol 56, No.2., pp. 256-293, 1988 
Richard Krugman and R. Lawrence: "Trade, Jobs and Wages", in: NBER Working Paper No. 4478,1993

Kevin Lang and Shulamit Kahn: "Efficiency Wage Models of Unemployment: A Second View," in: Economic Inquiry, 1990

Richard Layard, Stephen Nickell and Richard Jackman: "UnemploymentMacroeconomic Performance and the Labour Market," Oxford: Oxford University Press, 1991

Edward Lazear. "Agency, Earnings Profiles, Productivity, and Hours Restrictions," in: American Economic Review, 71, pp. 606-620, 1981

Edward Lazear and Robert Moore: "Incentives, Productivity and Labor Contracts," in: Quarterly Journal of Economics, 99, 275-296, 1984

D. Levine: "Test of Efficiency Wage and Rent-Sharing Theories: The Pay-Productivity Relation," University of California at Berkley, mimeo, 1988

Assar Lindbeck: "Microfoundations of Unemployment Theory," in: Labour, 5, pp. 3-23, 1991

Assar Lindbeck: "The West European Employment Problem," in: Weltwirtschaftliches Archiv, 132, pp. 609-637, 1996

Assar Lindbeck and Dennis Snower: "Wage Setting, Unemployment, and Insider-Outsider Relations," in: American Economic Review, 76, pp. 235-239, 1986

Assar Lindbeck and Dennis Snower. "Efficiency Wages Versus Insiders and Outsiders," in: European Economic Review, 31, pp. 407-416, 1987 
Assar Lindbeck and Dennis Snower. "Cooperation, Harassment, and Involuntary Unemployment: An Insider-Outsider Approach," in: American Economic Review, 78 , pp. $167-188,1988$

Assar Lindbeck and Dennis Snower. "Job Security, Work Incentives and Unemployment," in: "Information and Incentives in Organizations," Seppo Honkapohja, ed., Oxford: Basil Blackwell, 1989

Assar Lindbeck and Dennis Snower: "Demand-and Supply-Side Policies and Unemployment: Policy Implications of the Insider-Outsider Approach," in: Scandinavian Journal of Economics, 92, pp. 279-305, 1990

Assar Lindbeck and Dennis Snower: "Interactions between the Efficiency Wage and Insider-Outsider Theories," in: Economics Letters, 37, pp. 193-196, 1991

Niklas Luhmann: "Vertrauen - Ein Mechanismus der Reduktion sozialer Komplexität," Stuttgart: Enke, 1973

Michael Lynch, Ross Miller, Charles Plott and Russell Porter: "Product Quality, Consumer Information and 'Lemons' in Experimental Markets," in: "Empirical Approaches to Consumer Protection in Economics," eds.: Pauline Ippolito and David Scheffman, Washington D.C.: Federal Trade Commission, pp. 251-306, 1986

Bentley MacLeod and James Malcomson: "Implicit Contracts, Incentive Compatibility, and Involuntary Unemployment," in: Econometrica, pp. 312-22, 1989

Bentley MacLeod and James Malcomson: "Investments, Holdup, and the Form of Market Contracts," in: American Economic Review, pp. 811-837, 1993

Karl Marx: "Das Kapital-Kritik der politischen "Ökonomie," Hildesheim: Gerstenberg, 1867 
Kiminori Matsuyama: "Complementarities and Cumulative Processes in Models of Monopolistic Competition", in: Journal of Economic Literature, 33, pp. 701-729, 1995

Jacob Mincer. "Schooling, experience, and earnings," New York: Columbia University Press, 1974

Jacob Mincer: "Education and Unemployment," NBER working paper series, No. 3838, 1991

Jacob Mincer: "Investment in U.S. Education and Training," NBER working paper series, No. 4844,1994

Kevin Murphy and Richard Topel: "Unemployment, Risk, and Earnings," in: "Unemployment and the Structure of Labor Markets," K. Lang and J. Leonhard (eds.), New York: Basil Blackwell, 1987

Kevin Murphy and Finis Welch: "Wage Premiums for College Graduates: Recent Growth and Possible Explanations", in: Educational Researcher, 18, pp. 17-26, 1989

Joan Muysken and Thomas Zwick: "A Note on Incentive Wages with Human Capital Formation," METEOR research memorandum 96/022, University of Limburg, Maastricht, 1996

Joan Muysken and Thomas Zwick: "Insider Power Breeds Human Capitalists," in: "Aspects of the Distribution of Income," Franz Haslinger and Oliver StonnerVenkatarama (eds.), Marburg: Metropolis, 1998

Stephen Nickell and Brian Bell: "The Collapse in Demand for the Unskilled and Unemployment across the OECD", in : Oxford Review of Economic Policy, 11,1, pp. $40-62,1995$ 
Sren Nielsen, Lars Pedersen and Peter Srensen: "Environmental Policy, Pollution, Unemployment, and Endogenous Growth", in: International Tax and Public Finance, 2, pp. $185-205,1995$

Steven Nickell and S. Wadhwani: "Insider Forces and Wage Determination," in: Economic Journal, 100, pp. 496-509, 1990

Kiyohiko Niskimura: "Indexation and Monopolistic Competition in Labor Markets," in: European Economic Review, 33, pp. 1606-1623, 1989

OECD: "Employment Outlook," Paris, 1996a

OECD: "Education at a Glance," Paris, 1996b

OECD: "Employment Outlook," Paris, 1997

Hessel Oasterbeek: "Essays on Human Capital Theory," thesis, Amsterdam: Thesis publishers, 1992

Jan van Ours and G. Ridder: "Job Matching and Job Competition: Are Lower Educated Workers at the back of Job Queues?," in: European Economic Review, 39, pp. $1717-1731,1997$

Christopher Pissarides: "Loss of Skill During Unemployment and the Persistence of Employment Shocks," in: Quarterly Journal of Economics, 107, pp. 1371-1391, 1992

Metthew Rabin: "Incorporating Fairness into Game Theory and Economics," in: American Economic Review, 83, pp. 1280-1302, 1993

Eric Rasmussen: "Games and Information: An Introduction to Game Theory," Second edition, Cambridge, MA: Blackwell, 1994 
James Rebitzer: "Is there a Trade-off between Supervision and Wages? An Empirical Test of Efficiency Wage Theory," in: Journal of Economic Behaviour and Organization, 28, pp. 107-129, 1995

Gilles Saint-Paul: "Efficiency wages as a Persistence Mechanism," in: "The New Macro economics - Imperfect Markets and Policy Effectiveness," Huw Dixon and Neil Rankin (eds.), Cambridge: Cambridge University Press, 1995

Gilles Saint-Paul: "Dual Labour Markets-A Macroeconomic Perspective," Cambridge, Mass.: MIT Press, 1996

Steven Salop: "A Model of the Natural Rate of Unemployment," in: American Economic Review, 69, pp.117-125, 1979

Peter Sanfey: "Insiders and Outsiders in Union Models," in : Journal of Economic Surveys, 9 , pp. 255-284, 1995

Theodore Schultz: "Investment in Human Capital," in: American Economic Review, 51 , pp. 1-17, 1961

Theodore Schultz: "Reflections on Investment in Man," in: Journal of Political Econorny, 70 (5, supplement), pp. 1-8, 1962

Carl Shapiro and Joseph Staglitz: "Equilibrium Unemployment as a Worker Discipline Device," in: American Economic Review, 74, pp. 433-444, 1984

William Shepherd: "Contestability' vs. Competition," in: American Economic Review, 74 , pp. $572-587,1984$

Stanley Siebert: "Developments in the Economics of Human Capital," in: "Labour Economics," Derek Carline et al (ed.), Essex: Longman, 1985 
Adam Smith: "The Wealth of Nations," New York: Random House, 1937

Henri Sneessens and Fatemeh Shadman-Metha: "Real Wages, Skill Mismatch and Unemployment Persistence in France 1962-1989," Annales d'Economie et de Statistique, $37 \sim 38$, pp. $255-92,1995$

Dennis Snower: "Imperfect Competition, Underemployment and Crowding-Out," in: Oxford Economic Papers, 35, suppl., pp. 245-270, 1983

Dennis Snower. "The Low-skill, bad-job trap," in:Alison Booth and Dennis Snower (eds.): "Acquiring Skills-Market Failures, their Symptoms and Policy Responses", Cambridge: Cambridge University Press, 1996

Robert Solow: "Another Possible Source of Wage Stickiness," in: Journal of Macroeconomics, 1, pp. 79-82, 1979

Margaret Stevens: "Labour Contracts and Efficiency in On-the-job Training," in: Economic Journall, 104, pp. 408-419, 1994

Joseph Stiglitz. "Alternative Theories of Wage Determination and Unemployment in LDC's: The Labor Turnover Model," in: Quarterly Journal of Economics, 88, pp. $194-227,1974$

Joseph Stiglitz: "Technological Change, Sunk Costs, and Competition," in: Brookings Papers on Economic Activity, 3, pp. 883-937, 1987a

Joseph Stiglitz. "The Causes and Consequences of the Dependence of Quality on Price," in: Journal of Economic Literature, 25, pp. 1-48, $1987 \mathrm{~b}$

Richard Thaler: "Anomalies: Interindustry Wage Differentials," in: Journal of Economic Perspectives, 3, pp. 181-193, 1989 
Jean Tirale: "The Theory of Industrial Organization," Cambridge, Mass.: The MIT Press, 1988

Robert Topel: "Specific Capital, Mobility, and Wages: Wages Rise with Job Senionity," in: Journal of Political Economy, 99, pp. 145-176, 1991

Robert Topel: "Regional Labor Markets and the Determinants of Wage Inequality," in: American Economic Review, 83, pp. 110-115, 1993

Robert Topel: "Factor Proportions and Relative Wages: The Supply-Side Determinants of Wage Inequality," in: Journal of Economic Perspectives, 11, pp. 55-74, 1997

Winfried Vogt: "Theorie der kapitalistischen und einer laboristischen 'Ökonomie," Frankfurt/M: Campus, 1986

Michel De Vroey: "Involuntary Unemployment-From Keymes to the New Keynesians," paper presented on a seminar, Rotterdam 11/8/1995

S. Wadhwani and M. Wall: "A. Direct Test of the Efficiency Wage Model Using UK Micro-Data, London School of Economics, Centre for Labour Economics, Working Paper 1022,1990

Max Weber: "Wirtschaft und Gesellschaft-Grundriss der werstehenden Soziologie," Tübingen: Mohr Siebeck, 1972

Andrew Werss: "Job Queues and Layoffs in Labor Markets with Flexible Wages," in: Journal of Political Economy, 88, pp. 526-538, 1980

Robert Willis: "Wage Determinants: A Survey and Reinterpretation of Human Capital Earnings Functions," in: "Handbook of Labour Economics," Orley Ashenfelter and Richard Layard (eds.), Amsterdam: Elsevier, pp. 525-602, 1986 
Janet Yellen: "Efficiency Wage Models of Unemployment," in: American Economic Review, 74 (P\&P), pp. 200-205, 1984

Adriaan van Zon, Huub Meijers and Joan Muysken: "On Trickling Chimneys and Other Unemployment Misery," mimeo, MERIT research memorandum 97006, 1997 


\section{List of Symbols}

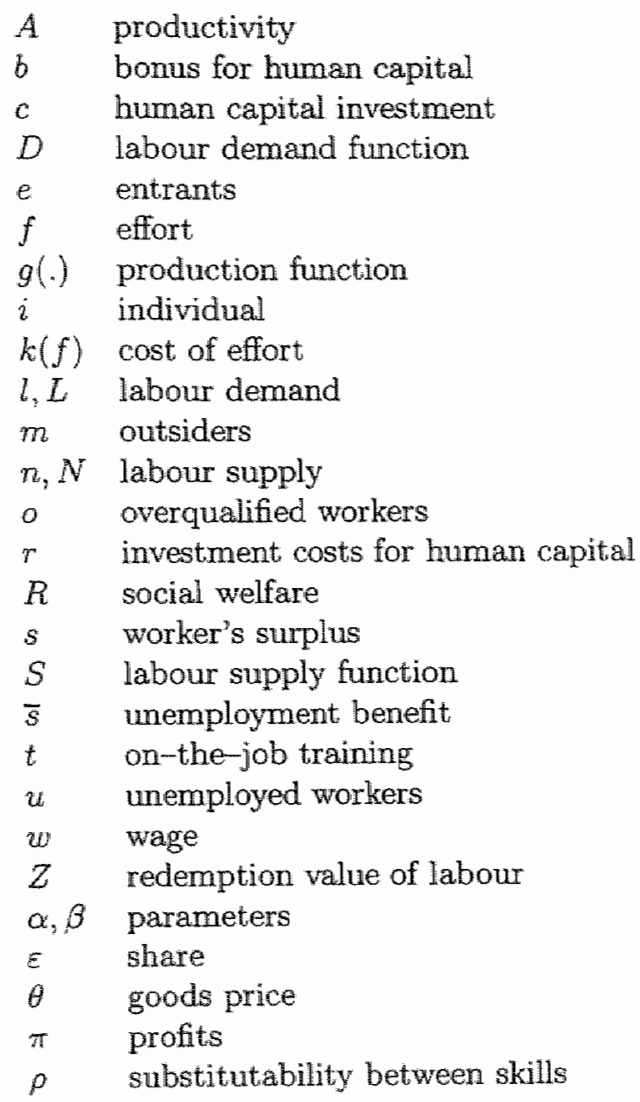




\section{Samenvatting}

Dit proefschrift concentreert zich op de samenhang tussen werkloosheid en de opbouw van menselijk kapitaal. Het onderwerp wordt vanuit verschillende richtingen benaderd, die allemaal samenhangen met onvolkomenheden op de arbeidsmarkt. Deze marktonvolkomerheden vloeien voort uit individueel rationaal gedrag en zijn karakteristiek voor arbeidsmarkten met opbouw van menselijk capitaal. In dit proefschrift wordt doorgaans ervan uitgegaan dat investeringen in menselijk kapitaal noodzakelijk zijn om de arbeidsproductiviteit op peil te houden. De marktonvolkomenheden, die met de opbouw van menselijk kapitaal verbonden zijn, worden vooral door verzonken kosten en door de creatie en verdeling van economische renten veroorzaakt.

Het eerste hoofdstuk omvat een beknopte introductie van de onderwerpen menselijk kapitaal en werkloosheid en een motivering van het onderzoek. Bovendien wordt de opbouw van het boek uitgelegd.

In het tweede hoofdstuk worden bekende theorieën over de opbouw van menselijk kapitaal en de literatuur over vrijwillige en onvrijwillige werkloosheid samengevat. Bij de theorie over de opbouw van menselijk kapitaal wordt de klemtoon vooral gelegd op de individuële motivatie om te investeren en de economische relevantie van investeringen in menselijk kapitaal. Het overzicht van werkloosheidsmodellen concentreert zich op micro-economische benaderingen. Hier staat de vraag centraal waarom werklozen het loonniveau niet willen of kunnen onderbieden. Het litereratuuroverzicht omvat vooral de efficiëntieloontheorieën en de insider-outsider theorieën, omdat deze literatuur de basis vormt voor het derde en vierde hoofdstuk. Een bijzonder oogmerk ligt hierbij bij de karacterisering van imperfecties op de arbeidsmarkten in de behandelde modellen.

Het derde hoofdstuk presenteert een insider-outsider model dat de opbouw van menselijk kapitaal omvat. Investeringen in menselijk kapitaal geven insiders een verdere mogelijkkeid om barrières tegen markttoetredingen op te bouwen. De strategie van insiders is precies zo veel in menselijk kapitaal te investeeren dat outsiders hen niet van hun werk kunnen verdringen. Dit leidt tot een minder dan efficiënte werkgelegenheid terwijl insiders economische renten kunnen afromen.

In het vierde hoofdstuk wordt aangetoond, dat hogere dan marktruimende lonen ook 
door de opbouw van menselijk kapitaal kumnen onstaan. Als werknemers zelf kunnen bepalen hoeveel zij in menselijk kapitaal willen investeren, dan is de opbouw van menselijk kapitaal een reden voor de werkgever om hogere lonen te betalen. Lonen hebben dan naast de marktruimingsfunctie ook een motiveringsfunctie voor investeringen in menselijk kapitaal. Deze investeringen zijn onder deze omstandigheden inefficiënt omdat de werknemers de eruit resulterende renten moeten delen met de werkgevers. Bovendien reduceert het risico de verzonken kosten te verliezen, de motivatie van de werknemers te investeren als de arbeidsvraag lager is dan het arbeidsaanbod.

Het vijfde hoofdstuk presenteert een model met monopolistische mededinging op de markt voor gekwalificeerde werknemers. Arbeiders kunnen vrij beslissen of zij zich willen kwalificeren of niet. Investeringen in kwalificaties geven arbeiders marktmacht die zij kurnnen gebruiken yoor hogere looneisen. De opslag voor lonen voor gekwalificeerde arbeiders ten opzichte van de lonen voor ongekwalificeerde arbeiders kan hoger zijn dan de kosten voor het verwerven van kwalificaties. In dit geval genieten de gekwalificeerde werknemers renten en is het loomiveau is hoger dan efficiënt. Het is mogelijk voor de gekwallificeerde arbeiders hoger dan efficiënte lonen te eisen als zij niet makkelijk door ongekwalificeerde arbeiders kunnen worden gesubstitueerd. Het model laat zien dat hoger dan efficiënte lonen voor gekwalificeerde werknemers leiden tot een reductie in de vraag naar arbeid, de welvaart en het verwachte nutsniveau van alle werknemers. Bovendien onstaat overkwalificatie, die de verwachte nutsniweaus van ongekwalificeerde en gekwalificeerde werknemers in overeenstemming brengt. Ongekwalificeerde arbeiders worden door de hogere lonen voor gekwalificeerd werk verleid in kwalificaties te investeren ook als er risico bestaat dat deze investeringen verloren gaan als geen passend werk kan worden gevonden.

In het zesde hoofdstuk wordt de noodzaak voor opbouw van menselijk kapitaal toegevoegd aan een traditioneel neo-Keynesiaans model met lonene die op korte termijn niet kunnen dalen. Het kan worden aangetoond, dat de werkgelegenheid in een boomfase in het model met menselijk kapitaal minder sterk stijgt en op lange termijn lager blijft dan in het tradtitionele meo-Keymesiaans model zonder menselijk kapitaal. Arbeiders eisen een risicoloonopslag voor hun investeringen in menselijk kapitaal als zij verwachten dat hun werkplek niet zeker is. Als de werkloosheid stijgt lopen zij het risico hun verzonken investeringen te verliezen. Bovendien moeten ondernemingen werklozen, die nieuw worden aangesteld, trainen omdat deze geen on-the-job training hebben genoten tijdens hun werkloosheidsperiode. In het geval van onvrijwillige werkoosheid leiden beide factoren ertoe, 
dat er minder nieuwe banen worden geschapen als de economie weer aantrekt.

Het zevende hoofdstuk beschrijft enkele resultaten van een economisch experiment. Dit experiment simuleert een arbeidsmarkt met volledige mededinging voor arbeidsplaatsten en met onvolledige arbeidscontracten. Arbeidscontracten zijn hier onvolledig, omdat arbeiderg alleen een bepaalde werkprestatie moeten beloven als zij cen werkcontract tekenen. Deze belofte is niet bindend. Door het experiment kan worden aangetoond, dat arbeiders renten kunnen afromen als arbeidscontracten niet volledig zijn. Dit is magelijk omdat ondernemingen niet consequent de werklozen kiezen, die de arbeiders onderbieden. Ondememingen veronderstellen - terecht-dat werklozen, als zij worden geaccepteerd, minder loyaal tegenover de onderneming zijn dan de vroegere arbeiders. Loyaliteit wordt in dit geval gemeten aan het verschil tussen de beloofde en de daadwerkelijke werkprestatie.

In het achtstee hoofdstuk worden uiteindelijk enkele consequenties voor de politiek genoemd, die uit de voorafgaande hoodstukken kunnen worden getrokken. 


\section{Zusammenfassung}

Die vorliegende Arbeit behandelt den Zusammenhang zwischen Arbeitslosigkeit und dem Anfbau von Humankapital. Dieses Thema wird aus verschiedenen Blickrichtungen betrachtet, deren gemeinsamer Fokus Unvollkornmenheiten auf dem Arbeitsmarkt sind. Diese Marktunvollkommenheiten resultieren aus individuell rationalem Verhalten und sind charakteristisch für Arbeitsmärkte in denen Humankapital gebildet wird. Die Hauptelemente der mit Humankapital verbundenen Marktunvollkommentheiten sind versunkene Kosten und die Entstehung und Verteilung von ökonomischen Renten. In dieser Arbeit wird durchgehend davon ausgegangen, daf Humankapitalinvestitionen notwendig sind, um die Arbeitsproduktivität zu erhalten. Die Haupthese ist, daf die durch Humankapitalinvestitionen hervorgerufenen Marktunvollkommenheiten zu einem niedrigeren als effizienten Beschäftigungsniveau führen.

Das erste Kapital bietet eine kurze Einleitung zum Thema Humankapital und Arbeitslosigkeit und eine Motivierung der Arbeit. Zudem wird der Aufbau diese Buches kurz erläutert.

Im zweiten Kapitel werden etablierte Theorien über den Aufbau von Humankapital und die Literatur über freiwillige und unfreiwillige Arbeitslosigkeit kurz zusammengefaßt. Bei der Humankapitaltheorie werden insbesondere die individuellen Anreize, in Humankapital zu investieren und der ökonomische Stellenwert von Ausbildung und Training hervorgehoben. Die Übersicht über Arbeitslosigkeitsmodelle konzentriert, sich auf mikroökonomische Ansätze. Hier ist die zentrale Frage, warum Arbeitslose das Lohnniveau nicht unterbieten wollen oder dazu nicht in der Lage sind. Die Literaturübersicht behandelt vor allem Effizienzlohntheorien und Insider-Outsider Theorien, da diese Literatur die Grundiage des dritten und vierten Kapitels bildet. Ein besonderes Augenmerk liegt hierbei bei der Charakterisierung der Arbeitsmarktunvollkommenheiten in den vorgestellten etablierten Modellen.

Das dritte Kapitel stellt ein Insider-Outsider Modell vor, das Humankapitalbildung einschließt. Investitionen in Humankapital geben Insidern eine zusätzliche Möglichkeit, Marktzutrittsschranken zu errichten. Insider versenken dann strategisch so viel Kosten in Humankapital, daß Outsider nicht in der Lage sind, sie von ihrem Arbeitsplatz zu 
verdrängen. Dies führt zu einer geringeren als effizienten Beschäftigung während Insider Renten abschöpfen

Im vierten Kapitel wird gezeigt, daß höhere als markträumende Löhne auch durch Humankapitalbildung hervorgerufen werden können. Humankapitalbildung ist ein Grund für den Arbeitgeber, höhere Löhne zu zahlen, wenn Arbeiter über die Investitionen in Humankapitalbildung selbst entscheiden kömnen. Löhne haben dann neben der Markträumungsfuntion auch eine Anreizfunktion für Hurnankapitalinvestitionen. Die Investitionen sind unter diesen Umständen verzerrt, da die Arbeiter Renten, die aus den Investitionen resultieren, mit den Firmen teilen müssen. Zusätzlich reduziert das Risiko, die versunkenen Kosten zu verlieren wenn die Arbeitsnachfrage geringer ist als das Arbeitsangebot, die Motivationen der Arbeiter in Humankapital zu investieren.

Das fünfte Kapitel präsentiert ein Modell mit monopolistischem Wettbewerb auf dem Markt für ausgebildete Arbeiter. Arbeiter können frei entscheiden, ob sie sich qualifizieren wollen oder nicht. Investitionen in Ausbildung verleihen Arbeitern Marktmacht die sie für höhere Löhne nutzen können. Der Aufschlag für die Löhne ausgebildeter Arbeiter auf die Löhne unausgebildeter Arbeiter kann höher sein als die Ausbildungskosten. In diesem Falle erhalten die ausgebildeten Arbeiter Renten und das Lohnniveau ist höher als effizient. Es ist den ausgebildeten Arbeitern möglich höher als effiziente Löhne zu fordern, falls ausgebildete Arbeiter nicht einfach durch fachfremde ausgebildete Arbeiter ersetzt werden können. Das Modell zeigt, daß höher als effiziente Löhne für ausgebildete Arbeiter zu einer Reduzierung der Arbeitsnachfrage, der Wohlfahrt und des erwarteten Nutzenniveaus aller Arbeiter führt. Außerdem wird Überqualifizierung hervorgerufen, die die Nutzenniveaus zwischen ausgebildeten und unæusgebildeten Arbeitern angleicht. Unausgebildete Arbeiter werden durch die hohen Löhne für ausgebildete Arbeit dazu gebracht, in Ausbildung zu investieren auch wenn das Risiko besteht, daB diese Investitionen verloren gehen wenn keine adäquate Arbeitsstelle gefunden wird.

Im sechsten Kapitel wird Humankapitalbildung bei einem traditionellem Neokeynesianischem Modell mit kurzfristig nach unten unflexiblen Löhnen hinzugefügt. Es kann gezeigt werden, daß die Beschäftigungserholung nach einem negativen Angebotsschock im Modell mit Berücksichtigung von Humankapital langsamer verläuft und zudem langfristig ein niedrigeres Beschäftigungsniveau erzielt wird als in einem traditionellem Neokeynesianischem Modell ohne Humankapital. Arbeiter fordern einen Risikolohnaufschlag für ihre Humankapitalinvestitionen falls sie erwarten, daß ihr Arbeitsplatz nicht sicher ist. Falls 
die Arbeitslosigkeit steigt, werden sie mit dem Risiko konfrontiert, ihre versunkenen Investitionen zu verlieren. Zusätzlich müssen. Firmen Arbeitslose, die nen eingestellt werden, ausbilden, da sie kein on-the-job training erhielten wahtend der Arbeitslosigkeit. Beide Faktoren reduzieren die zusätzliche Beschäftigung wenn die gesamtwirtschaftliche Nachfrage wieder zunimmt nach einer Phase unfreiwilliger Arbeitslosigkeit.

Das siebte Kapitel beschreibt einige Ergebnisse eines äkonomischen Experiments. Dieses Experiment simuliert, einen Arbeitsmarkt bei vollständigem Wettbewerb um Arbeitsplätze aber mit unvollständigen Arbeitsverträgen. Die Arbeitsverträge sind unvollständig, da Arbeiter beim Unterschreiben eines Arbeitsvertrages nur eine gewisse Arbeitsleistung versprechen müssen. Dieses Versprechen ist aber hinterher nicht mehr bindend. Mit: Hilfe des Experiments kann gezeigt werden, daß3 Arbeiter Renten abschöpfen wenn Arbeitsverträge unvollständig sind auch wenn ein Überangebot an Arbeitern besteht. Dies ist möglich, weil Firmen nicht durchgehend die die etablierten Arbeiter unterbietenden Arbeitslosen wählen. Firmen gehen zu Recht davon aus, daß Arbeitslose wenn sie akzeptiert wurden weniger fair gegenüber der Firma sein werden als die bisherigen Arbeiter. Fairness wird in diesem Fall gemessen an der Kluft zwischen versprochener und tatsächlicher Arbeitsleistung.

Im achten Kapitel schließlich werden einige Konsequenzen für die Wirtschaftspolitik genannt, die aus den vorhergehenden Kapiteln gezogen werden können. 


\section{Curriculum Vitae}

Thomas Alexander Zwick werd geboren op 29 juni 1968 te Alexandrië (Egypte). Yan 1978 tot 1987 volgde hij het voorbereidend wetenschappelijk onderwijs aan het Albreat-Altdorfer-Gymnasium te Regensburg (Duitsland). Na het behalen van het Abitur en de militaire dienst begon hij in november 1988 met de studie algemene economie aan de Universität Regensburg. In het academische jaar 1990/91 studeerde hij algemene econonie aan de Vanderbilt University in Nashville, TN (Verenigde Staten). De studie werc in december 1993 cum laude met de titel Diplom-Volkswirt afgesloten.

Per 1 februari 1994 trad hij in dienst als assistent in opleiding bij de vakgroep Algemene Economie van de huidige Universiteit Maastricht. Hij verrichtte onderzoek onder leióng van Hans Maks en Joan Muysken op het gebied van microeconomie en arbeidsmakteconomie. De meeste resultaten van dit onderzoek zijn weergegeven in dit proefschrift

Van 1 april tot 31 juli 1997 werkte hij als gastonderzoeker aan het Institut für limpirische Wirtschaftsforschung (IEW) in Zürich (Zwitserland). In samenwerking met de medewerkers van de groep van professor Fehr hield hij zich bezig met economische experimenten. Enkele resultaten van dit onderzoek zijn weergegeven in hoofdstuk zeven van dit proefschrift.

Sinds 1 februari 1998 werkt hij als wetenschappelijk medewerker aan het Zentrumfür Europäische Wirtschaftsforschung (ZEW) in Mannheim (Duitsland). 